\title{
"Nearby and Natural": Towards a Differential Geography of Organic Farming in South-Eastern Ontario
}

By Melanie Sommerville, B.Sc. (Honours)

A thesis submitted to:

The Faculty of Graduate Studies and Research

In partial fulfillment of the

requirements for the degree

\section{Masters of Arts}

Department of Geography and Environmental Studies

Carleton University

(C) Melanie Sommerville, June 2006 


$\begin{array}{ll}\begin{array}{l}\text { Library and } \\ \text { Archives Canada }\end{array} & \begin{array}{l}\text { Bibliothèque et } \\ \text { Archives Canada }\end{array} \\ \begin{array}{l}\text { Published Heritage } \\ \text { Branch }\end{array} & \begin{array}{l}\text { Direction du } \\ \text { Patrimoine de l'édition }\end{array} \\ \begin{array}{l}\text { 395 Wellington Street } \\ \text { Ottawa ON K1A ON4 }\end{array} & \begin{array}{l}\text { 395, rue Wellington } \\ \text { Ottawa ON K1A ON4 } \\ \text { Canada }\end{array}\end{array}$

Your file Votre référence ISBN: 978-0-494-18300-7 Our file Notre référence ISBN: 978-0-494-18300-7

NOTICE:

The author has granted a nonexclusive license allowing Library and Archives Canada to reproduce, publish, archive, preserve, conserve, communicate to the public by telecommunication or on the Internet, loan, distribute and sell theses worldwide, for commercial or noncommercial purposes, in microform, paper, electronic and/or any other formats.

The author retains copyright ownership and moral rights in this thesis. Neither the thesis nor substantial extracts from it may be printed or otherwise reproduced without the author's permission.
AVIS:

L'auteur a accordé une licence non exclusive permettant à la Bibliothèque et Archives Canada de reproduire, publier, archiver, sauvegarder, conserver, transmettre au public par télécommunication ou par l'Internet, prêter, distribuer et vendre des thèses partout dans le monde, à des fins commerciales ou autres, sur support microforme, papier, électronique et/ou autres formats.

L'auteur conserve la propriété du droit d'auteur et des droits moraux qui protège cette thèse. $\mathrm{Ni}$ la thèse ni des extraits substantiels de celle-ci ne doivent être imprimés ou autrement reproduits sans son autorisation.
In compliance with the Canadian

Privacy Act some supporting forms may have been removed from this thesis.

While these forms may be included in the document page count, their removal does not represent any loss of content from the thesis.
Conformément à la loi canadienne sur la protection de la vie privée, quelques formulaires secondaires ont été enlevés de cette thèse.

Bien que ces formulaires aient inclus dans la pagination, il n'y aura aucun contenu manquant.

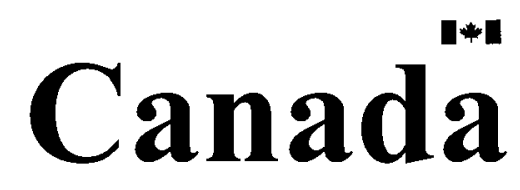




\begin{abstract}
Organic farming movements in Canada are growing rapidly and attracting increased attention from farmers, consumers, governments, and academics. Drawing on interviews with organic farmers in South-eastern Ontario, this thesis examines key discourses in the organic farming movement around naturalizing agricultural production and localizing the agricultural economy. The thesis shows that these discourses emerge as a critique of the industrialized and globalized agricultural system that predominates in Canada, and are central to farmers' efforts to regain a sense of agency in the processes of agricultural development. These discourses also challenge notions of the natural and the social, the local and the global as ontologically distinct, positing new visions, identities and responsibilities that instead frame these as interdependent and mutually constitutive realms. Finally, the thesis explores the intersection of these discourses with processes of institutionalization and conventionalization, examining the possible implications for the practice and development of organic agriculture in this region.
\end{abstract}

Key words: organic farming; organic agriculture; nature; society; local; global 


\section{Acknowledgements}

There are many people whose wisdom and support underpin this thesis. First and foremost, I would like to thank the organic farmers who participated in my research, who welcomed me onto their farms, and who were so generous with their time, thoughts, and insights. I consider myself incredibly lucky to have been able to work with a group of people who are so passionate and deeply inspiring, and who have been so warmly encouraging of all of my efforts. I would also like to thank my thesis co-supervisors, Dr. Fiona Mackenzie and Dr. Simon Dalby, who introduced me to and helped me to understand many new and important ideas, and who were always ready to entertain my difficult questions, even when some of them were asked repeatedly. I am also grateful for the help of Iain Wallace in making sure the thesis could be defended in a timely manner. Funding from the Social Sciences Research Council of Canada helped me to undertake the research.

The friendship of two colleagues from the Master's program has been particularly inspiring over the course of my research. I am extremely grateful to May Chazan and Emily Wilson, whose support and willingness to join me in re-examining and debating some of the most fundamental aspects of the world have certainly contributed to the thinking behind this thesis. Christopher Caners and Damian Crawley both offered support at critical moments which helped me to keep moving forward. And I am tremendously grateful to Brian Egan, whose solid feedback on many early drafts certainly made this a stronger piece, and whose broader support I very deeply appreciate. Finally, I would like to thank my family, for all of their encouragement along the way.

Thank you, all, for believing, and for helping me to do so too. 
Table of Contents

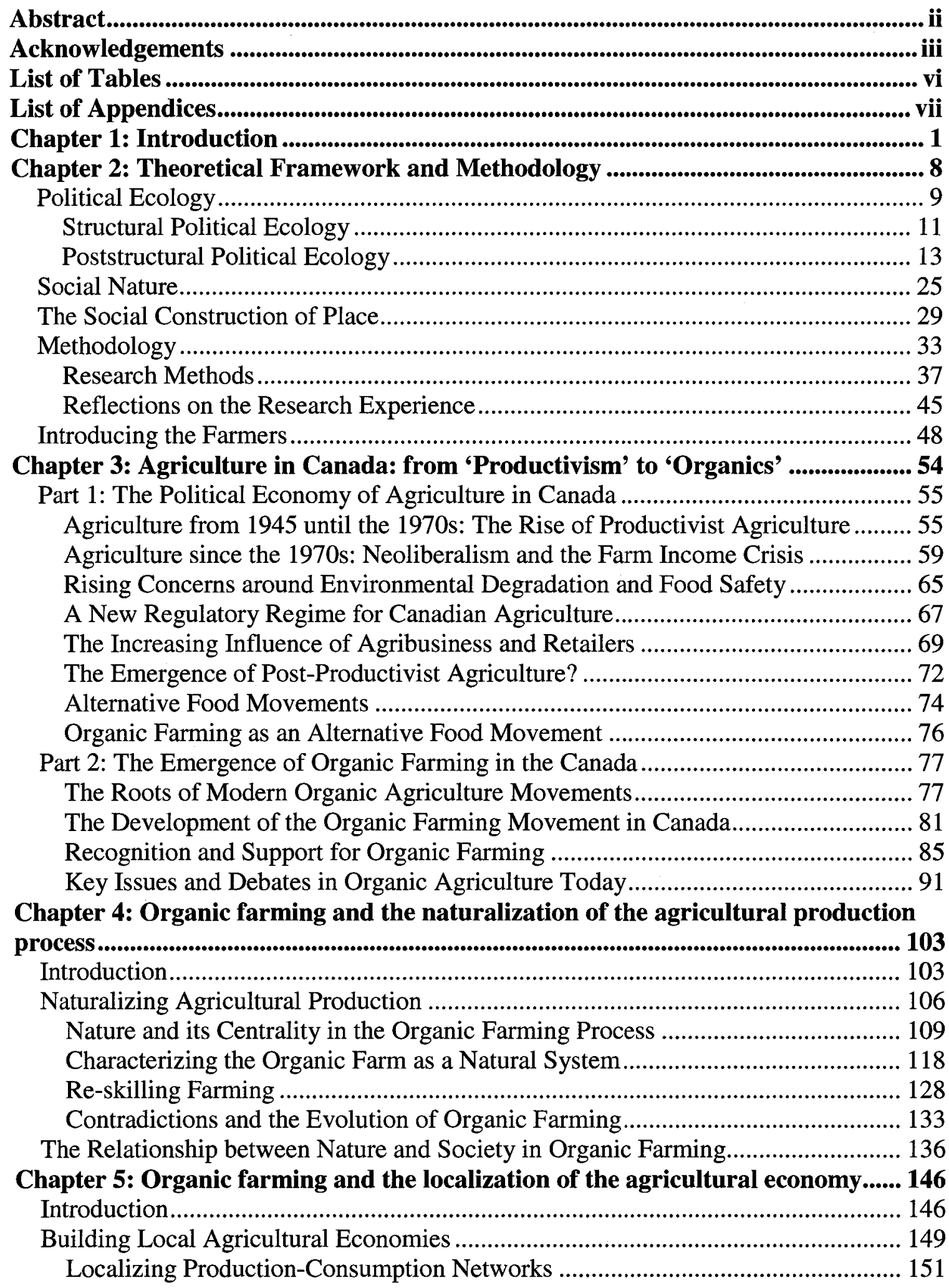


The New Economic Institutions of Organic Farming .......................................... 156

Challenges to Local Production-Consumption Networks...................................... 158

Social Dimensions of Building the Local Economy........................................... 161

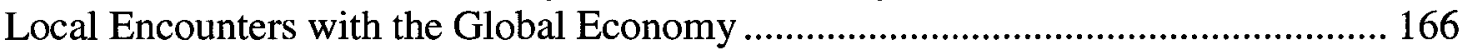

Local Farmers and the Global Organic Industry.............................................. 166

Globalizing Local Organic Production ........................................................ 170

Globalization and Localization of Organic Farming in South-Eastern Ontario ......... 174

Chapter 6: Conclusion............................................................................................. 184

Towards a Differential Geography of Organic Farming in South-eastern Ontario 190

Organic Farming in South-eastern Ontario and the Political Ecology Approach... 192

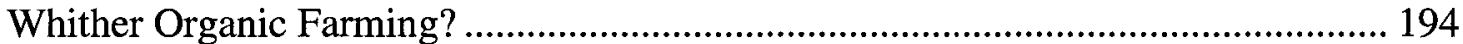

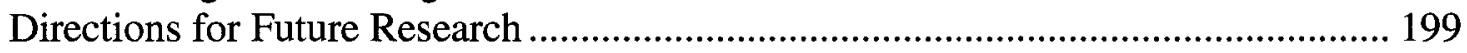

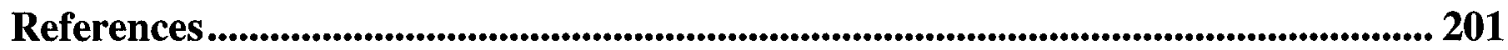




\section{List of Tables}

Table 2.1: Agricultural Products of Farms in the Study 51

Table 2.2: Agricultural Products of Market Gardens in the Study 52 


\section{List of Appendices}

Appendix 1: Guide for Semi-Structured Interviews with Participating Organic Farmers

Appendix 2: Socio-Economic Characteristics of Participating Farms and Farmers...... 222 Appendix 3: Organic Farming Practices amongst Organic Farmers in South-eastern Ontario 


\section{Chapter 1: Introduction}

Since its emergence in Canada half a century ago, organic farming has gone from a little known set of farming techniques to a high profile activity behind one of the fastest growing sectors of the national agricultural economy. Both the acreage of farmland under organic production and the number of certified organic farms have grown steadily over this time period. Growth has been especially rapid in the past decade, with the number of certified organic farms in Canada doubling between 1996 and 2001 (OMAFRA 2005b). At the same time, the domestic demand for organic products continues to grow at over 20 percent per year (OMAFRA 2006), and the demand in international markets far outstrips supply. This high level of growth is drawing the attention of an increasing number of farmers, governments, and agribusiness firms, eager to better understand, and profit from, this burgeoning sector.

As in other highly industrialized countries, organic farming in Canada originally emerged out of critiques of the productivist system of agricultural production which has dominated in this country for the last sixty years. The first organic farmers were concerned primarily with the deterioration of on-farm environmental conditions associated with the increasing industrialization of agricultural production under the productivist system, which many believed was associated with a similar decline in the quality of food (Howard 1940; Balfour 1943, 1977). Over the past six decades, the organic farming movement has developed in response to public concerns around a wide range of environmental issues both on the farm and off and at the national and international scales, even as parallel concerns for the health of both farm workers in the 
productivist system, and, especially in the wake of a recent series of food scares, for the health of the consuming public, have also encouraged the movement's growth. However, while a concern for the environment and for nature continues as a central theme in the movement, in more recent years, organic farming has increasingly been understood more broadly as one of a suite of "alternative food movements" which challenge the dominant agri-food system on the basis of its increasing globalization, corporatization, and commodification (Allen et al. 2003; Whatmore et al. 2003). These movements are concerned not only with the environmental and health crises of the dominant agricultural system, but also with its socio-economic and political consequences for small-scale farmers and for consumers. Together, these movements seek to create alternative systems of food provisioning which are more environmentally sustainable, economically viable and socially just (Allen et al. 2003).

Given the high levels of growth in organic production and organic markets around the world, and also the important symbolic dimensions of organic farming movements, organic farming has started to attract significant attention from geographers and other social scientists within the last decade. As empirical studies of local and regional organic farming movements have begun to be published, it has become increasingly clear that while these different movements may have emerged from a similar suite of concerns, there is at present significant diversity both between and within them in terms of the meanings they attribute to organic farming, their forms and structures, and the specific farming practices they feature. It has also become clear that organic farming movements in a number of highly industrialized countries are currently at a pivotal moment in their development. This is due in part to the growing institutionalization of organic farming 
over the last fifteen years in Europe, and five years in North America, which has increasingly codified organic farming practices and movements in national production standards, new regulatory regimes, and, in Europe, agricultural support programs. This process has resulted in the greater involvement of national and regional governments in what were once grassroots, independent and self-regulated movements. At the same time, a second, related issue regards the apparent 'conventionalization' (Buck et al. 1997: 14) of organic farming movements in at least in some locales, whereby they are gradually coming to resemble in their discourses, practices, and forms the dominant industrialist system of agricultural production that they initially set out to oppose. While these two processes are seemingly independent, they are in fact intimately related insofar as the way organic farming is institutionalized in a region has been shown to play a central role in the degree to which it becomes conventionalized.

Concerns around the institutionalization of organics are particularly relevant in the Canadian context, where the national government, in conjunction with other interests in the organic agri-food sector, has recently initiated a program to develop a national standard for organic production and an associated regulatory regime. This regulatory regime could come into effect as early as late 2006 . While researchers have suggested that organic farming in Ontario has for the most part remained distinct in its discourses, practices and forms from the conventional agricultural system which predominates in the province (Hall and Mogyrodovy 2001), the impending regulatory changes may significantly alter the provincial organic farming sector within the next five to ten years. Together, these impending changes, the high levels of growth in the organic sector in Canada, and the regional specificity of organic farming movements highlight the 
importance and timeliness of empirical studies of organic farming movements in specific locales in the country. Yet local organic farming movements in Canada have received relatively little scholarly attention—a gap that this thesis sets out to contribute towards filling.

The overall purpose of this thesis is to gain a nuanced understanding of the local organic farming movement in South-eastern Ontario. More specifically, this thesis has four broad objectives:

(1) To investigate the key discourses of the local organic farming movement;

(2) To investigate how these discourses are deployed and operationalized;

(3) To consider the practical and political implications of these discourses; and

(4) To consider how an analysis of these discourses can inform the way that organic farming is currently conceptualized, as well as broader debates in human geography.

This thesis draws on empirical research conducted with twenty three organic farmers in South-eastern Ontario between January and April 2005. It focuses primarily on how organic farmers understand their personal practices of organic farming and the local organic farming movement. In particular, I have chosen to investigate two discourses that emerge in the local organic farming movement: that of naturalizing the agricultural production process, and that of localizing the agricultural economy. In the course of my research, these emerged as key goals amongst local organic farmers; indeed, the suggestion of the first farmer that I interviewed for this research that organic farming was most centrally concerned with being "nearby and natural" (Farmer, field crop producer; 
male) inspired the title of this thesis. However, this thesis also considers how organic farming is currently framed within the recent attempts to institutionalize organic farming in Canada, and the complementarities and contrasts between this and the way the organic farmers who participated in this research understand their movement.

This research has been guided by a theoretical framework informed by political ecology approaches, and seeks to investigate the connections between the local organic farming movement and the broader political economy of agriculture at the national and international scales. In the chapters that follow, I draw on a critical reading of selected literature in the fields of political ecology, the political economy of agriculture, social nature, and the social construction of place to inform my analysis of the discourses mobilized by the organic farmers, as well of the framing of organics by the national and provincial government and the new organic regulatory regime.

I contend that naturalizing and localizing agriculture emerge as significant goals amongst organic farmers in South-eastern Ontario as they struggle to construct an alternative system of food provisioning to the industrialized, globalized, conventional agricultural system that predominates in the region. I illustrate how farmers in this study achieve these goals through an iterative process that involves both new ways of thinking about agricultural systems and a suite of specific production and economic practices. I suggest that the farmers' efforts to reground agriculture in nature and in the local are central to a project of regaining a sense of agency in, and influence over, the processes and outcomes of agricultural development, and hence in determining the future of agricultural systems in the region. In the midst of these efforts, the farmers draw into question the boundaries that would mark off the natural and the social, the local and the 
global as ontologically distinct realms, articulating new visions, identities and senses of responsibility which posit these as interconnected and mutually constituted. However, the farmers' blurring of these boundaries is intricately entangled with an effort to demarcate a boundary between organic farming and the conventional agricultural system, and so to set off their movement from that which it set out to oppose.

Thus, drawing together the empirical and conceptual elements of this research, I explore how organic farmers in South-eastern Ontario construct, draw on, and mobilize concepts of the natural and the local, concepts which a number of theorists have suggested are central to alternative food movements but which remain somewhat vaguely theorized within this context. In addition, I reflect on the centrality of both boundary elision and boundary-making to farmers' efforts to differentiate organic farming as an alternative food system, and through this to build more positive futures for local farm ecologies, communities, economies and cultures.

The remainder of this thesis is divided into five chapters. In Chapter 2, I present the theoretical and methodological frameworks which guided this research. I provide an overview of political ecology as a discipline and of the key insights it can offer to an analysis of organic farming movements. I also present my methodological approach, which is guided by insights from critical feminist theory, as well as my research methods. In Chapter 3, I provide an overview of the development of the contemporary productivist agricultural system which predominates in Canada today, from the post-War years into the present. I explore the socio-economic, environmental, and political crises brought about by the productivist system, and the rise of organic farming as one of the alternative food movements which seek to address these crises. I then review the development of the 
organic farming movement in Canada, and explore the key debates around the conventionalization and institutionalization of the movement and their relevancy in the Canadian context. In Chapter 4, I turn to an investigation of how organic farmers mobilize a discourse of naturalizing agricultural production, and the operationalization of this discourse in specific production practices. I explore how the farmers attempt to incorporate both a greater concern for the environmental impacts of agriculture and also an increased role for nature in the production process, and how this is set against the approaches of the industrialized agricultural system. I show that this discourse is also linked to a broader effort amongst the organic farmers to regain control of their farms against a perceived loss of control in the conventional agricultural system. In Chapter 5, I investigate and analyse the farmers' mobilization of a discourse of localizing the agricultural economy, and how this plays out in practice through the emergence of a range of new economic institutions. I show that this is linked to a concern to regain a sense of agency within and control over the processes and effects of agricultural development, amidst disempowering discourses of globalization in the conventional agricultural system. Finally, in Chapter 6, I provide a summary of my main arguments and reflect on how these can inform current discussions in human geography around social movements and the boundaries and connections between the natural and the social, the local and the global. I close the thesis by revisiting the impending institutional and regulatory changes in the Canadian organic sector, considering how these changes relate to the farmers' own understandings of organic farming, and examining the possible implications of these changes for the future of the organic farming movement. 


\section{Chapter 2: Theoretical Framework and Methodology}

As an approach increasingly adopted by social scientists, political ecology is broadly concerned with politicizing the relationship between human societies and the environment, uniting a political economy approach with a concern for questions around nature and natural resources. This makes it a useful theoretical framework for examining the discourses and practices of organic farmers, who, through their involvement in agricultural production, participate in one of the most fundamental and intimate relationships between societies and nature. Political ecology has developed rapidly over the past two decades, moving from a structuralist approach to understanding the humanenvironment relationship towards one that increasingly draws on insights from poststructuralist theory. As an approach or discipline, political ecology has been shaped by a number of internal debates. One of these debates concerns the way political ecology approaches have conceptualized the political, a critique which some scholars have attempted to overcome by considering new types of politics and political players. In this chapter, I suggest that this might also be approached by engaging with debates around the social construction of nature and of place, which expose as political the process by which any construction or understanding of 'nature' or of 'the local' comes to exist.

Even as poststructuralist theory can inform our approaches to understanding human-environment relationships, it can also inform the way research conducted in the field of political ecology is undertaken-that is, our research methodologies. In this thesis, I draw on the methodological insights of critical feminist theorists, who have engaged extensively with poststructuralist theory, and who encourage us to investigate 
our social positioning as researchers and to reflect on the way this might affect our research practice and relationships. This suggests a need to acknowledge that any knowledge created through the research process is partial and situated, and that all research relationships are imbued with power dynamics which may favour the researcher over the researched.

In this chapter, I detail the theoretical framework and methodology I have used to carry out this research project. I provide overviews of the bodies of work encompassed in the discipline of political ecology, within the field of 'social nature', and around the social construction of place, highlighting key insights from this field which have framed or contributed to my analysis in the remainder of this thesis. I then turn to a description of my research methodology, which includes an overview of the broader methodological framework which has informed my work, my research methods, and a short reflection on my own participation in the research process. I conclude the chapter with a brief overview of the organic farmers who participated in this research.

\section{Political Ecology}

Political ecology as a discipline has developed from diverse intellectual origins, having roots in human and cultural ecology and ecological anthropology, cultural geography, cybernetics and systems theory, natural hazards and disaster research, and political economy approaches ${ }^{1}$ (Peet and Watts 1996; Watts 2000; Gezon and Paulson 2005). Early political ecology approaches emerged as a way of conceptualizing the

\footnotetext{
${ }^{1}$ Given space constraints, I do not review in detail the intellectual lineage and emergence of political ecology as a discipline in this thesis. Interested readers are directed to Gezon and Paulson (2005) and Peet and Watts (1996), both of whom offer a concise yet detailed genealogy of political ecology as a discipline and an approach.
} 
relations between political economy and ecology in the face of the developing environmental movement of the 1970s, and were centrally concerned with explaining episodes of environmental degradation (Peet and Watts 1996; Walker 2003; Gezon and Paulson 2005). They borrowed heavily on ideas and analytical tools from political economy approaches, yielding a 'structuralist political ecology' with a strong Marxist flavour that developed through the 1980s. However, beginning in the 1990s, political ecologists have increasingly engaged with ideas from poststructuralism, yielding a 'poststructuralist political ecology' that has aimed to reconceptualize the intersection of politics and environmental change, engaging with discourse theory and ideas around the intersection of power and knowledge in the process. Concurrent with this shift, political ecologists have turned to consider a wide range of topics that, while not necessarily concerned as explicitly with questions of environmental degradation, continue to be broadly concerned with the politicization of the human-environment relationship. In the sections below, I provide a brief overview of both structuralist and poststructuralist political ecology. I focus my discussion on the particular elements of political ecology that are most relevant to my thesis, including the discipline's attempt to understand the political-economic drivers of ecological problems. I also explore current thrusts and gaps in political ecology to which this research contributes, including attempts within the discipline to engage with more nuanced conceptualizations of politics, to investigate the importance of discourses in framing environmental issues, to take more seriously ecology and the agency of nature, and to extend the remit of political ecology to include locales in the highly industrialized, capitalist countries. 


\section{$\underline{\text { Structural Political Ecology }}$}

The early political ecology approaches which emerged in the 1980s focused in particular on rural, agrarian communities in the so-called 'Third World,' and on the degradation of the environmental resource bases on which these communities relied. These early approaches brought from political economy an emphasis on analyses of the social relations of production, as well as a concern with questions around access to and control over resources (Peet and Watts 1996; Gezon and Paulson 2005). In one of the key political ecology texts from this era, William Blaikie and Harold Brookfield (1987: 17) describe political ecology as combining "the concerns of ecology and a broadly defined political economy" (Blaikie and Brookfield 1987: 17). Together, the early political ecology approaches of these authors and others shared a common concern to expose the political economic roots of environmental degradation in the locales that they studied (see, for example, Watts 1983; Blaikie 1985; Hecht and Cockburn 1989).

To this end, early political ecology approaches tended to be organized around four key themes. The first was an understanding that the resource use or environmental behaviour of any social group is fundamentally underpinned by social relations which may work to place the environment under intense production pressure (Watts 1983; Gezon and Paulson 2005). Social relations of production, exploitation and surplus extraction thus came to be seen as shaping the environmental conditions that played out in various locales around the world (Gezon and Paulson 2005). A second, related, theme concerned the importance of scale in analyses of local environmental conditions, for structuralist political ecology approaches saw local expressions of degradation as linked through social relations to extralocal political economic factors and processes (Blaikie 
and Brookfield 1987; Peet and Watts 1996; Gezon and Paulson 2005). Third, early political ecologists posited the economic, ecological and political marginality that results from these socially-based political economic processes as interlinked and mutually reinforcing (Blaikie and Brookfield 1987; Peet and Watts 1996). The fourth theme concerned the recognition that there are multiple perceptions of any local environmental condition, only some of which might understand it to be a 'problem.' These perceptions were seen to be underpinned by different interests and rationalities amongst the different groups that seek to interact with a given resource (Peet and Watts 1996; Gezon and Paulson 2005).

Together, the insights of the early political ecology texts offered a number of key advantages over earlier attempts to understand environmental degradation. First, they drew into question Malthusian ideas which posited degradation as the result of overpopulation, while also dispelling notions that it was linked to mismanagement, poor uptake of technology or an inability to read the market amongst local populations (Peet and Watts 1996). In the process, these studies shifted the notion of who was responsible for environmental degradation, bringing into focus a number of players beyond the local, impoverished, minority communities who were the primary managers of the resources (Gezon and Paulson 2005). Further, as Lisa Gezon and Susan Paulson (2005: 8) write, they also reassessed the solutions to environmental degradation that governments and development agencies had scripted, criticizing the tendency of these "to address ecological problems with immediate technical solutions and ignore ways in which nonlocal policies and capital flows influence and perpetuate resource-use patterns at local levels". 
It is with these key advantages in mind that this thesis begins its engagement with political ecology. Indeed, what will emerge is that organic farmers share with the discipline's early practitioners an appreciation that the environmental problems inherent in contemporary agricultural production emerge not from farmer mismanagement of the resource base, but rather from the political economic forces and factors that perpetuate the industrialized, productivist agricultural system. Further, in this thesis I consider that these environmental problems are thoroughly interlinked with the broader socioeconomic difficulties in which small-scale farmers and rural communities are now enmeshed, and I seek to problematize the solutions to the concurrent environmental and socio-economic agricultural crises that have been offered by Canadian federal government. However, my analysis also draws on ideas from more recent approaches to political ecology, notably those developed under the discipline's increasing engagement with poststructuralism.

\section{Poststructural Political Ecology}

Since its emergence in the 1980s, interest in political ecology has flourished amongst human geographers and scholars in other disciplines including anthropology, sociology, biology, and political science (Gezon and Paulson 2005). This has meant that political ecologists have analyzed an increasingly wide range of topics pertaining not only to environmental degradation but to the human-environment relationship more generally. However, since the mid-1990s, the structuralist flavour of early political ecology approaches has come under significant critique, due to the growing influence of poststructuralism in the social sciences. This has led to the development of a broader 
political ecology that has sought to consider more seriously the politics of humanenvironment relations, to engage with ideas from discourse theory, and to ensure that a concern with ecology remains central to political ecology analyses. This thesis can inform these new trajectories in political ecology through its focus on organic farming as a social movement, through its concern with the everyday practices of organic farmers within this movement, through its explorations of the way that farmers and the federal government discursively frame organic farming, and through its investigation of farmers' own understandings of the centrality of ecology in the agricultural production process.

\section{Social Difference and the Importance of the Political}

One of the fronts on which early political ecology research has been critiqued concerns its narrow focus on class at the expense of other important axes of social difference, including gender, race and ethnicity. Early political ecology studies overwhelmingly posited the land manager as male, thereby eclipsing women's important roles in resource use and management (Peet and Watts 1996). In response, feminist scholars have sought to develop a feminist political ecology which seeks to foreground gender concerns by recognizing the gendered nature of resource use and ownership and of resource-related responsibilities (Rocheleau et al. 1996). These scholars also have also sought to recognize the masculine character of what usually counts as valid environmental knowledge in Western societies, and the important role of women in activism around environmental and social issues (ibid.). As political ecologists have engaged more deeply with feminist and poststructuralist thought, scholars have also increasingly considered how environmental interests, practices and knowledges intersect 
with other axes of social difference such as race and ethnicity, especially in conjunction with processes of colonialism (e.g., Neuman 1998; Braun 2002). While gender, race and ethnicity were not major axes of analysis in this thesis, the organic farmers who participated did include both men and woman, as well as farmers of different ethnicities and races, some of whom had experience farming in other countries. To this end, I have noted in a few places insights into the interesting ways that these axes of social difference intersect with the project of organic farming in South-eastern Ontario ${ }^{2}$.

Political ecologists' efforts to incorporate a greater consideration of social difference is also linked to larger questions around the way early political ecology studies approached and conceptualized the political. In the early and mid-1990s, a number of theorists suggested that the approaches that emerged in the 1980 s were based on vague conceptualizations of political economy, and that, in prioritizing the formal interactions of local groups with the state, these approaches left out of their analyses other types of political activity which played an important role in environmental change. For example, amongst their critiques of early political ecology approaches Richard Peet and Michael Watts (1996: 9) note that "[p]articularly striking is the fact that political ecology has very little politics in it... There is no serious attempt at treating the means by which control and access of resources or property rights are defined, negotiated, and contested within the political arenas of the household, the workplace, and the state." To this end, feminist

\footnotetext{
${ }^{2}$ Kirsten Pedersen and Bente Kjaergard (2004) offer a more thorough examination of the intersection of gender and organic farming in their empirical study of women's roles in the organic farming movement in Denmark. They bring ecofeminist theory to bear on the discourses, construction of identities and the practice of gender amongst organic farmers, and evaluate the implications of the evolution of the Danish organic sector for the future of women's involvement in organic production, which they assess as bleak indeed. Readers interested in this topic are therefore directed to their important study.
} 
political ecology also provided important insights into the micropolitics of resource access, use, and control at the household level.

However, Gezon and Paulson (2005) note that many political ecologists still need to go some distance towards bringing to light the politics that exist amongst resource users and between resource-using communities. Similarly, Philip Stott and Sian Sullivan (2000: 6) also note the need for "revealing and clarifying circumstances whereby differences within local 'communities' mean that not all people of a place or context experience environmental ideas in the same way, or hold concordant views." That is, there remains a need for "a non-essentializing of local actors" (ibid.). This increased engagement with examinations of the micropolitics of resource use, including those within resource-based communities, also suggests a need to look beyond formal politics to a consideration of everyday interactions in order to acknowledge that these may also play a central role in the making, negotiation and contestation of claims to resources (Gezon and Paulson 2005). To this end, a number of political ecologists have usefully engaged James Scott's (1985) ideas around 'everyday forms of resistance.' Along these lines, in this thesis I set out to explore the everyday practices of organic farmers, which together constitute their efforts to establish organic farming as an alternative system of production to that which predominates in South-eastern Ontario. This thesis considers these everyday actions to be inherently political, a view that many of the participating farmers shared.

Finally, Peet and Watts (1996: 2) argue that there is a need to incorporate into political ecology analyses of new political players who increasingly play a role in shaping the way individuals and communities use resources. They are particularly concerned to 
include the social and environmental movements that have become significant sources of authority around environmental issues over the past few decades, and which they see as holding great promise towards the establishment of more ecologically and socially just futures. They also note as important "transnational environmental alliances and networks, multilateral governance, and local conflicts and resistances that may not warrant the term 'movement'." This thesis can also contribute to the initiative set out by these authors, in the sense that it investigates organic farming as one of the very social/environmental movements that Peet and Watts (1996) hold to be so promising, and further looks to how this movement engages both with the state and with civil society institutions.

Another significant component of poststructural political ecology's increased concern with the political is the turn towards incorporating discourse theory, and its emphasis on the politics of meaning and on the construction of knowledge. This 'turn' to discourse amongst political ecologists recognizes the interrelation of the material and the symbolic dimensions of struggles over resources, such that "as well as being practical struggles over livelihood and survival", these struggles also serve to contest the "truths, imaginations, and discourses through which people think, speak about, and experience systems of livelihood" (Peet and Watts 1996: 37).

\section{Discourse}

In recent years, political ecologists have been influenced by the increased engagement of their various disciplines with ideas from poststructuralist theorizing, and especially with Michel Foucault's ideas around discourse. This thesis draws on these 
ideas, focusing in particular on how organic farmers in South-eastern Ontario articulate discourses around nature and the local in their practice of organic farming, and on how this compares with recent government efforts to frame organic production in particular ways. As Gillian Rose (2001: 136) describes, the notion of discourse "refers to groups of statements which structure the way a thing is thought, and the way we act on the basis of that thinking." It is "a particular knowledge about the world which shapes how the world is understood and how things are done in it" (ibid.). Discourses give meaning to the world, for it is through them that "meanings are produced, connected into networks and legitimized" (Gregory 2000: 180). Discourses are not, however, only concerned with making things visible and meaningful. Rather, discourses are "concerned with a limited range of objects, a discourse emphasizes some concepts at the expense of others" (Peet and Watts 1996: 14); they "disallow certain themes and are marked by absences, silences, repressions, marginalized statements, allowing some things to be mentioned only in highly prescribed, 'discrete,' and disguised ways” (ibid.: 16).

As Judith Butler (1992) has pointed out, one of the central ways in which discourses participate in the production of meaning is by constituting the 'objects' of which they speak. These include both places and human subjects (Rose 2001); indeed, discourses produce our sense of self and social relations (Butler 1992). Discourses also participate in the normalization of certain knowledges as acceptable ${ }^{3}$. In constructing their topic, discourses also determine how things might meaningfully be known (Gregory

\footnotetext{
${ }^{3}$ Indeed, discourses are responsible for setting out which knowledge is considered to be 'true' (Rose 2001). In the poststructuralist view, then, 'true' knowledge is not constituted by "objective 'facts' about reality" (Peet and Watts 1996: 13), but rather is always a representation of an external reality. 'Truth' is an effect of discourse, rather than a universal quality that appears the same to everyone regardless of their social position (Flax 1992). For Foucault, it is the efficacy of discourses in setting what counts as true (and hence their ability to claim absolute truth) and not merely their location in socially powerful institutions that makes discourses so powerful (Rose 2001). This includes their ability to make certain things invisible and to hide contradictions (ibid.).
} 
2001). As critical social theorists such as Donna Haraway (1991) and Jane Flax (1992) have pointed out, this means that 'reality' can never be known from outside of one's social position; in this sense knowledge is never objective, neutral, or innocent, but is rather always partial and situated. A poststructuralist reading, then, considers the material and the symbolic dimensions of any given topic to be thoroughly intertwined, because there is no way of knowing or perceiving the material outside of how it is portrayed in discourse (Bryant 2001).

Foucault (1980: 93) suggests that discourses are embedded within social institutions, and as such are an effect of the "relations of power which permeate, characterise and constitute the social body," but are also the mechanism by which power operates, for "these relations of power can themselves only be established and implemented through the production, accumulation and functioning of discourse". Discourses circulate by way of various apparatuses, including not only literary texts such as books and journals, but also "instruments and equipment, in interactions and procedures" (Gregory 2001: 86); they are concurrently embedded in practices and serve to produce subjects who practice in particular ways (Rose 2001). Because the apparatuses and practices through which discourses circulate serve to produce and regulate knowledge, the diffusion of truth may itself become a function of political economic relations (Peet and Watts 1996). Accordingly, Foucault (1980) saw power and knowledge as deeply imbricated each in the other. However, discourses are also multiple and heterogeneous, because the knowledge they are based in is always partial and situated (Flax 1992). To this end, there are always multiple discourses operating that compete to frame topics and subjects according to their particular logic and rules. Thus, 
discourses are open to contestation and negotiation, which opens important possibilities for resistance (Foucault 1980; Rose 2001).

Discursive approaches have come to be popular in poststructural political ecology as a way of investigating the plurality of perceptions and definitions of environmental and resource problems that exist between and amongst social groups (Watts n.d.). In his effort to define a poststructuralist political ecology, Arturo Escobar (1996: 46) describes discourse as "the process through which social reality inevitably comes into being", and argues that discourse works with culture to mediate nature and the conditions under which it is produced. As one example, Escobar examines the rise of sustainable development as a new discursive regime through which the relationship between nature and society, and more particularly between nature and capital is articulated (ibid.). For Escobar, sustainable development "purports to reconcile two old enemies-economic growth and the preservation of the environment-without significant adjustments to the market system. This reconciliation is the result of complex discursive operations involving capital, representations of nature, management, and science" (49). Through this process, Escobar shows, the discourse of sustainable development plays a central role in maintaining the social and economic status quo, and also becomes the basis by which an increasingly intimate remaking of nature can proceed. He argues that we should thus not accept the notion of sustainable development uncritically, but rather must challenge and resist it with alternative discourses if we want to get to the heart of the assumptions that it makes (such as the idea that economic growth is inherently good) and so open ground for alternative projects and conceptualizations. Escobar's insights in this regard inform my exploration in this thesis in of how the Canadian federal government and 
organic farmers have each framed the need to respond to the environmental crises that beset the conventional system of agricultural production.

A number of political ecologists have also argued that scientific discourses are particularly important in shaping understandings of environmental change. Escobar sees these discourses as playing a central role in shaping the reinvention of nature and conditioning and effecting the operation of capitalism (Escobar 1996: 48). Peet and Watts (1996) note that scientific discourses are especially important in the diffusion of 'truths' about nature and the relationship between nature and society. Similarly, Stott and Sullivan (2000) suggest that science is critical to the emergence of "narratives concerning 'the environment"", and that scientific discourses intersect with moral discourses in the perpetuation of these narratives. However, few authors have attempted to trace the emergence and implications of scientific discourses around particular topics that fall under the political ecology rubric in any great detail. While such a tracing is not a main focus of this thesis, I do explore the increasing importance of science both in the federal government's approach to agriculture as well as in how organic farmers perceive the role of science in agriculture.

There is still significant room for political ecologists to engage with and draw on insights from discourse theory. Indeed, Peet and Watts (1996: 3) feel that the integration of ideas around discourse with a deeper consideration of politics holds promise for the development of a "more robust" political ecology. However, even as there is significant excitement around the use of discourse theory in political ecology, some theorists worry that the focus on discourse has had an unintended and potentially unwelcome side effect: that is, that the focus on the 'ecology' in political ecology has been lost. 


\section{The Ecological in Political Ecology}

While early (structuralist) political ecology studies tended to pay close attention to biophysical ecological change, there has been a tendency in more recent (poststructuralist) political ecology studies to place less emphasis on biophysical conditions (Walker 2005). This has led some scholars to suggest that political ecologists' increasing attention to matters of politics is squeezing the ecological component of political ecology out of the picture-or, as Pete Vayda and Brad Walters (1999:75) argue in an oft-quoted critique, that "overreaction to the 'ecology without politics' of three decades ago is resulting in a 'politics without ecology'." In this view, by foregrounding the social and discursive politics of access to and control over resources, many poststructural political ecology approaches have ignored or overlooked the important biophysical ecological implications of these struggles (Walker 2005) ${ }^{4}$. There are also deeper concerns that in "draining some of the 'naturalness' out of nature", such approaches have denied nature any explanatory power in environmental change (Bryant 2001). To this end, while political ecologists are keen to acknowledge the importance of human action in the environment, some have also sought new ways to acknowledge the role of nature and ecology in shaping the interaction between humans and the environment and thus in shaping environmental change. These political ecologists argue for the need to recognize that environmental problems are not only integrally social but also integrally ecological (Gezon and Paulson 2005), and to understand the environment

\footnotetext{
${ }^{4}$ In a recent review of the place of ecology of political ecology, Pete Walker (2005), assesses that critiques such as that of Vayda and Walters (1999) are only partly true, and that while some political ecologists may indeed neglect ecological detail in their analyses, others continue to give it explicit attention. For Walker (2005: 77), the bigger problem for those concerned about the demise of ecology in political ecology is perhaps "the seeming indifference to this trend among some leading political ecologists."
} 
to be both a question of knowledge and representation and a question of biophysical nature (Walker 2005). In this thesis, I engage with these concerns by highlighting organic farmers' understandings of the centrality of nature and ecological processes in the production of food, and of the agency of nature within agricultural production.

\section{Whither Political Ecology?}

The growing popularity of political ecology and the increasingly broad range of topics which are encompassed under its rubric have led some to argue that it lacks coherence as a field or consistency in its theoretical and methodological approaches (McCarthy 2002; Walker 2005). Indeed, Watts (2000: 592) has argued that "[p]olitical ecology has in a sense almost dissolved itself over the last 15 years as scholars have sought to extend its reach." However, even as some political ecologists acknowledge a lack of clarity and coherence in the approach, others note that there remain important gaps in the discipline that political ecologists might usefully strive to address.

One of these gaps pertains to the relative lack of application of political ecology to the environmental problems of the so-called 'First World'. As James McCarthy (2002) has pointed out, while political ecology has focused predominantly on rural, often agrarian, problems in the 'Third World', it remains a powerful, if underused, framework for examining environmental conflicts in the advanced capitalist countries. McCarthy notes that many of the core themes of political ecology are not specific to 'Third World' locales 5 . Indeed, although agrarian issues and conflicts in the global South have been

\footnotetext{
${ }^{5}$ McCarthy (2002) suggests that issues such as access to and control over rural land and resources (and the loss and criminalization of resource access), the complexities of property relations, state capacity with respect to resource management and conflicts, and concerns around the importance of scale all retain their relevance in highly industrialized and capitalist countries. Further, he suggests that processes such as "the
} 
perhaps the most common theme to be analyzed by political ecologists, agricultural issues in advanced capitalist societies have received little attention ${ }^{6}$, a gap that this thesis seeks to address. As such, while some researchers have suggested that political ecology is particularly well suited as an agenda for 'Third World studies' (see Bryant 1992, 1998), perhaps more appropriate is Walker's (2003) assertion that it is time for 'political ecology without borders'.

Political ecology also continues to struggle with attempts to devise yet more nuanced approaches to questions of politics. As part of this, political ecologists are increasingly trying to resist isolating nature from the social dynamics that shape human manipulations of the material world (Gezon and Paulson 2005), and rather to address nature as a political production and construction. Similarly, while political ecology has long been concerned with the links between local ecologies, cultures and politics and regional and global processes, questions around the politics inherent in scale and the production of place are also recognized as requiring further redress (ibid.). A greater engagement of the political ecology approach with some of the recent debates around the social construction of nature and of place thus has the potential to add nuance to our understandings of the centrality of the politics of nature and of localities to struggles over environmental resources in particular places. As such, in this thesis I engage with the bodies of work around 'social nature' and the social construction of place, examining the

transformation of nature by or in the service of multinational corporations, rapid urban growth, and affluent consumption in advanced capitalist countries would seem to have at least as much causal power in contemporary ecological and political economic dynamics as the struggles of agrarian peasant societies" (1297), although few political ecologists have as of yet taken up these themes in their analyses.

${ }^{6}$ Some of the work of Michael Watts (e.g. Watts 2004) is an important exception here. We are also beginning to see some important work linking political ecology and food consumption (see, for example, Bryant and Goodman 2004). 
political terrain under which particular understandings of nature and of the local come to exist in the organic farming movement, and the social effects of these understandings.

\section{Social Nature}

This thesis considers how organic farmers in South-Eastern Ontario discursively construct the concept of nature as part of their efforts to naturalize the agricultural production process. I investigate the experiences that underpin these constructions, the implications of the constructions for organic farming practice, and the view the constructions take of the relationship between the natural and the social in agricultural production, and in society more broadly. My approach here is informed by recent writing in the developing body of literature on 'social nature,' which takes as its starting point the idea that nature is intrinsically social - that is, that it is both materially produced and socially constructed in and through social interaction and relationships (Castree 2001). The idea that nature is socially produced is not new. Indeed, geographer Neil Smith (1984) explored the social construction of nature several decades ago. Smith's important work examines the rise of what he calls the 'essential dualism' that persists in how we conceptualize nature today: as simultaneously external to human society, and as universal and so both inclusive of and internal to humans ${ }^{7}$. He considers the importance of the labour process and the role of industry and production in creating particular conceptions of nature, arguing that human interaction with nature is central to the production process

\footnotetext{
${ }^{7}$ According to Smith (1984:2), the external conception of nature posits "nature as a thing, the realm of extra-human objects and processes existing outside society...pristine, God-given, autonomous; it is the raw material from which society is built, the frontier which industrial capitalism continually pushes back", while the universal conception of nature posits "human beings and their social behaviours [as] every bit as natural as the so-called external aspects of nature...the human species as one among many in the totality of nature"
} 
and so to our survival and development as social beings. However, industry has tended to objectify nature by treating natural materials as external objects of labour to be worked into commodities (1984: 15); Smith, on the other hand, argues that through production we not only materially transform nature, but, in fact, produce it anew, albeit in an altered form ${ }^{8}$. For Smith, this process of transformation and production is accelerated under capitalism. He argues that the externalization of nature which has persisted at some level in many Marxist analyses of the society-nature relationship is thus inadequate for conceptualizing this relationship. Rather, we need to move towards seeing the production of nature as a historical (social) process, determined by political events and forces (ibid.: 31).

Smith's idea that nature is 'physically reconstituted' by societies (Castree 2001: 15) has been taken up by a number of theorists who have sought to detail human involvement in the material production of nature, particularly through science and technology. These theorists argue that we are now more than ever involved in the production of nature, given the rise of biotechnologies which increasingly rework 'natural' entities that were once outside of the domain of social activity-and at levels as intimate as the molecular. Escobar (2001), for example, investigates the development of 'technonatures' under the scientific and technological relations that are so central to the functioning of industrial capitalism. He argues that as capitalism progresses, nature itself increasingly becomes a strategy and mechanism for the accumulation of capital by way of these productions. Further, these productions trouble any easy distinction between the

\footnotetext{
${ }^{8}$ Specifically, Smith refers to concepts that Albert Schmidt borrows from Hegel for use in his study 'The Concept of Nature in Marx'. These posit a differentiation between a so-called 'first nature' which is nature outside of and unaltered by man, and 'second nature', which is nature transformed by humans. Smith suggests that as capitalism proceeds, more and more first nature is transformed into second nature.
} 
realm of the natural and that of the social, for technonatures come to be products of both. Similarly, Sarah Whatmore (2002) investigates the 'hybrid' natures produced by our (social) intervention into natural entities and processes, hybrid because they trouble the ontological separation between the natural and the social that persists in so many academic and mainstream treatments of the 'question of nature'.

Theorists have also built on Smith's assertion that the way nature is conceptually produced (and understood) has important social and material consequences. Thus, scholars have turned to explorations of how nature as a concept is constructed, of how these constructions are circulated amongst human societies, and of the potential material and social effects of these constructions. For example, authors such as Bruce Braun (2002) and William Cronon (1995) have investigated the construction of nature as 'wilderness', one of the primary representations of nature in contemporary society and that which underpins modern environmentalism. In their investigations, constructing nature as wilderness is shown to posit nature as a purified zone lying outside of human productive activity. The idea of nature as wilderness hinges on a separation of nature and society, such that this construction becomes complicit both in our destruction of the natures inherent to non-wilderness spaces such as those in which we live and work (Cronon 1995) and in the exclusion of social groups which inhabit (or once inhabited) socalled 'wilderness' spaces (Braun 2002). Similarly, the works investigating scientific natures highlighted above also recognize these as, in part, social constructions of nature. Hence, current social nature analyses often focus on both the symbolic and material dimensions of nature, which must be understood as thoroughly intertwined (Escobar 1999). 
Different critics understand and approach the idea of nature as a social construction and the implications of this idea in different ways (Demeritt 2001). Given social scientists' increasing engagement with ideas of poststructuralism, one common approach investigates the central role of discourse in constructions of nature (Braun and Wainwright 2001, Demeritt 2001) ${ }^{9}$. Works such as those of Bruce Braun (Braun and Wainwright 2001; Braun 2002) start from the position that nature is (materially and symbolically) constituted through social relations, but that these are informed (and constituted by) particular discourses about nature and the nature-society relationship. For Braun, nature is thus thoroughly and inescapably social-not because a material nature or external reality does not physically exist, but simply because there is no way to know, represent, or talk about nature (as an external reality) without engaging with and entering into discourse (Braun and Wainwright 2001: 45).

The particular significance of this type of social constructivist work is that it establishes as political any attempt to specify what 'counts' as nature, highlighting that any reading of nature emerges from a particular social position, rather than from an objective observation of an external, pre-given entity. Importantly, the idea of nature as a social construction opens the way for alternative imaginings of nature to those which predominate in industrial capitalist societies—where nature exists mainly "as a stock of resources for the accumulation of wealth and for nation-building projects" (Braun 2002: 2). Indeed, Escobar (1999) suggests that we need to move towards an antiessentialist approach to nature, which recognizes it as having no essential identity but rather emphasizes that a multiplicity of understandings or 'regimes' of nature exist. These

\footnotetext{
${ }^{9}$ Readers interested in learning about other ways of understanding nature as a social construction are referred to Demerit's (2002) helpful typology and critique of social constructivist of nature accounts.
} 
emerge in different lifeworlds and landscapes, and the relationship they posit between nature and society are both historically specific and "related to modes of perception and experience, determined by social, political, economic, and knowledge relations, and characterized by modes of use of space, ecological conditions and the like" (ibid.: 3). Such an antiessentialist vision would thus recognize that "nature is experienced according to one's social position and that it is [also] differentially produced by different groups in different historical periods" (ibid.: 5). In its recognition of nature as socially produced and constituted, then, the literature on social nature poses the critical question of what kind of nature we want, and with what effects (Bryant 2001; Braun 2002). It is this question that I seek to examine from the organic farmers' perspectives within this thesis.

\section{The Social Construction of Place}

In this thesis, I also investigate how organic farmers in South-eastern Ontario discursively construct the local within their efforts to localize the agricultural economy. I explore the particular social and material effects of this discourse, and how it understands the relationship between the local and the global as it plays out in agricultural systems and social life more generally. In my analysis, I draw on recent theorizing from human geographers that centres around the topic of the social construction of place, space, the local and the global ${ }^{10}$ - that is, of what Doreen Massey

\footnotetext{
${ }^{10}$ In the literature I review here, there is considerable overlap between conceptualizations of some of these terms, and particularly between the local and place. The relationship between the local and place is not immediately clear in most theorists' accounts-while the former is sometimes characterized as a particular location in geographical space, and the latter as a scale by some writers, others use the two terms almost interchangeably. Because my primary concern in this thesis is with how organic farmers construct the local, I have tended to use this term more often, even though some of the theorists I draw on focus their efforts more directly on the concept of place. Here, I conceptualize the local both as the scale of farmers' everyday lives and at which they deliberately choose to practice, but suggest that its articulation in and
} 
(2004) has called 'spatial identities'. The body of literature that has arisen around this topic over the 15 years is substantial in both size and complexity. My intention here is not to provide a comprehensive review or genealogy of this literature, as such an undertaking is beyond the scope of this thesis; rather, I seek to provide a deliberately short and simplified introduction to key concepts from the literature that are of relevance to this thesis.

One of the primary goals of the literature around the social construction of space is to problematize the assumption that spatial identities, such as the local and the global, exist in a pre-given state, as self-evident spaces or scales that exist outside of social activity. Rather, it suggests that spatial identities such as places, the local, and the global are the products of social relations, of the complex interactions that make up social life (Massey 1997, 1999). Inherent in this understanding is the recognition that places or the local are not merely a physical site in geographic space, but that they also have important symbolic dimensions. By serving as the spaces of cultural practice and everyday life, places (or the local) serve as sites in which meanings and social (cultural) identities are generated and practiced, and come to carry these meanings within them (Escobar 2001). Thus, places have both material expressions and what Escobar (2001) has described as a phenomenological 'sense' to them. The body of literature on the social construction of space, then-like that on social nature - is concerned with how spatial identities such as the local and the global are produced in both the material and the symbolic senses.

through these practices means that it cannot be disembedded from its particular location in geographic space; that is, that for participants in this study the local is grounded in the specific local environments and cultures of South-eastern Ontario, where they live and work. As I discuss in the main text, I thus conceptualize the local as having both material and symbolic dimensions. 
The practice amongst theorists of recognizing spatial identities such as the local and place as socially constructed originated out of a desire to combat claims to place based on an essentialized notion of that place (Massey 2004). This desire is based in the idea that essentialist visions of place often exclude a proportion of those who reside therein or who wish for other reasons to make claims to that particular place (ibid.). Further, essentialist 'defence of place' or 'defensive localism' efforts may depolitize place/the local by positing these as purified, conflict-free zones (Goodman and DuPuis 2005). As I explore in Chapter 5, for example, a growing number of theorists working on food system localization have begun to question whether some localization efforts may hinge on narrow ideas of tradition or identity that actively exclude some local populations who do not meet these definitions, hence installing 'elite' conceptions of the local. Seeing space as socially produced and constituted establishes as political the terrain on which any spatial identity, such as the local, comes into being as a concept. The local, rather than being an essential identity with inherent qualities, is revealed as a political construction anchored in particular social positions, and with particular social effects.

Social scientists have been keen to detail the particular constructions of the local and the global that predominate today, particularly as they are articulated in discourses of economic globalization. Typically, these discourses have tended to construct the global as a site of homogeneity and formidable power and the local as a site of particularity and as powerless. As Escobar (2001: 155-156) describes, in globalization discourses "the global is associated with space, capital, history and agency, while the local, conversely is linked to place, labour and tradition". Of course, these discourses also inscribe a particular dynamic between the local and the global, whereby "the global is a force, the 
local is its field of play, the global is penetrating, the local penetrated and transformed" (Gibson-Graham 1994: 27). These discourses posit globalization as inevitable and local sites as lacking any significant agency to resist or even alter globalization's path (GibsonGraham 2002, 2003; Massey 2004). However, recognizing that such discourses rest on particular constructions of the local and global rather than on a reflection of their true essence allows us to see that there is nothing inherent about globalization, and that the fate of the local is not sealed. As J.K. Gibson-Graham $(2002,2003)$ has pointed out, recognizing the local and global as constructions allows us to ponder alternative constructions which posit the local as a site of power, as able to resist and even rework the global, hence opening new futures for the local other than those posited by globalization discourses. In this thesis, I explore how organic farmers' efforts to localize the agricultural economy challenge discourses of globalization and the future these offer to farmers and local communities in South-eastern Ontario.

Understanding the local and the global as constructions also renders problematic the notion of a clear distinction between them, revealing that each of these realms depends on the other for its very definition. Since the local and the global are each defined by what the other is not, they are recognized as participating each in the others' constitution (Gibson-Graham 2002). Further, as Massey $(1997,1999,2004)$ has suggested, in conceptualizing spaces and places as produced through social relations, we must also accept that these relations occur at a variety of scales, involving both those who reside in the particular places that we think of as local, and those in other locations, to whom the people in the local are irretrievably connected by flows of capital and ideas. As such, places come to exist through politics and processes occurring at a variety of 
scales, from the "unimaginably cosmic to the intimately tiny" (Massey 1999: 283). For Massey, this raises the danger that local populations might also fail to acknowledge and hence exclude the translocal interests embedded in local places, interests that should be considered in deciding those places' future trajectories. Against this, she suggests that we need to move towards a 'relational conception of place' which acknowledges place as both materially and symbolically constructed by people in a variety of locations and at a variety of scales, understanding it thus as open rather than closed or exclusionary, and as characterized by porous rather than strong boundaries. Similarly, for theorists such as Erik Swyngedouw (1997), the participation of both local- and global-scale politics in constituting social life raises questions as to whether localization and globalization are necessarily distinct processes; he suggests that they might be better conceptualized as interlinked in complex ways. Indeed, in his view, scales are understood not as distinct but rather as nested each in the other and as simultaneous (ibid.). In this thesis, I bring the ideas of these theorists to bear on the organic farming movement in South-eastern Ontario, investigating the complex ways in which the local and the global are mutually entangled.

\section{Methodology}

In undertaking this research, I have utilized a critical feminist methodological framework. Many feminist critiques of positivist research draw heavily on concepts from poststructuralist theory, and have many dimensions. Here, I specifically engage with their problematization of the notion of a universal 'truth' discovered through the research process, their insistence that care be taken in the interpretation and presentation of 
research results to avoid essentializing research participants and topics, and their emphasis on the power dynamics which mark all research relationships and which tend to distribute authority and control towards the researchers. These critiques emphasize the need for researchers to engage in reflexivity so as to examine their own positions and actions in the research process - a need that is echoed by political ecologists amidst the field's increasing engagement with critical theory (e.g., Gezon and Paulson 2005).

By reflecting on my own social position and its potential effects on my research, I seek to acknowledge that the knowledge produced by this research and recorded in this thesis is contingent, partial and situated, so as to avoid as much as possible the chance that it will result in the subjugation of other knowledges and knowledge-producers (Rose 1997) ${ }^{11}$. I have approached this topic out of support for organic farming and with an appreciation of the difficult situation of organic farmers (and indeed small-scale farmers in general) in Canada and many other countries around the world. I consider myself a supporter of the organic farming movement in both its ecological and social justice dimensions. The development of the organic farming movement as an alternative food system is inherently tied up with an agenda for social change, but I also desire to contribute to social change in my own actions, including through this research and this thesis. In common with other political ecologists, then, I conceptualize my work as committed to both understanding and action, that is, to contributing both to sound environmental management and to the empowerment of disadvantaged social groups (e.g. Peet and Watts 1996; Gezon and Paulson 2005).

\footnotetext{
${ }^{11}$ Although, as Rose (1997) has pointed out, I understand that the degree to which I am transparent to myself, and so can know the full effects of my social position on my research, is limited.
} 
I have aimed in this research to hear, record, and interpret voices that have been quieted by the persistent favoring of conventional agricultural approaches by national governments and international bodies, and private business interests. In this sense, I view my project as helping to put into wider circulation discourses of organic farming as an alternative to the current system of food production (c.f. Peet and Watts 1996: 34). This being said, I set out not to speak for organic farmers as a subjugated population, but rather to "speak of their struggles and speak with them" (Barron 2000: 94; emphasis hers). I attempt to show that organic farmers are powerful and that their efforts to set up alternative food systems are succeeding, even while documenting the farmers' constraint by the difficulties that beset any small farmer in Canada today. I seek to participate in a project that might reaffirm this success both to external parties and to the farmers themselves, thus, to approach research as a process that participates in the constitution of social identities (Gibson-Graham 1994). Further, I greatly respect the intense, evolving, grassroots, largely democratic, self-regulating history and nature of the organic farming movement, and consider myself as engaged in a process that might help the movement retain a similar evolutionary pattern into the future. In these endeavors, this research shares some similarities with action research approaches, which suggest that "it is the responsibility of the researcher to get involved in research that matters to the people affected by it" (Hoggart et al. 2002: 288).

In my research, I have also tried to avoid searching for or recreating an essentialized research subject, that is, to avoid making research subjects out to be more homogeneous, coherent, timeless, and different from other populations, than they might actually be (Abu-Lughod 1993: 7-9; see also Barron 2000). I have tried to emphasize 
nuance in my work and to highlight differences where they exist amongst the research subjects. In other words, I've tried to explore rather than silence contradictions that arose during the interviews ${ }^{12}$.

Finally, I have sought to acknowledge in my work that the relationship between the researcher and the research is power-filled, and to closely examine the dynamic between self and other that permeates the research process (Cotterill 1992; Fine 1994). Critical feminist accounts stress that research relationships are often slanted in favour of the researcher, because it is the researcher that designs and asks the questions and, perhaps more importantly still, interprets the answers (Rose 1997). Because I was worried about creating a very unbalanced research relationship, and specifically wanted participants to feel empowered rather than disempowered in/by this relationship, I deliberately chose to pursue interviews with a more conversational than strict or formal flavour, to follow procedures that would help to ensure the participants retained some measure of control over the interview process, and to disseminate my research broadly. With these thoughts in mind, I turn to a specific examination of my research methods, before returning to an examination of the research relationship as I experienced it while conducting and interpreting the interviews and completing the discourse analysis on which this thesis is centred.

\footnotetext{
${ }^{12}$ Interestingly, in doing this, I often felt I had to fight to overcome a certain desire to continually search for a view that would somehow expose the apparent contradictions to be non-contradictory, and, initially, to doubt my analysis when I couldn't find such a view, as though that meant I was getting my analysis 'wrong'. Eventually, I accepted that irresolvable contradictions are part of the inherent 'messiness' of research and of the way we as social beings think about the world; contradictions are part of what makes things interesting, and to this end I tried to detail rather than resolve them.
} 


\section{$\underline{\text { Research Methods }}$}

This research undertakes an analysis of the particular discourses that organic farmers draw on in their understandings of organic farming practice, and in their efforts to position and develop organic farming as an alternative system of food production to that which predominates in South-eastern Ontario. It investigates these discourses as they were articulated in a series of in-depth, semi-structured interviews completed with organic farmers in the region. It also compares these articulations with how organic farming is understood and represented by the Canadian federal government, and analyses the conflicts that arise between this discursive framing and that articulated by farmers in the region. To this end, it draws on government documents pertaining to the Canadian agricultural sector and its functioning over the past decade, as well as on academic literature analyzing the historical development of agriculture in highly industrialized countries over the past 60 years, including that which focuses on organic farming movements in particular.

\section{Participant Selection}

This research relied on in-depth interviews with 23 organic farmers from the South-Eastern Ontario area. The farmers who participated in the research were initially identified through directories available in print forms or on the internet ${ }^{13}$, and were initially contacted, informed of the research, and asked whether they would participate by

\footnotetext{
${ }^{13}$ Specifically, I used the Canadian Organic Growers Ottawa Organic Food Directory (http://www.cog.ca/ottawa/ottlist_2005.htm), the Kingston Organic Foodlink Brochure (http://www.kingstongreens.ca/mainPages/Kingston_Foodlink.pdf) and the EcoPerth Local Flavour Campaign Farmgate Sales list (http://www.ecoperth.on.ca/).
} 
e-mail and/or by phone. As the research progressed, participants recommended other farmers who might be willing to participate. Although I would have liked to specifically select participants covering a range of socio-economic conditions, genders and ages, I was constrained by the fact that there are not very many organic farmers within easy driving distance, and in the end I accepted as participants all those I could find who were willing to participate in the research. Similarly, while I originally intended to focus mainly on farmers producing organic field crops and/or livestock or animal products such as dairy or eggs, the small size of the local organic farming population encouraged me to expand my focus to consider a few organic market gardeners and an organic orchardist. Further, participating farmers tended to boost the diversity of farmers and farming activities encompassed in the overall sample since they frequently suggested people whom they thought had an innovative attitude about a particular type of farming (e.g., dairy), or farming activity (e.g., marketing) that they themselves were uninvolved in, had limited experience with, or felt they were weaker at performing.

\section{In-Depth Interviews}

My primary data source for this research was a series of in-depth, semi-structured interviews completed between February and April 2005. The interviews were completed in person at a time that was convenient for the farmer, usually in the farmhouse kitchen or elsewhere on the farm as the farmer went about chores. Prior to beginning the interview, I shared a one page description of my project and an informed consent letter with the farmers, which they signed before we proceeded. These assured the farmers that they could stop the interview at any time, choose not to answer a particular question or 
retract any answer they had given, and be afforded anonymity in the presentation of the results. In most cases where a farm had more than one active operator, I interviewed only one of the operators; however in a few instances a second operator or the operator's partner sat with us and participated in all or part of the interview. In the instances where I spoke with only one of the operators, it was often the farm woman that I spoke with, this seemed to result from their increased comfort in talking to me as another woman or in some cases from the fact that the woman was very actively involved in farm politics in the region ${ }^{14}$.

The interviews were semi-structured in that they were guided by a list of questions, which focused on the basic characteristics of the farm, the farmer's history with organic farming, their motivation to farm organically and their understanding of organic philosophy and practice, the constraints and opportunities to the organic sector, and the financial feasibility of organic farming (see the Interview Guide in Appendix 1). The interviews also included questions on particular issues that were identified as important based on a review of the academic and popular press, including the conventionalization of the organic sector, biotechnology and seed control and food and environmental politics more generally. The emphasis placed on different subjects or areas varied quite significantly between interviews. Questions were dropped and added as the first round of interviews progressed, in part due to a narrowing of my research focus. I realized, for example, that what I was interested in knowing about on-farm practices usually came out in general discussion and that I needn't have quite so many

\footnotetext{
${ }^{14}$ This led me to wonder whether the more social work of talking with people and farm advocacy and networking was consciously or unconsciously viewed by some participants as woman's work, while men were more concerned with the practical functioning of the farm. Indeed, as suggested earlier in the chapter, there are many interesting intersections between gender and organic farming which future researchers would do well to investigate more thoroughly.
} 
technical questions as I had in the first few interviews. Further, if a farmer had been identified to me as being a particular expert in or having a particularly novel approach to a particular subject or practice, I added more questions on the relevant topic. I tried to get a sense in the interviews of the aspects of organic farming that most interested the farmers themselves. In most cases I felt that the interviews naturally steered themselves in these directions; and rather than try to divert this flow I found that letting it happen often uncovered interesting diversions and subjects that begged further exploration. The result was a collection of transcripts that were perhaps less cohesive than they could have been, but that still had many commonalities and overlaps, and that I believe were richer for these unplanned discoveries.

The interviews were recorded on audio tape cassettes. The shortest interviews took only an hour and a half, but some stretched on for four or five hours (some farmers, it seemed, were intent to hold true to their warnings that they might talk my ear off if I came out to see them!). After answering a question themselves, many farmers asked about the answers other farmers had given, and many returned the question to me to answer or asked additional questions of their own - indeed, at moments I wondered who was being interviewed! Thus, the interviews usually had more the atmosphere of a relaxed conversation-over-coffee than a stiff or formal interview, albeit with a few farm touches such as a newborn lamb stumbling about our legs or with the tape recorder nearly buried under seed packages and dirt in a busy round of seed-starting.

Most farmers were enthusiastic discussants in the interviews, and they were all tremendously encouraging of my efforts. In many instances the farmer offered to take me on a tour of the barns (the fields, which were under snow at the time of the interviews, 
were more difficult to tour and so field operations were generally explained from a window with a good vantage point), and in each case I accepted. The farmers were also phenomenally hospitable, offering me meals and in one case providing me with accommodation when an unexpected blizzard made it suddenly and dramatically unsafe to drive such that I was stuck in the country for the night. I tried to repay these farmers' efforts by helping out with whatever small tasks I could during my visit, by finding information they requested or wondered about during our interviews, and by helping out at the rallies and events many of them are actively involved in organizing.

\section{Discourse Analysis}

Rose (2001) suggests that, among other things, a discourse analysis may: consider both how discourses are articulated and the practices they entail, analyze the social context of discursive statements (who is saying them, in what circumstances), look at how supposedly 'pre-existing' categories and specific views of the world are socially constructed, look for what isn't said and what is made invisible, look at the institutional location(s) of a discourse, address questions of power/knowledge, and consider the social effects of discourses. In this thesis, I have focused in particular on two discourses articulated by organic farmers in South-eastern Ontario, that concerned with naturalizing the agricultural production process, and that concerned with localizing the agricultural economy. During my analysis, these emerged as two of the primary goals of the local organic farming movement; however, they are certainly not the only significant discourses which organic farmers both mobilize and draw on. 
My analysis specifically investigates how farmers practice 'naturalizing the production process' and 'localizing the agricultural economy', and the particular constructions of nature and the local—both commonly viewed as self-evident, "preexisting' categories-which their practices and discourses mobilize. It investigates the conflicts that come up in the process of articulating these discourses (which inevitably leave out elements of organic farming practice), and addresses the social consequences of these articulations as they are experienced by the farmers.

\section{Participant Observation}

In addition to speaking with farmers through interviews at their farms, I was also able to interact with them at a number of events well-attended by the organic farming community. These included two conferences: the National Organic Conference held at the University of Guelph each January, and the EcoFarm Day conference organized by the Canadian Organic Growers each February. I also attended numerous public talks and discussions on issues pertaining to sustainable agriculture and biotechnology organized by non-governmental organizations, universities, and farm groups. Finally, I participated in rallies organized by the National Farmers Union and informal networks of farmers. In all of these places, and at farmers' markets during my own weekly shopping expeditions, I talked to farmers, discussing a wide range of issues and soliciting their comments on the perspectives offered by speakers and by the government in recent ministerial announcements. These interactions were instrumental in giving me a sense of the larger context within which my own research was situated. 
In June of 2005 after I had completed the interviews, transcription, and the first round of analysis of my findings, I began a paid job working half-time with the Ottawa Chapter of the Canadian Organic Growers. The experience I had gained in my thesis research was central to me getting the job. In the course of this work (which stretches through to April 2006), I have had innumerable other conversations with farmers and with some regulators of the organic sector, and have been plunged into the highly political terrain that is the organic food system in Canada. Because I did not have consent to use these conversations towards my thesis, in the account that follows I have included only farmers' comments from my original research. However, due to the iterative nature of analysis (and the fact that for me it happens largely in conjunction with the process of writing), this thesis has almost certainly been affected by my interactions in the course of my job.

\section{Review of Government and Farm Interest Group Documents}

Starting in the autumn of 2004 , documents relevant to the research topics issued by the Ministry of Agriculture and Agri-Food Canada (AAFC; federal jurisdiction), the Canadian Food Inspection Agency (CFIA; federal jurisdiction) and the Ontario Ministry of Agriculture Food and Rural Affairs (OMAFRA; provincial jurisdiction) were gathered from the organizations' websites and reviewed. Publications issued by interests group active on issues around small-scale and organic agriculture (especially the National Farmers' Union (NFU), the Ecological Farming Association of Ontario (EFAO), and the Canadian Organic Growers (COG)), such as position papers, issues of the monthly magazines, campaign literature, and other documents available on their websites or in 
print, were also reviewed. While I do not engage either the government publications or those of the interest groups extensively or directly in the following chapters, they certainly underlie my analysis of the issues in the organic farming community.

Review of Academic and Popular Literature

Organic farming has received and continues to receive significant attention in the academic and popular literature in the past decade. This research draws on academic journal articles published in leading social science journals, as well as books published by academic presses. The bodies of literature I have reviewed (see, especially, Chapter 3) have focused mainly on various aspects of the political economy of agriculture in Canada and other highly industrialized countries, on the rise of 'alternative food movements', and on organic farming movements around the world. I have also drawn on books published by social interest groups and indeed, farmers themselves. Finally, the thesis has drawn on print articles, and radio and television programs from national and municipal level media sources, as well as print articles from popular magazines.

\section{Research Dissemination}

I consider research dissemination to be a critical part of the research process, and conceptualize it as one way of returning the results of one's work to one's research community. To this end, I plan to disseminate the findings of my research broadly not only in the academic press, but also in the popular and farm literature. A number of the participating farmers have asked to read my thesis after it is finished, and I plan to 
contact all participants once it is complete and offer to send along copies. Further, I collected ideas for unique ways to disseminate my research during my interviews, and hope to pursue putting together a radio program and possibly using what I have learned to contribute to college curricula on organic agriculture.

\section{Reflections on the Research Experience}

From the vantage point of having (nearly) completed this research, I also wish to reflect further on the power dynamics inherent in doing research, and on whether my research achieves my initial goal of contributing towards social change. For me, power relations were first evident in the mixed experience of insider/outsider that one is plunged into as a researcher (Mohammad 2001). There were times during the interview that $I$ felt like an outsider, mainly among long-time farmers who themselves had come from farming backgrounds, if less so around new farmers, many of whom shared similar backgrounds to my own. I regularly had strong feelings of being an outsider when asked where I was from, for I had to admit that I grew up in Toronto, certainly not farming country and disparaged, it sometimes seems, by farmers everywhere. I sometimes imagined that what saved my credibility in those moments was the fact that I completed my undergraduate degree at the University of Guelph, the primary agricultural college in Ontario, which, despite its reputation for promoting intensive, chemical-based production methods, seems to resonate with farmers on a similar scale to the discordance of my home town. At the same time, while I am not a farmer, my love of organic gardening, my support for the organic farming movement, and my involvement in a number of advocacy and action projects around sustainable food systems meant that I often felt 
some measure of an insider position during the research. Further, my research led into an ongoing period of self-reflection as to my own goals in life, and whether becoming an organic farmer might be one of them. For many of the interviews, I felt that I existed in the space between insider and outsider, and between the self and the other-I was 'working the hyphen' between the researcher and the researched as Michelle Fine (1994) has put it.

Despite the assessment of many critical accounts that it is the researcher who holds the power in the research relationship, I often felt during the interviews that it was the farmers who had the power-possibly because they were so opinionated, passionate and forthcoming, but also because they never hesitated to turn a question back on me, a situation that I simultaneously felt to be only fair and somewhat intimidating. In this sense, my experience of doing research is that it is full of contradictory social positions, such that the power relationship between the researcher and the researched is complex, and always shifting (Cotterill 1992). Further, while it is true to some extent that the power is always in favour of the researcher, who can ultimately walk away at the end of the research, this has not been my experience, for I have continued to engage with the subject matter (and indeed some of the participants) of my research in my working life with COG, and I hope to continue to do so given my continuing commitment to establishing sustainable food systems. Finally, while the professional language of academic studies is inevitably a language of power (Abu-Lughod 1993), I have deliberately tried to write my thesis as much as possible in plain language in order to make it accessible to participants. 
Because the farmers who participated in this study were so very welcoming and encouraging, I suspect that my research was much easier than it might have been. I got the sense from some of the farmers that they found the interview affirming, whether out of the therapeutic experience of being able to talk to a sympathetic listener (Cotterill 1992), or because the research relationship served as a site where farmers could construct their identity anew (Gibson-Graham 1994). This was rewarding for me given that some farmers in my initial contact with them had complained of research fatigue, such that I had worried about 'troubling' them with my research. Few, if any, other researchers, it seemed, had focused on the farmers' personal experiences and philosophies, and many of the farmers clearly relished the opportunity to speak with an interested person about these topics. Still, I feel that the contributions farmers have made to my personal opportunity for learning (and of course towards obtaining my M.A.) far outweigh the direct benefits they might have received through their participation, and I remain unsure as to how or whether this situation might be resolved.

At the same time, I am increasingly aware that my research alone may not result in tangible social change, although I set out to pursue research directed towards this goal. I remain bothered by an experience at the session on social research at the Guelph Organic Conference in January 2005, which I attended immediately prior to beginning my interviews. It was at this session that, after listening to a steady stream of academics present their research over a 3 hour period, a farmer stood up and in a kind but pointed way asked what this research was really accomplishing in terms of changing the strangling circumstances in which farmers like him find themselves operating today. It was a question that none of the academics in the room could easily answer (no one 
attempted to), and it is one I continue to struggle with today. The only redress to it that I have yet found is in an insight I had when I had just begun the writing process, when it became evident that perhaps I was looking for social change in the wrong locations. It suddenly occurred to me that perhaps I had to look within myself. At that point I decided that if all this research amounted to was that it changed the way I ate, the way I shop for my food-if it left me unable to ever look at our food system the same way again, which indeed it has-then perhaps it would have met my initial goals after all. In this sense, my experience of the research relationship is that it can be transformative for the researched and the researcher alike (Kobayashi 2001).

\section{Introducing the Farmers}

In this, the final section of this chapter, I introduce the organic farmers who participated in this research. Below, $I$ focus in particular on the geographic region in which this study takes place, on the characteristics of the participating farms, and on the farmers' personal histories with farming. I have also collected more specific details of the farms into a table, presented in Appendix 2. Because I guaranteed the farmers that they would remain anonymous in my written results, where I quote them in the thesis I identify them only by their gender and by the nature of their farm or farm products. As such, the numbering scheme in Appendix 2 has no bearing on the remainder of this thesis.

The 23 organic farmers who participated in this research project farm in Southeastern Ontario, within the area bordered by Peterborough on the west, Lake Ontario and the St. Lawrence River in the South, and the provincial border with Quebec on the North 
and the East. The study region includes one major city, Ottawa (population 774,072), one mid-sized cities Kingston (population 114, 195) and numerous smaller cities such as Peterborough, Belleville, Trenton, Napanee, Brockville, Perth, Cornwall, and Hawkesbury. Most of the farmers live within an hour of at least one of these cities. As in much of the province and the country, agricultural production in the region continues to occur mainly on family-owned farms, whether conventional or organic. Amongst those farms in the region producing for the conventional agricultural system, the main products are dairy, beef, and field crops (grains and oil seeds).

The participants in this study are active in a range of different types of organic farming activities, which aim to produce a wide variety of different organic products and which operate over a range of scales. According to how the farmers themselves classify their operations, this study includes 16 farmers who operate farms, six who operate market gardens, and one who operates an orchard. Farms are typically larger scale operations than market gardens, and focus predominantly on producing livestock or animal products such as dairy or eggs, and/or producing field crops such as grains and oilseeds. Market gardens are smaller operations and they typically focus more exclusively on vegetable production than do full farms, sometimes augmenting this with herbs and/or cut flowers. Orchards focus on producing tree fruit. However, the participants in this study show the distinction between these types of operations, and especially between farms and market gardens, is a fuzzy one, since a number of the market gardens produced animal products, one grew crops as animal feed, and one was 
beginning to produce fruit ${ }^{15}$. A number of the farms and market gardens also produced seasonal products and/or value added products such as prepared foods.

The farmers who participated in this study, then, operate mainly mixed farms, that is, farms that are reasonably highly diversified in terms of the products they produce. Many of the farms focus on a primary product (dairy, beef, cash crops, or vegetables, for example) but supplement this with other products for sale and/or for personal consumption. This is an important contrast to conventional agricultural operations, which over the past 50 years have been undergoing a trend towards increasing levels of specialization ${ }^{16}$. With this qualifier in mind, four of the farms who participated in this study are primarily dairy farms. One primarily produces beef, and another a range of different organic meats. The remainder of the farms are difficult to classify because they are approximately equally involved in a range of different activities and products. Table 2.1 indicates the types of agricultural products produced by farmers in this study, and Table 2.2 those produced by market gardeners.

\footnotetext{
${ }^{15}$ Nonetheless, some distinction between farms and market gardens is important, since more than one farmer involved in a larger scale farming operation told me they didn't consider even the most diversified operators amongst their market gardening counterparts 'true farmers'.

${ }^{16}$ The diversified nature of organic farms is interesting given that increasing levels of specialization are a common attribute of productivist agricultural systems. In Canada, Ben Bradshaw (2004: 36) has suggested that the combination of subsidies and commodity price supports offered by federal and provincial governments as well as the availability of publicly funded crop insurance has yielded "the widespread adoption of a strategy of expansion and intensification based on a very narrow range of outputs", a trend exacerbated by farmers' attempts to take advantage of the specialized knowledge and equipment that increasingly came to characterize productivist agriculture, or more generally to pursue economies of scale. Most theorists have suggested farmers take up output diversification as a 'risk management' strategy (i.e., a way to buffer downturns in the market for and/or to mediate against production failures in any particular product; see Bradshaw 2004). Indeed, in the face of the farm income crisis at least some farm groups in Ontario - the National Farmers Union, for example-are promoting diversification as an effective risk management mechanism. However, as Chapter 4 will suggest, the organic farmers in this study are diversified not only for economic reasons, but also ecological ones. Further, a number of farmers suggested that organic farms were diversified because of a particularly innovative attitude amongst organic farmers.
} 
In this study, half of the farmers were working a combination of owned and rented land, while the other half owned all the land they worked. The smallest amount of land a farmer had in production was 60 acres, and the largest was 450 acres. Market gardens were more variable in size, with the simpler operations tending to be smaller ( 2 to 8 acres), and the more diversified operations tending to be larger (up to 80 acres). Farms and market gardens who kept livestock tended towards smallish herd sizes, ranging from 20 to 130 animals.

Table 2.1: Agricultural Products of Farms in the Study

\begin{tabular}{|l|l|}
\hline Agricultural Products & $\begin{array}{l}\text { Number of Farms in Sample } \\
\text { Producing Product }(\mathrm{n}=16)\end{array}$ \\
\hline Exclusively field crops & \\
\hline Mixed livestock and field crops & \\
$\rightarrow$ field crops as animal feed for use on the farm & 3 \\
$\rightarrow$ field crops as cash crops & 3 \\
\hline Mixed livestock and vegetables & 1 \\
\hline Mixed crops and vegetables & \\
\hline Mixed livestock, crops and vegetables & \\
\hline
\end{tabular}


Table 2.2: Agricultural Products of Market Gardens in the Study

\begin{tabular}{|l|l|}
\hline Agricultural Products & $\begin{array}{l}\text { Number of Gardens in Sample } \\
\text { Producing Product (n=6) }\end{array}$ \\
\hline Vegetables only (undiversified) & 1 \\
\hline Vegetables and animal products (meat, eggs) & 2 \\
\hline Vegetables and one field crop & 1 \\
\hline Vegetables and fruit & \\
\hline
\end{tabular}

Three of the organic farmers in this study entered farming with no previous family history in the agriculture sector, one of whom had retired to farming. Twelve of the farmers were previously farming under conventional methods before switching to organic production, many on the same properties which they now farm organically. Most of these came from farming families; one is the fourth generation of his family to farm on the property, and another the fifth. Two of the farmers had previously farmed in other countries (in Southern Africa and in Australia). One farmer recently emigrated with his family from Germany because he was determined to farm and could not afford land in that country. Two of the market gardeners had retired to farming, both of whom had grown up in farming families, one organic and one conventional. Of the remaining market gardeners, two had had minimal or no agricultural experience, one grew up on a farm, and one in a family with extensive gardens.

Two of the first farmers to take up organic production in South-eastern Ontario participated in this study. They have been farming organically for 21 and 22 years respectively. The majority of the participants, however, have been farming organically for somewhere between 5 and 10 years. The market gardeners were more evenly spread 
out in terms of the number of years they had been farming. Two were quite new to farming, having started their practices within the last 5 years. The others had been farming for longer periods of time.

Based on the manner in which they were selected, I consider the farmers who participated in this study to be broadly representative of organic farmers in South-eastern Ontario. To this end, I refer to them collectively at points in this thesis as the organic farming movement. However, I do so with the awareness that this necessarily homogenizes a heterogeneous group of people. As such, I would like to suggest, as has Timothy Vos (2000) that:

"At the outset, it is important to note that organic farming can not be viewed simply as a single unified or homogeneous social movement or political agenda, nor as only one particular style of agriculture. One can identify a diverse range of perspective and practices that fall under the rubric of organics. Most significantly, it is important to try to distinguish between the organic farming movement (as a "traditional grassroots coalition of small-scale producers) and the nascent organic farming industry...[T] he terms community, movement, or industry should be loosely construed, representing a more or less diffusely organized and heterogeneous group of people or organizations tending toward or favouring a generalized common goal or goals, and not at all without internal differences even regarding those common goals" (p. 245)

In the chapters that follow, I provide some additional details on the practices, experiences, and philosophies of the farmers who participated in this research. However, I first turn to an overview of the political economy of conventional and organic agriculture in Canada. 


\section{Chapter 3: Agriculture in Canada: from 'Productivism' to 'Organics'}

Over the past 60 years, the agricultural sector in Canada has undergone dramatic changes, changes that have had many important consequences for farmers, farm communities and farm environments. These changes and the contemporary agri-food system that has resulted have been actively shaped by national governmental policies and regulations, which in turn have been shaped by broader political economic forces and conditions. The productivist agricultural system that continues to predominate in Canada today arose in response to pressing concerns in the post-war period around food security and the stability of farm incomes and populations, and has been reshaped more recently by national policies which reflect neo-liberal concerns around removing production subsidies and barriers to trade, and around promoting agricultural exports. These policies have given rise to a number of problems, experienced most directly by small farmers, including recurring farm income crises and growing concerns about the environmental and health effects of conventional agricultural practices. These concerns have contributed to the emergence of an array of "alternative food movements", which seek to address a number of these problems. As one of these movements, organic farming has grown rapidly over the past few decades and has now attracted the attention of not only farmers and consumers, but also of governments and large agribusiness firms. As discussed in the final section of this chapter, the institutionalization and 'conventionalization' of organic agriculture are key topics of debate within the organic farming movement today. 
This chapter is divided into two main parts. In the first part, I aim to provide for the reader a sense of the broader political and economic context in which any small farmer in Canada_including, of course, organic farmers-currently operates. To this end, I provide an overview of the rise of the productivist agricultural system in Canada in the post-war decades, and of the neoliberal restructuring this system has gone through since the 1970s. I focus in particular on the consequences of both the productivist system and of the restructuring changes for farmers, farming communities and farming environments, highlighting the social and environmental crises that have emerged. I then introduce the alternative food movements that have arisen in response to these crises, before turning to look more specifically at the emergence of organic farming.

The second part of the chapter focuses more explicitly on the historical development and contemporary structure of the organic farming movement in Canada, highlighting in particular the roles that farmers, government and civil society have played in this process. Finally, I turn to a review of some of the key issues and debates in organic farming movements and the literature that describes them today. In particular, I focus on processes of 'conventionalization' and institutionalization which have the potential to radically transform organic agriculture.

\section{Part 1: The Political Economy of Agriculture in Canada}

Agriculture from 1945 until the 1970s: The Rise of Productivist Agriculture

In the period that spanned from the end of the Second World War until the late 1970s, the agricultural sector in Canada, as in most other highly industrialized countries, 
was shaped by a strong system of state intervention designed to stabilize and expand the agricultural sectors of the economy. Maintaining farm populations, incomes, and agricultural production levels in these countries in the face of industrial expansion was a politically and socially sensitive issue following the war, as were concerns over national food security. This sensitivity led developed nations to insist that agricultural commodities be excluded from the General Agreement on Tariffs and Trade (GATT), the agreement put in place by the Bretton Woods system as a way to lead the warbeleaguered nations towards economic recovery (McMichael 1994; Buttel 1997; Sharma 2000). Rather than being thrown open to the market, the national agricultural economies of these nations thus came to be regulated mainly by the nation-states themselves, which sought to institute a range of stabilizing and protective mechanisms which would contribute to the nations' broader, welfarist, rural development strategies (Marsden 1998) and serve to protect national food security from the potential threats posed by exposure to the international market ${ }^{17}$ (Sharma 2000). In Canada, as in may other developed nations, this resulted in the institutionalization of a strong system of state intervention in commodity markets and the development of government-funded farm support programs during this period (Huff 1997; Hall 2003). In turn, these developments leant a particular structure to the agricultural sector in much of Canada, encouraging in most regions the development and persistence of a system of small-holder family proprietor farms (Goodman and Redclift 1991; Buttel 1997).

\footnotetext{
${ }^{17}$ One objective of such protective measures was to enable nation-states to earmark domestic production for national needs in the event of a critical shortage of foodstuffs, for example, by placing export restrictions on domestically produced agricultural commodities. Exposure of producers to the unmediated market, by contrast, might mean that such commodities could be captured by other states, leading to a national food security crisis.
} 
The 'productivist' agricultural systems that grew up in the highly industrialized countries in the post-war period were focussed on mass production of inexpensive food as a means of addressing the significant shortages of food that existed in the shadow of the war ${ }^{18}$. National agricultural extension programs encouraged farmers to adopt a range of production-boosting farming practices, including intensive growing methods (Marsden et al. 1993), and the adoption of increasing levels of mechanization on their farms (Ilbery and Bowler 1998). The complex mix of national policies, agricultural price supports, and subsidized food programs also encouraged the progressive industrialization of agriculture (Goodman et al. 1987), which increasingly relied on scientific research and technology to overcome the constraints posed by nature to capitalist accumulation (Castree 2001, but see Mann 1989). However, agricultural industrialization proceeded by a course distinct from that of industrialization in other production systems, on account of the reliance of agriculture on biological and biophysical processes that can not be directly and uniformly transformed by capitalist relations of production (Goodman and Redclift 1991). As David Goodman et al. (1987) have argued, the industrialization of agriculture occurred primarily through processes of 'appropriation,' whereby parts of the agricultural productive process are moved off the farm, rendered into industrial activities, and subsequently re-incorporated into agriculture as industrial inputs, as well as through parallel processes of 'substitutionism', whereby agricultural products are reduced to industrial inputs and then replaced by non-agricultural components. This led to the

\footnotetext{
${ }^{18}$ Some agri-food scholars alternately use the terms 'Fordist' or 'Fordist-Keynesian' to describe what I refer to as the 'productivist' agricultural systems which arose in the wake of the Second World War. The former recognizes the influence on the developing agricultural systems of Fordist theories of production, which emphasized "the mass production of a standardized product which was sufficiently cheap that workers could afford to buy it" (Friedland 1997: 228). The latter recognizes both the influence of Fordism and also that of Keynesianism, which saw government intervention as necessary for maintaining an adequate level of employment.
} 
development of strong agribusiness-dominated "off-farm-sectors", which increasingly controlled the production of agricultural inputs such as agrichemicals and seeds, as well as the processing, distribution and retailing of agricultural products, and on whom farmers quickly became dependent. As we will see later in this thesis, this has had important implications for farmers' knowledges and power within the agri-food system.

As new, production-boosting technologies emerged through these processes, farmers were increasingly encouraged by provincial agriculture extension programs to take up their use on the farm-leading, for example, to the widespread uptake of agrichemicals (i.e., fertilizers, pesticides, and herbicides) on the farm. This got farmers started on what many refer to as the "technology treadmill", a self-reinforcing cycle of technological dependency ${ }^{19}$. Regulatory measures encouraged farmers to strive for continued increases in their productivity, and production-oriented subsidies built into the broader commodity- and farm-support programs ensured that they received financial rewards for their efforts in this regard (Marsden 1998; Burton 2004). However, within this period, productivism also came to represent something deeper to farmers, in that the 'productivist ethic' (Thompson 1995)—fuelled by what Frederik Buttel (1997: 346) has described as a sort of collective desire to "make two blades of grass grow where one grew before"- came increasingly to define both to farmers and to the nation what counted as

\footnotetext{
${ }^{19}$ In the technology treadmill, competition in the marketplace encourages farmers to adopt new agricultural technologies that allow for increases in efficiency and/or in the scale of production. While this results in a competitive advantage for the farmer (either in increased efficiency of production or in reduced costs per unit produced), it also means that they often carry high debts incurred through their purchases of technology input. Farmers are thereby encouraged to further increase the scale of their production so as to have the size of operations necessary to cover the debts they have incurred, leading to a demand for new technologies, and so on. At the same time, increasing numbers of small farmers are driven off the farm when they can not access the necessary credit to invest in the latest technology which is now essential to a competitive position in the marketplace. A more detailed explanation of the technology treadmill and its social and environmental consequences is available at: http://socialsciences.ucsc.edu/casfs/instruction/tofg/download/unit_3.3_environmental.pdf
} 
'good farming' and to identify those who produced according to this ethic as 'good farmers'. This moralization of productivism acted alongside the structural factors to ensure the perpetuation of productivist farming systems (Burton 2004).

Collectively, the structural and ideological motivators of production-oriented farming were highly successful. In fact, they were so successful that, by the 1970s, overproduction in grains was a considerable problem, resulting in a downward spiralling of commodity prices. This, along with farmers' growing reliance on the agribusinesscontrolled off-farm sectors increasingly pinned farmers between the high costs of farming inputs and the falling prices of agricultural commodities, leading to falling income/profit rates. Still, farmers were protected to some degree from these effects by state intervention in commodity markets and by farm support programs (Buttel 1997). These protective measures served to stem the rural exodus that might have otherwise resulted in the face of the falling commodity prices, the rapid growth of metropolitan labour markets, and rising real wages in the non-farm industry (ibid.), even as they continued to reproduce the overproduction problem (Hall 2003). However, by the late 1970s the collapse of the Bretton Woods system and the increasingly transnational flows of capital that grew up in its wake meant that internationalization forces were on the rise, putting nations under considerable pressure to begin to negotiate a competitive position for themselves in the world economy (McMichael 1994).

Agriculture since the 1970s: Neoliberalism and the Farm Income Crisis

In Canada, a heavy emphasis on expanding export markets helped to resolve the economic contradictions posed by the overproduction of key agricultural commodities 
and the resulting decline in prices for the duration of the 1970s. Indeed, a variety of factors and forces-national commodity- and farm-support measures, export-oriented policies and programs, low interest rates, heightened commodity prices, and inflated land values - encouraged farmers to invest in land and new equipment, resulting in a substantial increase in farm debt loads. This proved to be disastrous when, in the early 1980s, a combination of the world wide recession and the Third World debt crisis yielded a decline in export markets and commodity prices, a drop in farm land prices, and a dramatic increase in interest rates, bringing the longstanding problems of overproduction and price instability into clearer view (Hall 2003). The combination was catastrophic for Canadian farmers, especially those who had been encouraged to take on large debt-loads in the previous decade, and many lost their farms or were forced to seek off-farm employment to survive. The crisis resulted in an increased level of political militancy among farmers and a rising demand for farmer assistance programs, and drew into question the government's emphasis on increased production and the expansion of export markets to offset price declines (ibid.). In response to this crisis, and out of a perceived need to keep pace with the increasing liberalization of the international economy, the Canadian government moved to restructure and reorient agricultural production policies (Huff 1997; Hall 2003). This was done in such a way so as to bring them more into line with neoliberal ideas, which asserted a need for reduced government intervention in the domestic economy, and for more fully open markets to allow for free trade.

The increasing liberalization of the international economy over the past few decades has had important implications for the agri-food systems of highly industrialized countries such as Canada. Through this process, these countries' earlier welfarist rural 
development goals have been exchanged for more marketized and globalized ones, and as a result of this transition, systems of price support have been steadily losing their legitimacy (Marsden 1998). The contemporary agri-food systems of the advanced capitalist countries have witnessed a movement away from nationally-regulated agricultural economies, and towards development strategies hinging on agricultural trade liberalization and export-oriented policy (Goodman and Watts 1997). Accordingly, many countries have witnessed a scaling back of state subsidies and support programs for farmers, as national governments have shifted from pursuing national coherence within their agricultural sectors to an emphasis on national competitiveness (McMichael 1994: 5). This has serious implications for farmers in these countries, who have become exposed to increasing levels of competition and "new market realities...from which they were protected by earlier protectionist policies" (Winter 2004, p. 664).

Canada, a classic case in this regard, has undergone a significant shift in agricultural policy over the past twenty years, which, as Alan Hall (2003: 10) explains, has been "aimed primarily at sustaining economic growth through a neoliberal model of agriculture which emphasizes global markets, intensive cost-efficient management, flexible specialization and reduced government supports." In other words, the Canadian government has sought to address what it saw as key weaknesses in the structure of the agricultural sector nationally, which it felt were combining with external forces to yield the existing crisis (ibid.). The government has stressed the need to move towards greater market responsiveness in the sector, and to this end it has encouraged flexible production and emphasized a strategy of increased competitiveness through cheaper and more efficient production, citing the need to maximize cost efficiency rather than yields (ibid.). 
This emphasis on efficiency has sometimes been coupled with a suggestion that Canadian farms need to become fewer but larger such that farmers can partake in the increased efficiency seen to be associated with economies of scale. Understandably, this suggestion is generally not well received by farmers, who contest the very notion that they are inefficient in the first place (see, for example NFU 2003).

In tune with their emphasis on export market opportunities, the Canadian government's plan for greater self-reliance has emphasized deregulation and the elimination of trade barriers and support programs, which they saw as discouraging farmers from being cost-competitive and seeking new markets (Hall 2003). To this end, the Canadian government has reduced its production-oriented subsidies to farmers by $80 \%$ in the last 10 years (although other types of subsidies have remained important sources of income for farmers in the fact of recent food scares and weather-related crises $^{20}$, and is purportedly prepared to go further (see Canadian Business 2005). This has had dire consequences for Canadian producers, intensifying the already existing farm income crisis. Because of this crisis, farming without government subsidies is becoming increasingly untenable for small-scale farmers. This is evidenced by the fact that for 15 of the last 20 years the realized net income from the markets for Canadian farms (i.e., the net income returned from the markets alone, not including government payments) has been consistently at or below the level it was at in the Great Depression of the 1930s-a situation that one farm association has referred to as "the most spectacular market failure

\footnotetext{
${ }^{20}$ At least until the last few years, Canadian farm supports routinely came in at less than the Aggregate Measure of Support (AMS) value that we are allowed under the GATT. For example, in 2000, the total value of Canadian supports for farmers was only $\$ 848$ million (CDN), well below the Canadian AMS threshold of $\$ 4.3$ billion (CDN). Government supports have, however, increased dramatically in the past five years, in light of the BSE crisis beginning in 2003 and poor weather conditions on the prairies in 2002. In an interview in December 2005, Pierre Pettigrew, then the federal minister of international trade, suggested that the Canadian AMS had climbed to $\$ 3.7$ billion, however it was unclear which year he was reporting on (see Canadian Business 2005).
} 
ever" (NFU 2003: n.p.). For 2004, the realized net income of Canadian farmers was estimated at negative $\$ 20,000$ per farm (ibid.).

Just as the crisis of the 1980 s led to an increase in political militancy among farmers, so has this recent worsening of the crisis in farm incomes, with Ontario farmers staging a series of demonstrations in front of provincial and federal government offices over the past two years. These demonstrations, which have become both larger and much more frequent over the period of this research, have begun to draw significant media and public attention, not least because the farmers travel to and from them in 'tractorcades' along major highways, holding up traffic with their slow-moving farm vehicles. The farmers' focus in these protests has increasingly been on "levelling the playing field" on which Canadian farmers have to compete with their American and European counterparts, who each receive more substantial subsidies from their respective governments than do Canadian farmers, and whose governments have undertaken significantly less aggressive reductions in agricultural support than has the Canadian government in recent years ${ }^{21}$. For farmers, the solution to the farm income crisis lies in an infusion of government support into the agricultural sector and more stable support programs, but the federal government has been more ambivalent. Rather than seeing a need for more support for Canadian farmers, the past two federal ministers of international trade have both called for the US and the EU to take a leadership role in cutting subsidies in their respective countries (see Daly 2003 and Canadian Business

\footnotetext{
${ }^{21}$ When calculated according to the Organization for Economic Cooperation and Development's Produce Support Estimate - a measure which includes as direct and indirect financial transfers from a government to its producers-Canada decreased its support to farmers by $14 \%$ between the $1986-88$ base period and the year 2000 , as compared to decreases of only $3 \%$ in the U.S., and $6 \%$ in the E.U.
} 
$2005)^{22}$. Yet on the other hand, in his 2001 report to the Premiers of Canada in 2001 entitled 'A Fair Deal for Canadian Farmers', Lorne Calvert, then Premier of Saskatchewan, suggested that amidst entrenched American and European resistance to reducing their subsidy programs, there was a very real need for an enhancement of domestic subsidy programs to support farmers who were nearing desperation. The question of subsidies has been further complicated by the refusal of a bloc of developing countries to participate in GATT negotiations until developed nations as a group agree to reduce their subsidies. In any case, rather than reinstitute a consistent and stable system of subsidies (such as that institutionalized in the post-war system of price supports), or turn away from the productivist system more generally, the Canadian government has so far opted to pursue irregular programs of direct income supports. These tend to be doled out in response to the various crises faced by farmers in different sectors such as grain and oilseeds (due to heavy European and American subsidization of these crops) or beef production (due to the BSE crisis which closed American and Japanese borders to Canadian beef).

Cumulatively, these changes have led to a higher profile for farming and food issues amongst the general public. Public response seems to be mixed; while some members of the public seem to be becoming increasingly sympathetic to the real financial difficulties of farming today, others suggest that they are tired of listening to farmers 'whine', and that farmers, like so many other resource dependent communities, should just come to grips with globalization and adjust or get out of agriculture. The changes in

\footnotetext{
${ }^{22}$ It should be noted that Canada has a number of programs in place, including the supply-management systems for dairy, chicken and eggs and the Canadian Wheat Board, which other countries consider subsidies and regularly demand be abolished in GATT negotiations. The position of the Canadian Government is rather that dairy, chicken, eggs and wheat are "sensitive products" whose management programs do not constitute subsidies (see Canadian Business 2005).
} 
agricultural supports have affected every farm to some degree, but small-scale farms which are carrying substantial debt loads and which do not have substantial capital behind them to help them weather economic storms, have been especially hard hit.

\section{$\underline{\text { Rising Concerns around Environmental Degradation and Food Safety }}$}

At the same time that a farm income crisis associated with the globalization of agri-food systems has been developing, the environmental consequences of the intensive agricultural production methods that were normalized under the productivist approach to agriculture have become increasingly evident. These environmental problems include a long-term reduction in soil fertility and increased rates of soil erosion, the pollution of land and water sources with nutrients derived from livestock waste and with toxic agrichemical residues, the development of pesticide-, herbicide-, and fungicide-resistant pests, weeds and diseases, and the deleterious impacts of agrichemicals on wildlife populations both on-farm and off (Altieri 2000; Guthman 2004b). In more recent years, concerns about the depletion of agricultural biodiversity due to the reduced range of crops grown across the country (and often in monoculture conditions), about the high 'greenhouse gas' emissions associated with agriculture, and about the potential negative environmental effects of genetically-modified crops and animals have been added to these concerns (ibid.). Whereas farmers were once revered as stewards of the environment, as the environmental deterioration associated with productivist agriculture has become more apparent, the public has increasingly framed farms and farmers as environmental culprits (Wilson 2001). 
In response to these varied concerns about the ecological impacts of agricultural policies and practices, and in order to quell the power of the movements that have arisen around them, the Canadian government has sought to acknowledge publicly the need for agriculture to become more environmentally sustainable, making this a prominent feature in national agricultural policy and discourse since the early 1990s (Hall 2003). However, as Allan Hall (2003) has pointed out, their acknowledgement has hinged on a particular construction of sustainability, in which it becomes subsumed to governments' broader efforts to modernize and globalize agriculture. In this construction, "the problem of sustainability is reduced to technical issues as if the intensifying emphasis on competitiveness and productivity were irrelevant to farm practices that impact on the environment" (ibid.: 211). In other words, and as Escobar (1996) has suggested is true in sustainable development discourses more broadly, ecological sustainability is made to seem compatible with capitalist economic development, and any contradictions between these objectives are hidden. Under this vision, making agriculture more sustainable has come to hinge on a suite of voluntary environmental planning and management programs, and on an emphasis on technological innovation, while other more sustainable production methods that would also rework capitalist social relations are ignored (Hall 2003).

However, rising alongside of the public awareness of the environmental consequences of productivist agriculture has been a second concern: its effects on human health, as consumers become increasingly concerned about the quality and contents of the food they eat. Consumer awareness of the presence of agrichemical residues in food has existed at least since Rachel Carson published Silent Spring in 1962, and a small segment 
of the population reacted by choosing food produced by non-chemical means, such as that produced through organic methods. But consumer concern has been driven to new levels amidst debates around the potential health problems associated with the consumption of genetically-modified foods (enhanced in Canada by the government's refusal to label foods that contain GM products) and in the wake of a spate of food scares over the past 5 years, starting with the outbreak of Foot-and-Mouth disease in the U.K in 2001 and including the Bovine Spongiform Encephalopathy (BSE) infections in the U.K and in North America as recently as 2006. The supposed threat of an Avian Influenza pandemic seems already to have become the next event which, if not directly related to food, is certainly linked to agricultural practice and the interaction between humans and animals in agricultural regions. Theorists have argued that these agri-food crises have combined with questions around the environmental sustainability and social justice of conventional agricultural practices to result in the emergence of what DuPuis (2002) calls the "reflexive consumer". This is a consumer who is theorized to be "more conscious of not only the types of food they eat but also its origin and transfers" (Marsden 1998: 265), and to have significant agency in shaping contemporary agri-food systems by way of their consumption choices (see also DuPuis and Goodman 2002; Goodman 2002; and Lockie 2002). This increasing concern with food safety has been reflected in the emergence of a new regulatory regime for Canadian Agriculture.

\section{A New Regulatory Regime for Canadian Agriculture}

National governments must respond to the farm income, environmental, and food safety crises of the productivist agricultural systems if they are to retain their legitimacy 
in the eyes of their citizens (McMichael 1994). To this end, governments in highly industrialized countries have increasingly institutionalized new regulations, especially in the areas of diet, health, and the environment (Marsden 1998). In this sense, the retreat of nation-states from nationally-regulated agricultural economies does not mark their disappearance in national agri-food systems as much as it does a shift in their role, since the 'deregulation' initiated by the pulling back in national farm support programs has occurred in conjunction with re-regulation elsewhere in the sector. In Canada, this reregulation process has focused especially on food safety and quality, resulting in the emergence in 1997 of a new governmental agency, the federal Canadian Food Inspection Agency (CFIA) with whom farmers must increasingly interface. Environmental management has been a secondary focus of the new regulatory regime. Together, these changes have meant that farmers are faced with an increasingly complex and interlinked suite of regulations emerging from the federal, provincial, and municipal levels.

One example of this new approach to regulation is the Ontario government's move, as part of their emerging food quality and safety system, to regulate farmers and farmers' markets more forcefully, so as to make them subject to the same standards, level of inspection and food handler training as any other agroindustry producer or retailer. One consequence of this was a provincial crack-down in the autumn of 2005 on the sale of ungraded eggs in farmers' markets, in which the government insisted that farmers must get their eggs professionally graded at their own cost if they are to be sold off the farm premises (Farmers' Markets Ontario 2005). There has been some suggestion that a similar body of regulation would soon prevent farmers from selling homemade preserves and home baked goods at farmers' markets (ibid.). As another example, an attempt to 
reregulate maple syrup production from an agricultural to industrial activity in 2004 would have resulted in a massive increase in municipal taxes for farmers who keep sugar bushes had it not been overturned after fierce lobbying from these farmers (MPAC 2004).

For farmers, the net effect of this new regulatory regime has been twofold. First, it actively restricts the degree to which farmers can diversify their farm businesses into certain product or value-added sectors and markets, a curious situation given the government's increasing emphasis on the need to maintain 'flexibility' and market responsiveness. Second, it represents the downloading of significant management costs onto farmers who are already cash-strapped. Farmers are also faced with increasing levels of regulation around environmental issues. For example, the development of the Ontario Nutrient Management Act in 2002 means that many farmers will have to make costly upgrades to manure storage facilities at their farms in an effort to curb ground- and surface water pollution. However, since some government funds have been set aside to help farmers cover the costs of the new infrastructure, meeting these regulations is somewhat less onerous for the farmer than are those around food quality and safety or around sales points such as farmers' markets.

The Increasing Influence of Agribusiness and Retailers

The restructuring of agro-food systems at the global level has had significant consequences for Canadian farmers by encouraging the emergence of new, powerful players in international and national agricultural economies. These include transnational corporations (TNCs), large-scale agribusinesses, and retailers. Indeed, the efforts of TNCs to stabilize the conditions of production and consumption so as to be able to better 
plan investment, sourcing and marketing has contributed to restructuring within national bounds (Goodman and Watts 1997). Through complicated processes of horizontal and vertical integration both within and amongst specific commodity chains, agricultural TNCs now control both the manufacture of inputs including machinery, agrichemicals, animal feed and seeds and the processing, marketing, distribution and sales of agricultural outputs, especially grain and oilseeds and meat (Friedmann 1993; Hendrickson and Heffernan 2002).

The activities of TNCs have also contributed to the stretching of food production chains over greater geographical distances and indeed to the global scale (Friedmann 1993). Indeed, as Harriet Friedmann (1993) has pointed out, TNCs have played an important role in the diminishment of national regulatory models. While these national regulatory models had, by way of their commodity support programs which encouraged farmers' dependence on agri-food corporations, initially provided the climate in which TNCs could flourish, TNCs have increasingly found them to be barriers to further integration of a potentially global agro-food sector (ibid.). The 'new' structure of the international food economy, then, is comprised of a small number of input producers who sell products to a large number of farmers, who then sell their products to a small number of firms, who in turn move their product to the millions of final consumers-a system that involves "alternating movements of oligopoly and competition" (Marsden 1997: 175). 
Further, while farming itself has not, for the most part, been directly vertically integrated into the TNC chains of control ${ }^{23}$, production in some high-value commodity sectors in some regions has nonetheless become increasingly dominated by large-scale agribusinesses. For example, in Ontario, large-scale chicken producers have worked in concert with the province's supply-management system to limit any production of chickens for sale as meat in the province to those who hold quota in the system ${ }^{24}$. Unfortunately, the cost of quota (approximately $\$ 14,000$ a share) is well outside of the reach of small farmers who wish to produce small numbers of birds to be sold directly to customers as a means of economic diversification. While many small farmers have ignored the regulation and continued to produce small numbers of chickens on their farms for direct sale, surveillance of these farms has increased dramatically, with a number of farmers reporting being visited by Chicken Farmers of Ontario (CFO) inspectors and told to cease production or face legal action (EFAO 2004). Some farmers are being forced by the CFO to sign affidavits when they purchase their chicks from the hatchery, attesting that they will not sell any of the grown chickens. In a similar way, agribusiness has infiltrated the distribution networks in some product sectors. For example, in Ottawa, large-scale distributors have worked in cohort with municipal bylaws gradually to exclude farmers from the main farmers' markets in the city, using these to sell food they have purchased from wholesalers, much of which is grown in the US (City of Ottawa 2001). According to a bylaw passed by the city in 1995, the farmers

\footnotetext{
${ }^{23}$ Firms have long felt that farming holds too narrow an opportunity for capitalization to interest them, and further have preferred to download the risks of production to farmers while controlling prices for inputs and outputs (Whatmore 1995).

${ }^{24}$ Some provinces in Canada, such as Alberta, have a quota exemption which allows small farmers to raise a certain number of birds (in Alberta, up to a maximum of 2000) which can only be sold direct to consumers from the farm or from a farmers' market stall. The Ecological Farmers' Association of Ontario has recently undertaken a campaign to pressure the Chicken Farmers of Ontario and the provincial government to come up with a similar program for the province.
} 
who do continue to sell through these markets are not allowed to distinguish themselves as local growers through signage or labels at their stalls, such that there is no easy way for consumers to determine if they are buying truly local produce (ibid.).

The restructured agricultural economy also provides more traditional retailers with a key role in the shaping contemporary commodity chains (Barrett et al. 1999). Their regulation of the sector via product specifications and quality, and their involvement in grading, merchandizing and logistics - all rationalized in the name of consumer demand - increasingly require of the farmer a new labour process, what Buttel (1996) calls 'precision farming'. The increasing power of retailers in the sector means that the value of food is, to a much greater extent than it was previously, constructed in the post-farm parts of food networks (Marsden 1997), even as the farmer receives a smaller share of the food dollar paid out by the consumer.

The Emergence of Post-Productivist Agriculture?

The cumulative effects of the decline in state financial support to farmers, the increasing costs and restrictions incurred under the emerging new regulatory regime, and the changing landscapes of power in the agri-food sector have made it very difficult to survive as a small-scale farm in most regions in Canada. The concurrent crises of dismal farm incomes, environmental degradation, and health scares have resulted in cracks in the increasingly industrialized and globalized agri-food system that, as Betsy Donald and Alison Blay-Palmer (forthcoming) have recently pointed out, resonate from the global right down to the bodily scale. There is a substantial and lengthy debate in the literatures on contemporary agri-food studies and rural development-and especially in pieces 
addressing the U.K and Europe-regarding whether attempts on the part of the nationstate, or perhaps the sector as a whole, to mediate these crises have led to the development of a 'post-productivist' approach in agricultural systems ${ }^{25}$. This is seen to be characterized by the extensification of production (Ilbery and Bowler 1998), by flexible specialization (Friedland 1997) or diversification on the part of producers and an associated rise of pluriactivity on farms (Evans and Ilberry 1993), and by the prominence of critiques of the commercialization, commoditization, and corporatization of agriculture (Lowe et al.. 1993). On the policy side, scholars have also associated post-productivism with the retreat of the state from production supports, and furthermore with a greening of agricultural policy (Lowe et al.. 1993).

While the literature that champions the arrival of a post-productivist turn in agricultural production may well suitably describe the agricultural systems that are coming to predominate in some European countries, it does not seem to be as convincing when turned to the situation in Canada. In this country, the vast majority of the food grown is still produced using intensive growing methods that focus on maximizing the amount of food produced per unit of land, and which emphasize large-scale production on highly specialized farms ${ }^{26}$. The regulatory regime in Canada remains focused on production, albeit in more cost-effective and efficient forms. The relationship between the agri-food corporations and the government, particularly in Ontario and the prairie provinces, where the agrichemical lobby remains very strong, means that there has not

\footnotetext{
${ }^{25}$ This shift in the mode of agricultural production is often theorized to occur as part of or in conjunction with a broader paradigm shift in rural development. Those scholars who prefer the term 'Fordist' or 'Fordist-Keynesian' to describe productivism may similarly prefer the terms 'post-Fordist' (Potter and Tilzey 2004) or 'Sloanist' (Friedland 1997) to post-productivism. The debate over whether we have moved to a post-productivist agricultural or rural development regime has been going on for over a decade and seems to be far from dead. Wilson (2001) has recently provided an excellent overview of the debate. ${ }^{26}$ Indeed, some scholars have refuted the 'post-productivist turn' by arguing that this is also true of most other countries in the industrialized world (e.g., Friedland 1997, Evans et al. 2002).
} 
yet been any substantial encouragement of more environmentally-friendly farming techniques by provincial or national governments. To this extent, the available evidence seems to suggest that Canada has to date been very slow to let go of a productivist focus, if indeed we have started moving down this path at all.

This is not to suggest that some of the diverse trends that various authors have associated with a movement towards post-productivism are not beginning to emerge in at least some agricultural regions or sectors in the Canadian context. For example, in some regions farmers are increasingly diversifying their farms or shifting into pluriactivity as an economic survival strategy. This has encouraged some farmers to turn towards production for local, ethnic and specialty markets, marking a 'quality turn', that is, a turn from focusing on quantities of production towards quality production (Goodman 2002, 2004). However, farmers' involvement in such initiatives has not been supported by any coherent shift in agricultural policy. Further, rather than occurring on a region- or sectorwide basis, these initiatives are mainly rooted in smaller groups of farmers who have begun to build alternative systems of food production, distribution and marketing as a way of addressing the various crises of productivist agriculture. In many cases, such initiatives have emerged or developed in conjunction with wider social movements, producing a set of 'alternative food movements' whose goal is not only to challenge the dominant agri-food system, but to propose and mobilize new systems in its place.

\section{$\underline{\text { Alternative Food Movements }}$}

So-called 'alternative food movements' have received a significant amount of scholarly attention from geographers and other social scientists over the last decade. This 
group of movements includes a wide range of initiatives, many of which fall under the banner of 'short food supply chains' (where short refers to the shortening of geographic distance and/or of the number of social actors involved), including Fair Trade systems, buy- or eat-local campaigns, local labelling projects, and direct marketing initiatives (such as Community Supported Agriculture or box delivery programs or farmers' markets). The second main suite of alternative food movements are those surrounding sustainable agriculture, including, of course, organic agriculture movements. Together, these initiatives mark the "fractures and frictions" (Whatmore et al. 2003: 389) of the contemporary agri-food system, and "share a political agenda to oppose the structures that coordinate and globalize the current food system and to create alternative systems of food production that are environmentally sustainable, economically viable and socially just" (Allen et al. 2003: 61). Further, these initiatives are seen as "countermovements" that "challenge the attempt on the part of food corporations and national and global institutions to subject the food question to market solutions" (McMichael 2000b: p. 21).

Alternative food movements are widely believed by both theorists and their participants to have significant potential for a restructuring of the agri-food landscape that runs counter to that proposed by processes of economic globalization and global restructuring. Sarah Whatmore et al. (2003: 289) argue that these movements share a "constitution as/of food markets that redistribute value...against the logic of bulk commodity production; that reconvene trust between food producers and consumers; and that articulate new forms of political association and market governance." Further, alternative food movements are heralded as a step towards overcoming the 'doublefetishism' of the market, by serving to connect consumers to both the social and 
environmental conditions of food production (Allen and Kovach 2000). As Raymond Bryant and Michael Goodman (2004: 438) explain, the alternative commodities produced by these systems "veritably shout to consumers about the socio-natural relations under which they were produced".

\section{Organic Farming as an Alternative Food Movement}

Particularly in the early literature on alternative food movements, sustainable agriculture movements such as the organic farming movement have typically been conceptualized as primarily motivated by environmental concerns, whereas short food supply chains have tended to be seen as motivated primarily by a commitment to more socially just agri-food systems. In the case of the organic farming movement, this characterization doubtless emerges from examinations of the movement's historical roots as a set of farming practices directed towards rectifying the soil fertility problems associated with increasingly intensive agricultural production methods. More recent treatments of organic farming have tended to understand organic farming more broadly as a social movement rather than merely a suite of farming practices. This movement is seen to be supported by a wide range of public actors, including farmers but also related businesses such as health food stores or restaurants, consumers and social activists (Tovey 1997). In line with the broader theorization of alternative food movements, the organic farming movement is theorized to arise from broader concerns with the globalization of food production systems as well as their industrialization, centralization, corporatization and commoditization (Goodman 2000; Raynolds 2000; Allen et al. 2003). The environmental sustainability of increasingly industrial methods of food production is 
indeed drawn into question in these studies, but so are the social and economic difficulties faced by small-scale farmers as they are increasingly exposed to the international market and its effects on the contemporary agricultural systems in which they operate. Further, concerns with a system that removes food from its local context, leading to a demise in both the cultural and economic well-being of rural areas, and then transports it extreme distances, leading both to additional environmental problems such as air pollution and climate change as well as to declines in food quality, freshness, and healthiness, are increasingly seen as the basis for the growing attractiveness of organic production and consumption.

Organic farming and food has begun to receive a good deal of attention from agrifood scholars, with attention developing around a number of key themes and debates. In Part 2 of this chapter, I detail the emergence of the organic farming movement in Canada, before turning to an overview of these debates and an initial consideration of their particular relevance to the farming movement in South-eastern Ontario.

\section{Part 2: The Emergence of Organic Farming in the Canada}

\section{The Roots of Modern Organic Agriculture Movements}

The roots of modern systems of organic agriculture reach back to the early $20^{\text {th }}$ century. As Timothy Vos (2000) has documented for the development of organic agriculture in the U.S., the organic movement in Canada took its initial inspirations 
mainly from the work and writings of three prominent agriculturalists: Sir Albert Howard, Lady Eve Balfour, and John I. Rodale. Howard, a British agronomist, is often credited as the father of the modern organic farming movement, but the organic agriculture techniques that his writing espoused were in fact derived from his observations of traditional peasant farming practices during his placement as an agricultural advisor in Northwest India between 1905 and 1924 (Reed 2001; Holden 2004). There, Howard observed that the local cultures had evidently managed to sustain self-sufficient food systems for hundreds of years, if not millennia, by using intricate practices designed to sustain soil fertility, including the returning of waste to the soil and the utilization of systems of crop rotation. Howard, who had been sent to India in order to spread the 'Western' model of agriculture, apparently realized that it was rather he who had to learn from the peasants. To that end, he set up a series of three research stations to document, research, and further develop the peasant methods (Holden 2004), most notably by adding to them scientific methods of compost-making (Reed 2001). Howard recorded his methods in a series of books, of which the most famous is 'An Agricultural Testament', published in 1940.

Howard's writings had significant influence amongst scientists and farmers at the time and served as particular inspiration for two people who went on to start two of the most important institutions of organic agriculture to date. The first was Lady Eve Balfour, a farmer in Suffolk, England, who upon reading Howard's work, launched 'The Haughley Experiment', the first scientific, side-by-side comparison of organic and conventional farming, which she carried out on farmland in England (Soil Association n.d.). After publishing 'The Living Soil' in 1943 which summarized her initial findings, 
Balfour went on to co-found the Soil Association, a group that is largely responsible for the popularization of organic farming in the U.K, and which has served as a key international organic farming advocacy group. Meanwhile, in the U.S., Howard's readings and practices were taken up by J.I. Rodale, who, in the face of nitrogen shortages during the Second World War, made a mission of developing and demonstrating natural mechanisms for soil fertility (Rodale Institute n.d.). Rodale began publishing 'Organic Farming and Gardening', a publication to which many farmers in Canada and the U.S. subscribed-indeed, two of the farmers who participated in this study remember getting the publication at their families' homes when they were children. Eventually, he went on to start the Rodale Institute near Kutztown, Pennsylvania, a group which continues to undertake research and advocacy work on organic farming issues today.

Howard, Balfour, and Rodale all emphasized the connections between healthy soils, healthy and high-quality food, and public health, a theme which remains salient in the movement today (Vos 2000; Reed 2001; Mansfield 2004). The emphasis in their writings was on practices for maintaining soil health, especially through compost. Balfour's work in particular is geared towards cultivating the living component of the soil (microorganisms), which she understood as critical to maintaining stocks of the minerals necessary for plant growth (see, for example, Balfour 1977, 1948). The three authors were early critics of agricultural industrialization and what they perceived as its negative environmental and public health effects (Vos 2000) - a vast decrease in soil health, and a corresponding 'famine of quality' (Howard 1947) in the resulting food. As for the specific term "organic", it appears to have first been widely used by another U.K. 
scientist, Lord Northbourn, in his book 'Look to the Land', published in 1940. There, "Northbourn used the term to describe farming systems that focused on the farm as a dynamic, living, balanced, organic whole, or an organism" (MacRae 1990: n.p.). The word was an accurate descriptor for the farming practice it encompassed at the time, given the emphasis on natural fertilizers and on the living characteristics of the soil. In many of the countries in Europe and North America, the organic farming movements that developed have also been influenced by their interaction with a second type of sustainable agriculture: biodynamic farming. Biodynamic farming was developed by Rudolf Steiner, a German philosopher, and first promoted by him in a series of talks beginning in Germany in 1924. Biodynamic farming-which was only one component of Steiner's larger 'spiritual science' of Anthroposophy-is a "holistic system of agriculture [that] aims to help spiritual development as well as heal the living Earth" (McMahon 2005: 99). Biodynamic farming considers the role of cosmic energy and the movement of the stars and moon in the planting and growing processes, and relies on the application of 'preparations' to the land which seek to "draw new life forces from the cosmos" (ibid.). While the organic and biodynamic farming movements are distinct movements, most biodynamic farmers also classify themselves as organic farmers, and many farmers practicing one system have been influenced by the ideas of the other ${ }^{27}$.

\footnotetext{
${ }^{27}$ In Southeastern Ontario, the influence of biodynamic farming on organic farming, and vice versa is readily apparent. While only one of the farmers in this study considered themselves a biodynamic farmer (with one of the market gardeners in the process of transitioning to biodynamic methods), many of the farmers were influenced by ideas from Steiner's writing which the biodynamic movement has developed in the intervening years.
} 


\section{The Development of the Organic Farming Movement in Canada}

In Canada, the organic agriculture movement first emerged in the 1950s, aided by the spread of the European, British and American literature. By 1953, Canada had its first organic organization, the Canadian Organic Soil Association, later re-named the Land Fellowship ${ }^{28}$, which went on to organize speaking tours on organic farming across the country, hence encouraging slow but steady growth of the movement through the early 1960s (Hill and MacRae 1992). The publication of Rachel Carson's 'Silent Spring' in 1962 , which exposed the hazards of the pesticide DDT, and the resulting public outcry and eventual banning of DDT in Canada (1969) and the U.S. (1972) refocused public attention on the environmental and health impacts of industrial agriculture. This, and the birth of the modern environmental movement—in which Carson's book played a seminal role-led to a surge in the popularity of organic farming in the late 1960s (EAP 1995).

The alternative lifestyles ('back-to-the-land') movement, which spread from the U.S. into Canada in the 1970 s, further increased the popularity of organic agriculture, as people moved to rural areas in order to escape the perceived corruption of the city and to create simpler lifestyles that were felt to be more harmonious with nature (EAP 1995; Vos 2000). An emphasis on independence from the structures of conventional society meant that people increasingly explored ways of growing their own food. In the face of the new levels of global concern about the environment, sustainable and organic agricultural systems were regularly featured as part of cultural exhibits and displays across the country (MacRae 1990). By the end of the 1970s, there were organic agriculture organizations in six provinces. These included the two main organizations

\footnotetext{
${ }^{28}$ The Canadian Organic Soil Association was founded by Christopher Chapman, a filmmaker and popular educator who produced two influential Canadian documentaries on organic farming: 'Understanding the Living Soil' and 'A Sense of Humus'.
} 
which continue to serve Ontario organic farmers today: the Canadian Organic Growers (COG), formed in 1975, and The Ecological Farmers Association of Ontario (EFAO), formed in 1979 (EAP 1995). Neither the federal nor provincial governments, however, had yet directed any real attention to either questions of sustainability in agricultural systems, nor specifically to organic agriculture.

The first organic farmers in the South-eastern Ontario region that is the study area of this thesis first moved into the area or switched over into organic production in the early and mid 1980s, making it a younger movement than in some other regions of Canada. In the country as a whole, the movement continued to grow; the 1980 s saw the first comprehensive surveys of organic farmers and consumers, and the first efforts of a small number of researchers in Canadian universities to begin any formal experimentation with organic production techniques. While organic courses were developed in a few universities and colleges, the main agricultural colleges still focused overwhelmingly on intensive, chemical-based agricultural production practices. The government gave small research grants for targeted studies assessing the economic and agronomic viability of organic farming; however these were limited in number and in scope (Hill and MacRae 1992). Several organic certification bodies and programs were established in the 1980s, and some farmers began to pursue certification for their farms ${ }^{29}$. By the time sustainability was identified by Agriculture Canada as a key goal for the sector in 1989, the country already had 600 certified organic farmers (Hill and MacRae

\footnotetext{
${ }^{29}$ In Canada, certification of organic farms is currently voluntary, although this will change when the new national regulatory regime comes into effect. Farmers who choose to certify their farms are able to claim their products as "certified organic", which acts as an assurance for customers that the food was grown according to organic methods. In Canada, certifying bodies are independent from the government. Farmers can choose from a range of certifiers, and they pay a fee for the certification services. Certification is a complex and divisive issue amongst the organic community, as discussed in later the main text.
} 
1992). The late 1980s also saw the first discussions on regulatory support to control the use of the term "organic" in the marketplace, with a formalized definition of organic coming into effect in 1989 under the Consumer and Corporate Affairs Food Labeling Guidelines (EAP 1995).

The development of the organic farming movement in the 1990 s continued to be characterized by a steadily growing interest in organic farming amongst both producers and consumers, a burgeoning certification sector, targeted research by the government and a few dedicated university researchers, and the slow process of institutionalizing organics. By 1995 there were 1575 certified producers in Canada and many more who were either in transition or were practicing organic methods but had chosen not to certify (EAP 1995). National farm gate receipts for the organic sector were estimated at somewhere between $\$ 50$ and $\$ 70$ million (ibid.), and the demand for organic products was already significantly outstripping supply.

In December 1996, the Canadian Organic Advisory Board and Agriculture and Agri-Food Canada (AAFC) initiated the development of a national standard that would address the conversion to organic production, organic production practices, processing, labeling, storage and handling (the National Standard of Canada for Organic Agriculture) with the help of a committee of 58 representatives from across the organic sector. The committee prepared and reviewed six draft standards before achieving consensus in February 1999; the National Standard was ratified and published in June 1999, replacing the 1989 regulation of organic agriculture by Consumer and Corporate Affairs (CGSB 2005). Since its inception, the National Standard has been a voluntary standard, rather than a federal regulation. This means that both the certification of individual organic 
producers and handlers by independent certification bodies and the accreditation of these bodies by the National Standard is fully voluntary across Canada, with the exception of in the province of Quebec, which requires that growers be certified by a body accredited by a provincial regulation. This regulatory system, however, is currently in the process of being re-scripted, ostensibly as a way to support the rapidly developing organic sector (OTF 2006).

If the organic farming movement in Canada was developing at a steady clip in the 1990s, around the new millennium it picked up a dizzying speed. At the federal level, the Canadian government seems to be increasingly interested in tracking the development of organic farming in Canada. Farmers were first given the chance to identify their farms as certified organic in the 2001 agricultural census, and in the coming 2006 census they will have the further option of listing them as organic but not certified. By all measurements, it seems that organic production in Canada has continued to expand steadily in the last five years: in 2003 there were 3,317 certified organic farms in Canada (487 in Ontario) and over 966,000 acres of certified land (over 91,000 in Ontario) (Macey 2004). This is up from 2,230 certified organic farms in Canada according to the 2001 agricultural census (405 in Ontario), and is more than double the comparable numbers for 1996 (OMAFRA 2004). Since neither the provincial nor federal governments have yet tracked the number of farmers producing organically but without certification, and given that certification is not favoured by all farmers, these numbers may significantly underestimate the number of farmers producing organically in the province and the country. 
The market for organic agriculture has also experienced rapid growth in Canada in the past decade. The retail organic food market was estimated at $\$ 1.3$ billion in Canada in 2003 (OMAFRA 2003) and the retail value of organic farming products in Canada at the farm gate is estimated at $\$ 500$ million annually (OMAFRA 2001). This growth is not limited to Canada; organic food sales in North America are estimated to have grown around 20 percent per year for the past decade (OMAFRA 2004), and growth is predicted to stay between 15 and 20 percent for the next few years (OMAFRA 2003). In 2000 , the most recent year for which calculations have been completed, about 22 million Canadians (71 percent of the population) bought organic foods at least once (Environics International Ltd. 2001).

\section{$\underline{\text { Recognition and Support for Organic Farming }}$}

While consumer support for organic foods has grown rapidly, governments have been slower to recognize the value of organic agriculture. Historically, neither the federal nor provincial governments have directed much attention or support towards organic farming. Similar to what Timothy Vos (2000: 247; drawing on Merrigan 1997: 167) has suggested is the case in the U.S., Canadian organic farmers have tended to see the provincial and federal governments as 'captured agencies': that is, they are seen to be characterized by the same values, priorities and approaches that characterize industrial agriculture and to be "overwhelmingly influenced by and beholden to agribusiness interests." Indeed, given broader attempts of the federal government in particular to act in ways that seem to be directly against the interests of organic and small-scale farmersfor example in their attempt to overturn a moratorium on genetic use restriction 
technology (or, as it is more popularly known, "terminator technology") in February

2005-some of these farmers' advocates assert that in the coming growing seasons

"farmers will have to keep one eye on their fields and one on the government" (Pat Mooney, National Farmer's Union Save Our Seeds Rally, March 5, 2005) ${ }^{30}$.

Currently, neither the federal nor provincial governments in Canada offer any

form of financial incentive or subsidy for farmers who enter into or are engaged in

organic production. This contrasts with the situation in some highly industrialized

countries, such as those of the European Union, where governments have been far

quicker to recognize organic farming's important contributions to environmental

management and rural development ${ }^{31}$. Nonetheless, government attitudes to organic

farming have changed considerably over the past five years, with both the provincial and

federal governments putting an increasingly positive spin on organics. While the

provincial governments have tended to focus on the continued growth of the domestic

sector and the good prices farmers have been receiving, AAFC has focused on the

potential to develop stronger links between the domestic "organic industry" and the

\footnotetext{
30 "Terminator technology", initially developed by the transnational seed/agrochemical industry and the US government, refers to plants that have been genetically modified to render sterile seeds at harvest. Terminator technology, presented by the industry as an intellectual property mechanism that will protect and so sustain private investment in seed development, will restrict farmers from saving seed stock from year to year, ensuring that they must return to the TNC for new seed every year and so also ensuring these companies an annual profit. It may also have detrimental ecological effects. In February 2005, shortly before the talk quoted here, a de facto moratorium put in place by the United Nations Convention on Biological Diversity (CBD) on the field testing of terminator technology was almost overturned at a meeting of the scientific advisory council of the CBD. A memo leaked to news media revealed that the Canadian government delegation had gone to the meeting with instructions to introduce language allowing for field-testing and commercialization of Terminator Technology, and to block any decision that would uphold the moratorium. This was averted due to the interventions of other governments, but cast Canada in an unflattering spotlight amongst international farmers' rights groups. At a CBD meeting in Curitiba, Brazil, in late April 2006, the moratorium on Terminator Technology was upheld. For more information, see: http://www.banterminator.org/

${ }^{31}$ In these countries, the Common Agricultural Program offers incentives and subsidies for farmers to convert land that was previously under intensive agricultural production to organic production as one possible form of agricultural extensification (i.e., of moving towards less intensive forms of agricultural production).
} 
international market for organic products. Rather than emphasizing organic agriculture as a potential source of rural development, then, AAFC has focused on the contributions the organic sector can make towards establishing Canada as a competitive player in the global agricultural system. In order to achieve this, the federal government has increasingly inserted itself into the organic movement, which until the very late 1990s existed almost completely independently from the government, and largely outside of its reach. Their efforts in this regard have been directed towards two key tasks. First, they have sought to increase the amount of research done on organic agricultural systems across the country. Second, they have initiated a redrafting of the National Standard of Canada for Organic Agriculture, as well as the development of a broader national organic regulatory regime around this standard.

Until very recently, there has been very little centralized research conducted on organic production techniques at the regional, provincial or even national levels. Research at the federal network of Experimental Farms-which itself has been substantially scaled back in recent years-has focused on conventional methods of production, and government funding for organic research programs at other institutions has been meager at best. With AAFC's increased recognition of the significance of the organic sector, however, the agency has also recognized a knowledge and technology gap that they see as holding back the organic sector from reaching its full potential. In 2001, AAFC established the Organic Agriculture Centre of Canada at the Nova Scotia Agricultural College to address this gap. The centre is directed towards providing "broad support for organic farmers and those in transition, through the development of new research programs, courses and deployment of effective methods for disseminating 
information" (ATS 2005: n.p.). In keeping with their focus on developing the interface between the Canadian domestic sector and international markets, the research on organic production techniques and technologies the centre undertakes will be directed towards giving Canada's producers an advantage over international competition and helping the industry to access opportunities for growth in major markets such as the United States, Europe and Japan (AAFC 2001).

In addition, there have also been a number of recent significant developments at regional and provincial colleges and universities in Ontario which together should result in more research on organic agriculture being undertaken and in additional training opportunities for potential and existing organic farmers. For example, the ongoing development of a diploma program in organic production at the University of Guelph (the primary agricultural college in Ontario) may encourage more research on organic production. This is a significant step since such research was previously limited to the activities of one or two faculty members at this university whose initiatives and organic advocacy work were very much against the grain of their host institution, which is notorious amongst organic farmers for its focus on chemical-based intensive methods of agricultural production. The University of Guelph also operates two smaller agricultural colleges within the study region of this thesis, an anglophone college in Kemptville, Ontario, and a francophone college in Alfred, Ontario. In the past, these facilities have undertaken a small amount of research on organics by way of occasional projects by faculty members. However, Alfred College in particular is likely to become a major player in organic research given the conversion of its fields and dairy herd to organic production in the autumn of 2005. 
Given the historical gap in government and research institution support for organic farming and the movement's grassroots history, it is perhaps not surprising that strong civil society organizations have developed around organic farming; most notable in this regard and in the Southeast Ontario region are two not-for profit groups, the Canadian Organic Growers (COG) and the Ecological Farmers Association of Ontario (EFAO). Both organizations are coordinated and run by members of the grassroots organic movement, and share broadly similar goals while differing in a number of other important respects. While EFAO's membership consists mainly of farmers, COG's membership also includes organic gardeners and others interested in supporting the organic movement, including consumers, restauranteurs, distributors and retailers, and activists. At the local level, chapters of both COG and EFAO organize kitchen table meetings on particular issues of interest to organic farmers such as composting or marketing farm products, as well as farm tours where farmers can share and learn from their local knowledge and experience. Local chapters of COG maintain a regional directory of organic producers, organize a yearly conference on organic agriculture, coordinate events that aim to establish connections between local organic producers and consumers, and generally promote their local organic movements throughout their region. At the provincial and national levels, COG is starting to get involved in more advocacy work to support the organic sector. Across the province, EFAO runs acclaimed courses on ecological agriculture, which have been instrumental in assisting local farmers wishing to convert to or starting to farm organically. EFAO has been actively involved in advocacy work aimed at policy change on issues that threaten small organic farmers, including genetically-modified crops and the current chicken quota regulations. 
Beyond COG and EFAO, there are a number of smaller organizations and initiatives whose work also supports organic farmers in the South-eastern Ontario region. These include a suite of campaigns encouraging urban consumers to support farmers in their local rural areas, organized by groups in Perth (EcoPerth's Local Flavours campaign, featuring conventional and organic farmers), Kingston (the Kingston Organic Food Link, featuring organic farmers), and Ottawa (the Ottawa Food Security Council's Buy Local campaign, featuring both conventional and organic farmers). In the summer of 2005, residents of Lanark County initiated the first chapter of the Slow Food Movement in rural Eastern Ontario, an organization which, amongst other goals, opposes the standardization of taste in agricultural products, protects cultural identities tied to food and gastronomic traditions, and safeguards food quality. While such local initiatives may not expressly focus on organic farming and food, they share certain goals and themes with the local organic movement, and as such are important sources of support for organic farmers indirectly if not directly. Cumulatively, these groups show that there is a strong interest in and significant energy around issues relevant to organic farming and food in the Southeastern Ontario region.

Together, the rapid development of the organic farming movement in Ontario and Canada, the changing government attitude around organic agriculture, and the lively civil society organizations that have developed around organic farming combine to position the organic farming movement and the farmers within it at a critical juncture. Today, the movement is confronted with a number of key issues which are generating considerable debate amongst organic farmers and their allies. Two of these issues, the institutionalization of organic farming and its possible conventionalization, have the 
potential to re-shape the organic farming movement significantly. These issues and debates, which provide important context for the discussions about the naturalization and localization efforts of organic farmers which follow in later chapters, are explored in the final section of this chapter.

\section{$\underline{\text { Key Issues and Debates in Organic Agriculture Today }}$}

In the burgeoning literature on organic farming movements in North America and Europe, attention has focused on a number of key themes or areas of study. Perhaps not surprisingly given that organic farming first emerged as a critique of the environmental consequences of industrialized agriculture, a series of scholars has turned to consider questions of ecology and nature, and relatedly, of human health as they pertain to and are mobilized within particular organic farming movements (e.g. Goodman 1999; Kaltoft 1999; Murdoch and Miele 1999; Marsden 2000; Goodman 2001; Kaltoft 2001; Mansfield 2004). A second theme that has engaged agri-food scholars in Europe is a consideration of the potential role of organic agriculture in local economic and rural development (e.g. Banks and Marsden 2001; Pugliesse 2001; Goodman 2004; van der Ploeg and Renting 2004; Darnhofer 2005), while scholars in the U.S. have begun to consider the possible connections between organic farming and the politics of food system localization more generally (e.g. Hinrichs 2003; DuPuis and Goodman 2005). Because I address questions of ecology (or nature) and local economies in later chapters, I will not review them here. Rather, I will turn instead to a consideration of two key debates which have emerged in the agro-food studies literature and their relevancy in the Canadian context. 
The most controversial of these debates concerns whether organic farming systems in various parts of the world are slowly coming to resemble their conventional (i.e., industrial) counterparts as market development and changes in institutional support for organic production lead to the entry of new players beyond the grassroots farmers who were the movement's original participants. Here, agri-food scholars have directed their attention towards detailing the 'conventionalization' of organic farming systems in particular locales, or alternately the continued resistance of these systems to conventionalization processes (e.g., Buck et al.. 1997; Coombes and Campbell 1998; Guthman 1998, 2000; Hall and Mogyorody 2001; Guthman 2004a,b). A second point of focus in the organic farming literature has been on the role of differing systems of institutionalization in shaping contemporary organic agriculture systems. Considered here are organic certification practices, production standards, state support, and other forms of regulation (e.g. Tovey 1997; Vos 2000; Campbell and Liepins 2001).

Usefully, work on these overlapping themes has focused not only on the material forms of emerging and developing organic agricultural systems, but also on the symbolic content of the organic farming movement and the social/discursive/political construction of the concept of organic. In the sections below, I provide a brief overview of the debates around the institutionalization of and conventionalization of organic farming, giving particular attention to the relevance of these debates to the situation of organic farming and farmers in South-eastern Ontario, as further context to the remainder of this thesis.

\section{Corporate Organics and the Conventionalization Debate}

Possibly the most hotly contested debate in contemporary studies of organic farming movements regards whether organic agri-food systems are slowly coming to 
resemble their conventional counterparts as market development yields the entry of multi-national corporations and individuals motivated more by the opportunities for profit-making than by the agro-ecological and social concerns that motivate more traditional organic growers. Amongst scholars, this debate was initiated in a paper by Daniel Buck et al. (1997) and further elaborated in papers by Julie Guthman (1998, 2000, 2004). Together, Buck and Guthman suggested that the organic agriculture sector in California was undergoing 'conventionalization' (Buck et al. 1997: 14) through three main avenues. First, agribusinesses were increasingly taking over the production of the most high-value crops only to abandon the agro-ecological and social practices associated with the grassroots organic movement. Second, in contradiction to long-standing organic philosophy, growers were increasingly relying on purchased inputs developed off the farm, typically provided by agribusinesses, to boost or maintain soil productivity. Third, the most lucrative segments of the organic commodity chain—namely the processing, marketing and distribution of organic products-were also quickly being over taken by agribusiness firms. Buck and Guthman suggested that, by driving down prices, this conventionalization process would eventually undercut the efforts of even the more committed, small-scale, grassroots-oriented farmers to continue to farm in a more ecologically and socially sustainable ways.

While Guthman has been careful to stress that the contemporary, increasingly 'conventionalized' structure of the California organic food system results at least in part from the historical structure of agriculture in that state, some scholars have taken the arguments put forth by her and her colleagues as suggesting that all organic agriculture systems were being—or inevitably would become—conventionalized, and have set out to 
refute this idea. In this vein, Brad Coombes and Hugh Campbell (1998) suggest that despite the increasing involvement of agribusiness in organic agriculture in New Zealand, small-scale organic producers persist, in large part because agri-businesses seem to have targeted production for export markets, leaving the domestic and local markets to the more grassroots-oriented producers. Importantly, Alan Hall and Veronika Mogyorody (2001: n.p.), examining the conventionalization argument amongst Ontario organic farms, found that most organic farms in the region "retain the central features of an alternative approach, including an emphasis on small, diverse, mixed operations, marketing directly and locally to customers", although certain types of farms (especially those producing field crops) seemed to be more conventionalized than others. They caution that this may be explained by the relative inactivity of agri-business in the Canadian organic sector as of yet.

What has emerged from these studies is an understanding that the forms of the organic farming systems that develop in particular regions will be strongly influenced by the history of both the conventional and the organic sector in a region, as well as the way in which organic farming is regulated and institutionalized through certification bodies, standards, and government support programs. These will thus influence the degree to which the organic system draws on or replicates the practices, structures and ideas of the conventional system. With this in mind, I now turn to a review of the current attempts to institutionalize organic farming in Canada, followed by a reflection on the implications of these attempts given other countries' recent experiences in this area. 


\section{Institutionalizing Organic Farming}

Since 2000 , the federal government has become an increasingly prominent player in the development of the organic sector-or, as they refer to it, "the organic industry". This has largely been achieved through the direct involvement of both AAFC and the Canadian Food Inspection Agency (CFIA) in the revision of the National Standard of Canada for Organic Agriculture, and through their efforts to develop a broader national organic regulatory regime around this standard. At the request of AAFC, the National Standard, which has existed as a voluntary standard since its drafting in 1999, came under review by the Canadian General Standards Board (CGSB) in January 2002. The main aim of this review process - consistent with AAFC's emphasis on developing export market opportunities for the Canadian agricultural sector as a whole — was to ensure that the standard was at least equivalent to those used by Canada's main trading partners (the United States, the European Union, and Japan), in the interest of easing trade in organic commodities between the countries (OTF 2006).

Originally, organic farmers and other representatives of the organic sector were to be heavily involved in the revision of the standard, with each participating directly in the revision committee ${ }^{32}$. Between 2002 and the spring of 2004, the committee prepared a series of new draft standards, but were unable to achieve consensus on any of them, a required step before the standard could come into effect (CGSB 2005). As a result, in the autumn of that year, the government turned over the process of revising the standard to the Organic Production System Task Force (OTF), a newly developed body comprised of regulatory and trade specialists from the Canadian Food Inspection Agency and AAFC,

\footnotetext{
${ }^{32}$ The committee revising the National Standard consisted of 118 members ( 40 with voting privileges, 78 to provide technical information) and included members of the original committee that drafted the 1999 standard, as well as other invited sector representatives.
} 
with International Trade Canada contributing expertise as required (OTF 2005a). The OTF was tasked with consulting with "industry" representatives and with provincial governments and federal institutions towards the further development of the Standard, with the aim of having it ready for the December 31, 2006, deadline that the European Union has set for third-country equivalence for national organic production systems ${ }^{33}$. The agreement was that the draft of the standards that the OTF prepared would still have to pass by the consensus of the original CGSB committee (including its member organic farmers) before it came into effect. The OTF has now successfully drafted the standard two times over, however neither of these drafts has achieved the required consensus, such that a new version of the standard is not yet in place. At the time of submission of this thesis, the newest draft of the standard had just gone to a vote, and although the CGSB and OTF has not formally acknowledged the results of this vote, their continued work on the standard suggests that consensus was not achieved once again ${ }^{34}$.

The OTF mandate, however, does not stop at revising the National Standard. The body has also been tasked with developing a national organic regulatory regime based around the standard. The main arguments for such a regime is that it would serve to protect the system from opportunistic cheating (i.e., producers labeling products

\footnotetext{
${ }^{33}$ This is a deadline which the Canadian sector must meet if we are to retain access to the European market for trade in organic commodities.

${ }^{34}$ The difficulty that both the original CGSB revision committee and the OTF have faced reaching consensus on drafts of the standard is an interesting situation, but is perhaps not surprising given that there are considerable differences in the form and structure of organic systems between and even within regions in Canada. For example, in Ontario, the sector is dominated by smaller farms which may focus on a particular product but which are often quite mixed or diversified, whereas in the prairies there are many larger farms that focus more exclusively on grain and oilseed production. However, the difficulty the boards have faced in achieving consensus on the standards also speaks to the fact that organic farmers are a heterogeneous bunch of strong minded individuals, and they and other actors in the sector clearly have different ideas about what constitutes proper organic conversion, production, processing, labeling, storage and handling procedures.
} 
produced by conventional methods 'organic' in order to take advantage of the price premiums organic products receive), and hence to preserve consumer confidence in organics. This has long been a concern amongst organic farmers in the country, and has earned the OTF and regulatory regime development process the support of a significant subset of the organic farming community across the country. Like the revised standard itself, the regulatory regime will also help retain access to international markets.

To these ends, the OTF assessed a range of different possible regulatory models and, in March 2005, proposed a model that would make the national standard the mandatory minimum standard for organic agriculture, a standard established and maintained by the organic industry, but enforced by the federal government (OTF $2005 \mathrm{~b})$. In the proposed new regulatory system, the 46 organic certification bodies that are active in Canada-which have hitherto been independent in terms of the certification standards they set, since the national standard has until now been voluntary-will apply to the government for accreditation of their programs. This has an important consequence for organic farmers. Until now, certification has been optional, with some farmers choosing to certify their farms, and others choosing not to. Under the current system, both of these groups of farmers could continue to claim they produced by organic methods, and, accordingly, to call their products organic. However, under the new regulatory system, all farmers, regardless of size or sales, will be required to certify with one of the certification bodies if they are to call their product "organic". Farmers who do not certify and either label or verbally assert their food as "organic"-or any of the equivalent terms, which are still under discussion-would be susceptible to a fine and 
possibly jail time (Laura Telford, Canadian Organic Growers Executive Director, personal communication).

The new regulatory system will hold important changes for how organic farming is practiced in Canada. Until now, organic farmers have been free to some extent to practice organic farming as they see fit. Their production practices have not been policed unless they choose to certify with an independent certification body, but not all farmers have chosen to do so. This is not to say that guidelines and practices have not been 'standardized' to the extent that they are well accepted or commonly utilized, but rather to say something about how these have been set out, that is, through a series of "ongoing conversations, a complicated set of negotiations and contestations" that together make up an "intensely local grassroots process" (Vos 2000: 353). Through this process, the movement has openly evolved to encourage certain practices and discourage others, and although these have been captured to various degrees in the different independent certification standards, given that certification has been voluntary and that there are a number of competing certification bodies with whom a farmer might choose to register, farmers' exact practice on their farms has been to a large extent a matter of their own choice and personal interpretation of organic philosophy.

Indeed, certification (which relies on some level of standardization) is a contentious issue amongst organic farmers, despite the fact that it first emerged as an independent, grassroots effort amongst some members of the movement. Some feel it is necessary to protect the organic sector from opportunistic cheating by producers who wish to benefit from the price premium of organic goods without truly adopting organic production methods. These farmers argue that certification protects the organic market 
by assuring customers of the production conditions of their food. Others find certification to be financially untenable given the small size of their farms and the limited incomes they make from production, or disagree with it on a deeper philosophical or ideological basis. These include farmers who would prefer to rely more exclusively on direct communication with customers to explain the precise practices that have gone into producing their products and so verify that organic practice is being followed. The developing regulatory regime is likely to encounter deep resistance amongst some of these farmers - and even amongst some of those who have chosen to certify with independent bodies-who worry that the new standardization process will serve to 'freeze' the definition of organic, making it difficult to amend (and especially, to make more stringent) in response to emerging environmental or social concerns because of its incorporation into complicated socio-political structures, or bureaucratic 'red tape'. They worry that the regulatory regime will close down the history of open discussion and personal interpretation by which the definition of organic has traditionally evolved.

Some farmers are also concerned that the process of developing a regulatory regime has been turned over to a government committee-albeit one that has conducted extensive consultations within the sector, and which will need approval from sector members to pass the standard they draft—since the government is "considered by many to be in a compromised position with regard to the regulation of organic food and farming" (Vos 2000: 247) because of their sympathies to the industrial model of agriculture. There also seems to be a feeling that by increasing the 'transparency' of organic practice, the regulation may open the doors to individuals in it primarily for the money, rather than out of broader environmental and social concerns. Further, the 
standardization process-at least from the perspective of the federal government-seems to be designed to steer the domestic agricultural sector towards an increasing engagement with global markets. However, as I discuss in Chapter 5 of this thesis, questions around the degree to which the local organic agriculture movement should participate in the burgeoning international organic movement, and to which it should interface with or utilize the structures and ideas of the global food system, are both reasonably contentious issues amongst organic farmers in South-eastern Ontario.

A number of other countries have already installed regulated standards for organic agriculture, notably the EU nations (1990s), Japan (2001), and the US (2002). Since these initiatives have been quite recent, it is difficult to say what the consequences for the structure and practices of the organic farming sector as a whole, and specifically for small organic producers, have been. The U.S. is the only country where extensive work on this issue has been done. Julie Guthman (2004) has suggested that the national standard installed in that country (the National Organic Program's Final Rule) tended to have a middling effect on organic farming practices, encouraging some growers to abide by more strict agroecological practices, but also encouraging some to move towards less strict allowable management practices that were easier to achieve. The Rule also seems somewhat to have favoured or encouraged the entry of large-scale growers into the organic sector, particularly for some products, and has enabled the development and continuation of mixed organic-conventional operations. What Guthman finds most worrying from the perspective of small growers, however, is that it has eroded to some degree the price premium that organic farmers receive for their goods by encouraging the rapid development of the sector. 
However, what is crucial to remember is that the changes in the Californian organic sector that Guthman has detailed resulted in large part from the specific nature of the national standard enacted therein. The point, therefore, is not that all efforts to regulate and institutionalize particular methods of production, distribution, and marketing will necessarily result in negative effects for local organic farming movements. Rather, it is the character of the regulation that will determine its consequences, or as one farmer who participated in this study put it to me, "the devil is in the details" (Farmer, diversified market garden; male) This being said, it is enough at this point to note the controversies around the developing Canadian organic regulatory regime. At this point, the specific implications of this regime for small farmers remain unclear.

As the discussion in this chapter has made clear, the conventional agricultural system, shaped by policies that reflect shifting national priorities and broader political and economic (and ideological) influences, is seen by many observers as deeply mired in a series of economic, social, and ecological crises. This has been recognized for some time by Canadian organic farmers, who have sought over the past 50 years to develop an alternative system of food production, one that reflects a concern with the environment but also with the quality of food and with the economic and social conditions of local communities. Over this time period, organic farming has developed into a social movement, supported not only by farmers but also by consumers, related businesses and activists. The movement has grown rapidly in the past few decades, and together with the increasing levels of consumer concern around food issues has led to the development of a significant market for organic foods in Canada. However, until quite recently, the Canadian government paid minimal attention to organic agriculture, focusing instead on 
institutionalizing an intensive, industrial, and chemical based model of food production that continues to predominate in the nation today.

In recent years, the Canadian government's attitude about organic farming has changed significantly, as they have increasingly come to see organic commodities as an opportunity that could be developed for export given the high demand for organic food amongst Canada's trading partners. To this end, they have increasingly involved themselves in research on organic production and, more importantly, in developing and installing a regulatory regime around organic production based on a revision of the National Standard. Ideologically speaking, their efforts herein are in line with a broader prioritization of the neoliberal model of economic development, which prioritizes open, barrier-free trade. However, as I will show in subsequent chapters, the governments' efforts to institutionalize organic farming may bring them into conflict with grassroots organic farmers, who have developed their own visions of the organic farming movement and of its goals. In the next two chapters, I turn towards exploring these visions and goals, particularly as they relate to the themes of the natural and the local, before turning in Chapter 6 to a brief consideration of how these visions and goals might intersect with the developing organic regulatory regime. 


\section{Chapter 4: Organic farming and the naturalization of the agricultural production process}

\section{Introduction}

Agriculture is foundational to the very existence of modern societies and represents, as Timothy Vos (2000: 246) puts it "the arena where human beings encounter and most intimately interact with nature, in order to produce the necessaries of everyday existence". However, there has been widespread concern that the increasing industrialization of agricultural production has resulted in the degradation of nature. This process of degradation has a number of consequences. It has undermined the productive capacity of agricultural systems, reduced the quality of the food that is produced by these systems, and compromised adjoining ecosystems and wildlife populations. Further, conventional agricultural practices such as the use of chemicals have had implications for the health of farm workers and consumers.

A concern with the environmental and health consequences of the conventional system of agricultural production is understood to be central to the historical development of organic farming movements (Guthman 2000; Vos 2000; Guthman 2004a, b; Holden 2004; Mansfield 2004). Current work on organic agriculture points to the continued importance of environmental concerns for farmers' conversion to organic production. Indeed, Susanne Padel's (2001) review of a suite of 'conversion studies' suggests that farmers are increasingly listing a concern with the consequences of conventional farming for on-farm natures (e.g., its contribution towards soil erosion and fertility decline) and for nature more generally (e.g., concerns around stewardship and conservation) as among their primary reasons for moving into organic production. Similarly, Stewart Lockie et 
al. (2000) frame the rising popularity of organic farming and organic food consumption as part of the emergence of 'green foods', whereby foods become socially imbued with environmental symbolism in response to the increased global salience of environmental issues and the corresponding emergence of discourses around environmental sustainability and sustainable agriculture.

In this context, it is not surprising that social scientists have been attracted to examining "the significance of organic agriculture...in the context of the environmental/ecological imaginary of contemporary culture" (Vos 2000: 245). In parallel with a broader movement to investigate different 'cultures of nature' held in agricultural systems, a number of scholars have sought to reflect on the visions of nature held by the organic farming movement, and especially on the relationship between nature and society that these entail. These scholars increasingly posit organic farming as based on a different type of relationship between society and the natural world than that which predominates in the agro-industrial model of production, and indeed in contemporary highly industrialized societies more generally (Goodman 1999; Mansfield 2004, Vos 2000). Thus, David Goodman (1999:32) suggests that organic farming “contests the industrial orderings or eco-social relations based on instrumentalist utilitarian rationality". Similarly, Vos (2000: 246) suggests that we might see and analyze the organic farming movement "as a radical gesture of reconciliation with nature," and as "an embodied attempt to change the way we actually live" in the agricultural landscape. He likens organic farming to an "ecological resistance movement, which both "challeng[es] the hegemony of the agro-industrial paradigm, and propos[es] and explor[es] alternative society-nature relations" (ibid.). 
Increasingly, scholars working on this topic have also suggested that those participating in the organic movement hold largely non-dualistic (or, what some scholars have perhaps problematically referred to as 'non-modern') perspectives on the naturesociety relationship. Goodman (1999:32) suggests that the organic farming movement is based on "an alternative world view [that] directly subverts the modernist dichotomy of nature/society", and Pernille Kaltoft $(1999,2001)$ notes that the majority of organic farmers hold some type of a holistic perspective on nature (which she refers to as either pre-modern or reflexive/post-modern), although a minority of organic farmers (those whom she characterizes as 'modern') do exercise dualistic thinking.

In this chapter, I explore how organic farmers in South-eastern Ontario construct, mobilize and draw on the concept of nature in their organic farming practice. I examine how the farmers conceptualize the relationship between the natural and the social in the context of their organic farming practice, and reflect on what these understandings can contribute to broader theorizations of the intersection of society and nature. I argue that naturalizing the process of agricultural production emerges as a central goal amongst the organic farmers who participated in this study. The farmers' efforts in this regard emerge out of a critique of the industrialized conventional agricultural system on the basis of the on- and off-farm environmental degradation it has generated, as well as its efforts to minimize the role of nature in agricultural production. I contend that the organic farmers seek to enact an alternative approach which both minimizes ecological degradation and maximizes the agency of nature in the agricultural production process. This alternative approach hinges on an understanding of their farms as complex, dynamic, and highly interconnected natural systems, and requires both new ways of thinking about the role of 
the farmer in agricultural production and the development of a range of new farming skills. I further suggest that the re-skilling of agricultural production that is required by the organic farmers' desire to maximize nature's agency in the agricultural production process also helps them gain an increased sense of agency and control over their farms and within the agricultural system more generally. In all of this, the farmers' efforts to naturalize agricultural production also serve to problematize the notion of nature and society as ontologically distinct and mutually exclusive realms.

\section{Naturalizing Agricultural Production}

Concerns with the environmental and health problems associated with conventional farming were among the primary factors that motivated the farmers who participated in this study to take up organic farming. A number of the farmers had experienced these problems first hand when they or their families had been involved in conventional farming. For example, some of the farmers who themselves grew up on farms noted that they had watched the soil conditions and productivity on their family's land slowly deteriorate as the farms had become more and more dependent on chemical use, as this farmer relates:

"I grew up on this farm, and I remember back before we started using chemicals. It would have been in the 1950s sometime, and we carried on with them until the 1980 s, about 30 years. When we started, it was okay for the first few years. We had big yields, the soil was still in good condition. But after the first decade, I can remember being in the fields and looking at the soil and thinking, you know, that it was not what it once was. It was compacted, the structure wasn't good. It didn't seem to hold water as well, less organic matter. And we weren't getting as good yields as those years went on."

(Farmer, mixed farm; male) 
The farmers were also deeply concerned about the effect of agrichemicals on their own health and that of their families, as well as on wildlife living on or near the farm. Many of the farmers who had farmed conventionally prior to switching over to organic production related stories of suffering from constant allergies or of feeling ill after spraying pesticides. Sometimes these farmers were 'frightened' into organic production by a particularly threatening environmental- or health-related episode ${ }^{35}$, but more often they switched because of a longer-term discomfort with conventional production and its detrimental effects in these regards. Those who came into organic farming from a nonfarming background were also motivated by environmental concerns, choosing organic over conventional production because of the association of the latter with pollution and environmental degradation. For one of the relatively new farmers, becoming an organic farmer was the only way he could provide food that he trusted to his family. Similarly, a number of the farm families who switched to organic from conventional farming had maintained vegetable gardens organically for their personal and family use even when the rest of the farm was in conventional production. When the families had children, however, the women in the family had initiated the switch over of the properties as a whole out of concerns for the children's health, as this farmer relates:

"I had started the bend towards organic from the garden's point of view. We had small kids and I didn't want them spraying the lawns and putting stuff on the gardens...then we moved to cattle, so that was all along the way. And our kids were born in ' 74 and ' 76 so from that point on the gardens would have been

\footnotetext{
${ }^{35}$ For example, one farmer found that a pesticide which he had stored in the basement of his house over the winter had eaten right through the container it was stored in, leading it to spill all over his basement when he tried to retrieve it the following spring. Another found that the very tiny amount of pesticide residue that remained in a well rinsed container which was used in a subsequent year to load additional agrichemicals for a different crop all but destroyed a portion of that crop, leading him to better appreciate the effect of these chemicals on living matter. Finally, another family decided to contract their pesticide spraying out to a custom operator one year, however, when the operator arrived, it was in a machine and protective gear that looked so terrifying that it initiated a discussion that ended with the woman of the farm persuading her husband to begin the transition to organic shortly thereafter.
} 
organic. So it would have been early 80 s when we actually converted. Seeing how sick it was making [her husband], I didn't want the kids around that."

(Farmer, beef producer; female)

Emerging from these concerns and experiences, the farmers who participated in this study have sought to develop as organic farmers an alternative system of agriculture which avoids the environmental degradation that has been shown to be associated with the industrialized conventional agricultural system, and what they perceive as its expression in industrially produced food-that is, a reduced quality and healthiness in the food that goes on to compromise the health of its consumers. For these farmers, the poor quality of farming environments and food in the conventional system results from the efforts of agricultural industrialization to degrade, disregard, minimize or indeed overcome the role of nature in the act of agricultural production. Against this, organic farmers understand their practice as recognizing and nurturing the centrality of nature in the production process, and so as geared towards the dual goals of minimizing ecological damage and maximizing ecological capacity. This understanding centres on a notion of the farm as part of a highly interconnected and diverse natural system. It requires a new understanding of the nature of the agricultural production process and of the respective roles that nature and humans play within this process. In conjunction with this, it also requires a new approach to farming and a range of new farming skills and practices. In the sections below, I investigate each of these ideas in more detail. 


\section{Nature and its Centrality in the Organic Farming Process}

"First and foremost, organic farming is preserving the land, is based on conservation, rather than degradation. It's based in sustainability. I think that's a key thing: it tries to produce food sustainably. Second, it is about producing safe and healthy food. The food that's produced by conventional, by industrial farming - it's become increasingly clear that it's unsafe. Whether it's because of excess pesticide use, the improper use of diseased material in animal feed, the use of human waste in sewage sludge, the use of contaminated irrigation water. Producing organically yields safer food: clean veggies that are uncontaminated, field grade beef, free range chickens that are healthier because they've been raised in a healthier environment. Organic farming is producing good clean food raised with a concern for mother earth."

(Farmer, mixed farm; male)

In the discourses of organic farming, the relationship between agriculture and nature is complex and has multiple dimensions. For the organic farmers who participated in this study, the first dimension is that agricultural practices are understood as affecting the natural environment. As the farmers understand it, the conventional system of agricultural production has, over the past 50 years, left both on-farm and off-farm natures in an increasingly degraded state. This degradation, which is perceived to result primarily from the industrialized nature of the conventional system, has compromised the ability of the conventional system to produce reasonable quantities of high quality food; it has, in other words, compromised the sustainability of the agricultural production process. By contrast, many of the organic farmers couch their own practice of farming around the concept of sustainability, that is, they seek to enact a system where food can be extracted without compromising that system's current or future productive capacity. As such, organic farming is seen by them as a way to provide for what is probably the most basic need of human society while exercising a concern for both the present and the 
future condition of the earth: it seeks, as the farmer above puts it, to produce "good clean food raised with a concern for mother earth."

However, a closer examination of the way these organic farmers talk about nature and their practice reveals that they have a particular conceptualization of sustainability, one which is based not only on not compromising the environment and the natural productive capacity of land, but indeed on enhancing it. This relates to the fact that, from the farmers' perspectives, the impacts of agriculture on nature need not be negative ones. They believe that certain kinds of agricultural practice can also make contributions to or enhance nature, particularly the types of nature that they encounter in their farm fields and barnyards. A number of the farmers conceptualize organic farming as capable of 'restoring' and 'improving' the conditions of land. As one farmer suggested:

"Organic farming, it's restorative. While conventional farming leads to the restructuring of landscapes, it disturbs soil structure, makes soil more prone to erosion, organic farming is just the opposite: it restores. For me, organic farming is an attitude. It's about reducing our negative impacts on the environment, but through contributing something as well."

(Farmer, diversified market garden; male)

For the organic farmers, then, agriculture is seen as capable of improving the productive capacity of nature, rather than merely degrading it. This is an important capability given the increasingly polluted air, water and soil the farmers encounter in their farming practice amidst growing levels of global environmental degradation.

This first dimension of the relationship between agriculture and nature (agriculture as affecting or impacting nature) is thus closely related to a second view held by the farmers who participated in this study, which is the idea that nature plays a central role as an agent in the production process. Here, agricultural production is viewed not 
only as highly dependent on natural processes, but indeed as a natural process itself, such that food is also understood as a product of nature. One farmer suggested:

"We have to remember that [agricultural systems] are, at the most fundamental level natural systems. We can't just ignore that, though we might have tried to. It's through natural cycles and forces that food grows...It doesn't work to use an approach that just tries to take over, to kill all that [nature] off, to take it out of the process. I don't understand that mentality at all. I try to respect nature on my farm."

(Farmer, mixed farm; male)

In other words, for the organic farmers, nature is a quality and hence a capacity within agricultural production, even as it is simultaneously a condition and result. Indeed, it is this natural quality, and through it, the agency of nature, that the farmers seek to avoid degrading and rather that they seek to enhance through their own practices.

This perspective also emerges as a critique of the industrialized conventional system, since, for the farmers, the degradation of nature that characterizes this system is based in part on the tendency of agro-industrialization to neglect the centrality of nature (as a capacity or an agent) in the production process. They perceive that industrialization has sought to intervene in agricultural systems in ways that attempt to undermine or even overcome this centrality. However the participants in this study saw this to be a fundamentally misguided endeavour, an assessment which reflects their understanding that it is the natural quality of agricultural systems-the fact that nature functions within them as an agent - that is the ultimate source of healthiness and value in the food they produce. Good ecological functioning of the farm is understood as underpinning both the short-term viability and long-term sustainability of the farm, both ecologically and financially speaking. As one of the farmers who participated in this research explained to a group of other organic farmers in a session she led at a regional organic farming 
conference, maintaining the ecological cycle on the farm thus becomes of primary importance:

"In order to have the economic cycle, you must first have the ecological cycle. In this sense, the ecological cycle is far more important that the economic cycle. Unless you can get [the ecological cycle] to go round, to happen, you are never going to be able to extract any money from your farm."

(Farmer, diversified market garden; female)

For the farmers, focusing narrowly on maximizing productivity on the farm (and so their economic return in the short run) without understanding this as underpinned by a healthy farm ecology will inevitably result in the degradation of the farm's natural resource base, whether in the land, the crops, or the livestock, requiring the farmer to put more money into the farm to return it to proper functioning. In these senses, the organic farmers suggest a notion of the economy as embedded in ecological systems.

Given their concern with respecting and nurturing the centrality of nature in the agricultural production process, the practices of the organic farmers who participated in this study can be read as an attempt to naturalize agricultural production. The farmers enact farming systems that seek to maximize nature's agency in the production process by ensuring that the health of their farm's natural environment is at all points either maintained or enhanced. Hence, it was common for farmers to assert that organic farming is a system that tries to work "with nature" or "in harmony with nature". Importantly, however, this also reworks the farmer's role in production, which becomes centred on mobilizing the natural processes on their farm into the production of healthy, high quality food. The organic farmers in this study understand themselves and their work as engaged in an interactive, dialectical process with nature; they become coproducers with nature in the production of agricultural products. 
Collectively, the organic farmer's understanding of the complex relationship between agriculture and nature yields a view of organic farming as having a dual focus: minimizing ecological damage on the one hand, and maximizing ecological capacity on the other. In this sense, organic farming as a suite of practices is based simultaneously in the protection and the production of nature. In many ways, the efforts of the organic farmers in this study to farm in a manner that maintains the natural resource base that underpins agricultural production resonates with traditional notions of agrarian stewardship, which posit the farmer as the caretaker of these resources and of the productive capacity of the land. Many of the farmers in this study felt that stewardship concerns had been squeezed out of farming in the conventional system amidst its emphasis on production and the profit margin. As one farmer related:

"I think, you know, you could tell a lot about agriculture by looking at the language that's now used, you know, to describe the activities, like agribusiness, and that whole terminology. Every time you look at a farm paper, you see it, and it's heartbreaking, because terms like land stewardship and animal husbandry are so old fashioned - or so old fashioned to some people's ears - and yet those are the kinds of concepts, or terms, that were historically associated with a good farmer, someone who took care of things."

(Farmer, grain farm and milling company; male)

As such, a desire to reintegrate a role for the organic farmer as a steward of the land into the process of growing and raising food serves as a motivator for some of the farmers. However, in line with their understanding that organic farming is centrally concerned with improving the ecological functioning of the land, the farmers' articulate a notion of care taking which focuses on building or making contributions to the land:

"It's the only way to farm in our opinion. Some people feel there's other ways, but we at least can sleep at night. We feel that we are not polluting our 
environment, and that we're building our land rather than depleting it, so that we can pass it on to the next generation, whoever that may be."

(Farmer, beef producer; female)

"It really makes you feel like you are doing something meaningful, you know? ...It's just really doing something meaningful and sharing your harvest with people while feeling like you're a good steward of the land and depositing instead of withdrawing. I think that's probably where it starts."

(Farmer, dairy farm; female)

As these two quotes suggest, the idea that they will improve rather than degrade the land is central to their understandings of themselves as both good farmers, and as moral individuals.

For some of the farmers, farming organically brings to mind a traditional way of farming that existed before the widespread uptake of the use of agrichemicals and intensive growing methods, and which most of the farmers perceive as having been less environmentally damaging. This is especially the case for those farmers whose families have been farming for multiple generations and who can thus remember what farming was like before the ascendance of the current model of production in the conventional system. As one farmer suggested:

"There's sort of something special about being organic on a farm that's fifth generation family, too. You sort of feel that you're carrying on a line, in a sense. And, you know that your land is constantly improving."

(Farmer, beef producer; male)

At the same time, a number of the participants in this study stressed that organic farming isn't merely a reversion to the old way of farming in South-eastern Ontario. Rather, they suggest that organic farming tries to transcend faults in this system that existed even before the adoption of chemical-based, intensive growing methods; indeed, long-standing concerns about the loss of soil fertility and the decline in food quality were what 
motivated organic farming pioneers such as Sir Albert Howard and Lady Eve Balfour.

One farmer in this study referred to these longstanding problems as being part of the

"first" ecological crisis of agricultural production, in that it preceded the "second"

ecological crisis of agriculture associated with farmers' increasing chemical

dependence ${ }^{36}$. "Organic farming," this farmer argued "tries to transcend both of these ecological crises" (Farmer, diversified market garden; female). From her perspective, organic farming should not be understood as going back to an old way of farming, but is instead about building a new way, with long-term sustainability at its heart.

At the same time, the comments or actions of some of the organic farmers who participated in this study suggest that they feel that there is a certain stigma attached to the particular type of relationship with nature that organic farmers try to create on their farms. This leads some to problematize some of the traditional imagery associated with the organic farming movement, and to look for a more modern approach to organic farming. For example, when I asked one farming couple what they felt were the central principles of organic farming, they looked at each other, grinned, and without missing a beat drawled in perfect unison "It's in harmony with nature...." (Farmers, beef producers; male and female) - their sentence abbreviated by their collapse into a fit of laughter. Yet these particular farmers are very committed to the ecological and health

\footnotetext{
${ }^{36}$ Interestingly, this farmer argued that the roots of this first ecological crisis of agriculture lie in the fact that the conventional farming system continues to be embedded in a shifting cultivation approach to farming, that is, one which depletes or exhausts the natural resource base on a given parcel of land, before moving on to another parcel and letting nature restore the first. She suggested that this approach originates from human societies' hunter-gatherer roots; shifting cultivation uses the same mindset as a huntergatherer, except it collates our food in one location to save us from having to travel to it. In her view, modern agriculture remains embedded in this pattern of production despite the fact that private property rights and a growing world population have meant that most agriculturalists in the industrial world have been settled in one place for generations. But the effects of this are becoming clear: "there is nowhere to move on to but we keep farming in the same manner, finding that we get less and less in every generation of seeds." It is these effects that the farmer tries to transcend in her practice of organic farming.
} 
benefits of organic farming, and quite highly involved in the local organic political scene. What emerges in such comments is the residue of the longstanding discrediting of the organic approach — based largely on its approach to nature in agricultural production on the farm-by the conventional agricultural community. A number of farmers suggested that over the last 50 years, the use of agrichemicals to artificially enhance growing conditions and using intensive growing methods to maximize yield have become what defines a "modern" or "progressive" farmer. Organic farmers' deliberate refusal of these methods, and the fact that they prioritized a concern for the environment over maximizing their yields, meant that they were perceived by the conventional community as somehow backwards or "unmodern." In the past, this has affected farmers' relations with agricultural extension representatives. As one farmer put it to me, "there was a time when if you had to call the ag. rep. because you had a problem, you hid the fact that you were organic, because that was the problem" (Farmer, mixed farm; male). Similarly, some of the farmers related stories of having been ridiculed by their colleagues on the basis of their beliefs and approaches to farming in what is a highly competitive profession.

The participants of this study suggested, however, that there is an increased level of acceptance of organic farming amongst extension representatives and even amongst farmers in the conventional system, due largely to the financial premiums organic production now brings to farmers. This comes as a relief to a number of the organic farmers, because it is not easy to be cast as an outsider in one's community, as one farmer explains:

"You know, farmers watch each other. Farmers are very competitive...They drive by each others' farms really slowly. We're very, very competitive, and it's 
really difficult for farmers to stick their necks out and do something different from what their neighbours are doing. There's a lot of scorn involved. And some can be resentful when you really step out of that [conventional farming] hamster wheel, when you step out of that and do something differently. They become very defensive"

(Farmer, mixed farm; female)

It is this new-found acceptance for organics that the farmers who participated in this study do not want to compromise. As a result, a number of the farmers are keen to assert a 'modern' image for organic farmers which, while not necessarily downplaying its environmental concerns, also presents it as a competitive method of food production. To this end, some are uncomfortable with particular labels or images that were at one point (and to some extent continue to be) connected with the organic farming movement, such as its association with hippies or the back-to-the-land movement. The farmer quoted above, for example, suggested that it bothers her to meet this type of organic farmers, who may be environmentally concerned, but who are less serious about the production aspect of farming:

"I cringe a bit when I see some really crappy organic back-to-the-landers. It sort of makes me cringe. It's just that with the competition, well, we have to make sure organic is seen as viable, as a real opportunity."

(Farmer, mixed farm; female)

For this farmer, maintaining a particular 'image' for organic farming which posits it as both ecological and productive (and thus, in accordance with the latter, as modern), is an important goal of her practice.

Despite the prevalence of environmental concerns amongst the farmers in this study, few of them connected their practice with the ideas or activities of the mainstream environmental movement, as they are expressed in the study region or in Canada more generally. This seems to be mainly due to the fact that the major environmental groups 
active on the regional and national political science (such as the Sierra Club, Greenpeace, or the Canadian Parks and Wilderness Society) have focused almost exclusively on a strategy of nature preservation, articulating a vision of nature as that which exists outside of the productive activity of society and emphasizing the enclosure of this nature in parks and wilderness preserves. The farmers in this study question the efficacy of this strategy vis-à-vis the protection of nature:

'This system of [nature] preserves, that's almost frightening, isn't it? You get preserves, but what about the rest?! It allows you a carte blanche to destroy everything else. I think there's some sense that that may be the only way to do it, but I find that sad because of course the better way to do it would be to live with nature...There's room for man in the landscape, but you've got to try to balance it."

(Farmer, grain farm and milling company; male)

For the farmers, the environmentalist strategy is marred by a major fault, and that is that it tells us nothing about how to meet even our most basic human need, that is, the need for food, while living in balance with or exercising a concern for the non-human natures which the farmers understand as underpinning and central to the processes of food production. Against this environmentalist perspective, the organic farmers articulate a new vision of how to understand, live, and work with nature on the farm.

\section{Characterizing the Organic Farm as a Natural System}

Given their understanding of organic farming as anchored in a suite of natural processes, it is perhaps not surprising that many of the organic farmers who participated in this research think of their farms as natural systems. Indeed, a number of the farmers 
expressly referred to their farms as an "ecosystem" or even as a unified organism" ${ }^{37}$. This understanding hinges on a particular vision of nature and of how nature unfolds on the farm, a vision which borrows heavily on ideas from agroecology. The organic farmers understand and experience nature as highly complex, living and dynamic, and above all, interconnected. For the farmers, the main goal of their agricultural practice is to sustain, nurture, and enhance these interconnections, which in turn maximizes the ecological functioning of the farm and, through this, improves the food that is produced.

The farmers feel that their understanding of nature as complex, dynamic and interconnected is very different from that which characterizes the conventional agricultural system. For them, the conventional system treats the living systems of the farm as though they were mechanical systems, or as inert substrate for farmers' practice. In contrast, the organic farmers see food as a living, natural product that cannot be produced by an industrial process, as would be a machine:

"That's the main problem, I think: we cannot treat agriculture as industry. Agriculture is a very very basic thing of human living. It's one of the most important things, and you can not treat it as industry, like producing machines. It's not the same thing. You are dealing in life. You can not treat plants and animals like machines, try to produce them like machines." (emphasis in original)

(Farmer, meat producer; male)

Thus, the organic farmers understand the organic process of producing food to be less characterized by an "assembly-line vision" (Farmer, mixed farm; male) and more about

\footnotetext{
${ }^{37}$ Conceptualizing the farm as an organism is particularly common amongst those farmers who draw on ideas from biodynamics (or biodynamic agriculture) as developed by Rudolf Steiner. In his writings, Steiner (1924) developed the concept of the "whole farm organism" as a way of conceptualizing the farm as an enclosed system; he proposed strictly limiting the amounts of farm imports by creating all nutrient inputs for the farm on the farm.
} 
seeing the various natural components of the farm (e.g., the soil, crops, and animals) as being characterized by a high degree of agency and interdependence.

For the farmers, the mechanistic understanding of nature that permeates the industrialized, conventional system is enhanced by that system's reliance on positivist science perspectives, which tend to atomize the natural components of agricultural systems. The contradictions that arise between these positivist discourses and the farmers' agroecological discourses mean that "science" is a contested subject for the organic farmers. A few of the organic farmers in this study were quick to classify their farming practices as 'scientific', outlining in great detail in the interviews the science behind their choices of specific crops, or describing experiments organized around elaborate plot trials of certain crops or species that they replicated over multiple years in the interest of obtaining 'scientific results ${ }^{, 38}$. Indeed, two of these farmers even claimed that they had entered organic farming because they "understood the science" behind the environmental problems associated with pesticide and fertilizer use. Most farmers, however, expressed suspicion of, or even outwardly derided, the idea of a 'scientific' approach to agriculture, and were equally sceptical about the Canadian government's increased emphasis, in recent years, on "science-based" agriculture. Many of these farmers associated "science-based" approaches with the intensive, chemical based approaches of conventional farming, as though the two were interchangeable. Indeed, even those farmers who specifically defined their own approaches as 'scientific' were frustrated that the "science-based" tag had been used to continually legitimize conventional techniques even as other scientific studies have revealed their disastrous

\footnotetext{
${ }^{38}$ Notably, each of these farmers came into organic farming after careers in science and engineering, and clearly took much satisfaction from applying their personal renditions of a scientific approach.
} 
consequences. For the farmers, "science" as it is popularly used in the conventional agricultural system has ceased to hold its foundings as an "objective" system of thinking and evaluation, becoming rather a rhetorical device that furthers the interests of the powerful agrichemical companies. Science, for them, has thus becomes meaningless. As one farmer scoffed: "Science-based! What the hell does that mean?! It doesn't mean anything..." (Farmer, mixed farm; female)

To this end, the organic farmers in this study stress that organic farming requires a different approach, a "whole systems approach" (Farmer, diversified market gardener; female), rather than the atomistic approach of conventional agriculture and the positivist science on which it is based. For the farm to function smoothly as a whole-as a natural system—necessitates that the farmer understand the interconnections and interactions between the various processes which, in sum, comprise the farm. As one of the organic farmers in this study pointed out, this positions the organic farmer in a role akin to a practicing ecologist:

"I wouldn't ever have dreamed of being an ecologist, but in a curious sort of way....as an organic farmer and as a person interested in land, I became an ecologist through the back door. Not as a study, but as a practice." (Farmer, grain farm and milling company; male)

Here the farmer's purpose is to understand the form, dynamics and function of ecological relations on the farm, each of which the farmers recognize to be highly complex. Given this, it is not surprising that the organic farmers in this study placed a high degree of emphasis on observation and on building up site-specific experience on one's own farm. This necessitates being regularly present in the fields and in the barnyards: organic farming requires, in other words, a high level of attention to nature as it unfolds in the 
various sites and processes of the farm. The organic farmers contrasted this with the approach of conventional farming, which one likened to a more "remote control" operation (Farmer, mixed farm; male).

Amongst the organic farmers in this study, it seems that organic farming is a process- rather than outcome-focussed system. The emphasis is more on the connection between the soil, the hay that grows in the soil, the cow that the hay feeds, and the milk that the cow produces than it is on any of these particular physical entities in and of themselves. In a sense, the soil, the hay, the cow, or the milk become only the physical expression of relationships, and their qualities at any given moment depend on whether the farmer has successfully nourished the natural systems that underlie and connect them. As such, the organic farmers conceptualize their agricultural products as the culmination of the natural processes and relations that underpin them, rather than as a freestanding product.

For the participants of this study, farming organically means that one must always be thinking about how action (or, for that matter, inaction) at any given 'moment' in the farming system will affect the functioning of the remainder of the system, both in the present and in the future. This means that the farmers give every new activity careful consideration before starting it out on the farm, and often do trial runs or small-scale experiments on a small section before introducing any practice, animal or crop in a larger area. Indeed, as one of the farmers who runs a very diversified farm and who is finding himself overtaxed because of it related, the organic farmers also have to give careful consideration to the potential effects of taking any one practice, crop or animal out of the mix. As this farmer suggested, organic farming is not simply about identifying things 
that do not make money or that cost more to produce or even that take a lot of labour, but rather about establishing what is critical and what is not to keeping the system as a whole running smoothly. Practices and interventions, then, are designed on the land or in the barnyard, through a sort of reading of or even dialogue with nature; in the farmers' experience these emerge from the ground up rather than being imposed from above, which one farmer described as trying to "bend nature to fit a preconceived idea of what you should be doing" (Farmer, market garden; female).

This close attention to, and understanding of, nature forms the basis for decisionmaking on the farm, where the broader agroecological effect of any practice becomes the primary consideration in whether a farmer begins, alters or discontinues that practice on the farm. For example, in deciding which crops to grow, aside from whether it was biologically possible to grow the crop (i.e., based on the available heat units or soil conditions), the organic farmers in this study consistently identified that the agroecological benefits or services of that crop was their primary consideration when deciding whether to add it into their rotation. This is quite remarkable when one surveys what they rank as secondary considerations, a list that includes, but is not limited to, the price they would receive for the crop, the labour involved in production, their familiarity and experience with a crop, and the availability and quality of seed stock. This provides insight into the perspective of organic farmers and the priority they give to ecological concerns. It also contextualizes a type of comment that was common in the interviews with the organic farmers in this study, whereby farmers articulated that they were raising cattle primarily as a source of manure for their fields rather than out of a particular interest in selling beef, or even that they are raising chickens because of their ability to 
add Selenium to their soils despite the fact that the birds do not bring any additional income onto the farm. Rather than seeing the cow or the chicken primarily as a product, the organic farmers see them as an integral part of properly functioning agroecological system.

This understanding has important implications for the form and practices of farms in the study. Specifically, it resonates with a broader interest in self-sufficiency that is common amongst the farmers, leading them to attempt to build their farms as selfsustaining systems or cycles. Many of the farmers thus work to reduce as much as possible their reliance on off-farm inputs, including feed for their animals, or fertilizer for their fields. Rather, the farmers attempt to farm in a way that will produce these inputs on the farm from their own farm resources. This means that those who raise field crops tend also to have animals on hand to produce manure for their fertilizer needs, even as those who have animals tend to raise their own field crops to feed the animals. In turn, the farmers understand this as a better replication of a full, functioning natural ecosystem, as the farmer below suggests:

"I also think, and I've really come around on this, that you've got to have animals in your mix somewhere. They are the nutrient recyclers. I can conceive of ways that you could farm without animals, and I'm talking on a global scale. But, I think there'd have to be a lot less of us, because a lot less land would be producing food. All the marginal lands that are now grazed will not grow crops for more than a few years....If one of the understandings is that farming should imitate nature as much as possible, we cannot have plants without animals, and vice versa."

(Farmer, mixed farm; male)

This further explains why most of the farmers in this study maintain mixed farms (i.e., farms that produce both field crops and livestock). Although it is somewhat less common for the market gardeners to keep animals given their reduced land base for growing food 
or providing pasture, some do keep chickens or other animals in order to have a regular supply of fertilizer for their land. In other words, the farmers' desire to replicate in the farm a self-contained, natural system is a significant factor in their efforts to create high levels of ecological (and, through this, economic) diversification.

The main limitation that the farmers in this study face in their desire to maintain diversified farms, and specifically to take up certain farming activities based on their agroecological benefits, is the regulation that increasingly characterizes particular agricultural subsectors. Often, the problem with this regulation is that it doesn't differentiate between small-scale, mixed farmers who produce small quantities of the particular product, usually for direct sale to customers, and large scale producers who sell the same product through more traditional mechanisms. The most common complaint amongst farmers in this regard was the regulation of chicken production in the province such that the farmers are not allowed to produce birds for commercial sale unless they hold quota. Most of the farmers would like to raise small flocks of chickens as part of their farming activities, and question the necessity of disallowing this type of small-scale production, given that all the organic farmers in the province put together would only take up a very small portion of the current market for chicken. Many of the farmers run 'illegal' chicken operations, but this is becoming more difficult with the increased surveillance of their farms. The farmers in the study also complained about the increasing insistence that eggs sold at farmers' markets be professionally graded, and of the changes that municipalities had tried to install around taxes for maple syrup production. The overall effect of this regulation is well communicated by the following 
farmer, who was due to speak at a public forum on farming issues the day after I interviewed her:

"I'm so frustrated, I just don't know what I should do. Well, what I'm thinking I should do is this-at this talk tomorrow, I should just go to the front of the room and write the following list on the board: chickens, eggs, milk, maple syrup, marijuana. And then ask the audience: 'Which of these is illegal to produce on my farm?'. Because the answer is all of them! But the public doesn't know this. They don't know what's going on."

(Farmer, diversified market garden; female)

As she suggests, farmers find the regulation situation extremely frustrating because, while protecting large scale, specialized farms and agri-businesses, it severely restricts small-scale mixed farmers.

The organic farmers in this study stress that the process or whole-system focus of organic farming requires a very different kind of thinking than that used in conventional agricultural production. Organic farming is based on intervening in nature selfconsciously, with the attitude that one can learn from nature, and with a willingness to adapt agricultural practice according to what one learns. For those who farmed conventionally before turning to organics, this is a significant shift-indeed, a number of the farmers identified the difficulty of making this shift in thinking as the foremost factor keeping conventional farmers from converting over to organic growing. As one farmer put it:

"Philosophically [organic farming] is a whole different quadrant of thought...I mean you just wake up thinking differently every morning when you're organic than you do when you're conventional. You think of things like in the long run, not whether there will be drought but how can I drought proof my farm. You're always thinking about systems and ways of looking after your soil and your land so that you won't have to intervene in a big chemical bang. I mean, we don't think of chemicals at all. We're always thinking of systems."

(Farmer, beef producer; female) 
Similarly, the farmers stressed that understanding the farm as a natural system also requires a re-thinking of what constitutes a 'problem' in farming systems, and, consequently, what might constitute a solution. Indicators of a problem in conventional farming are not necessarily so in the organic system, where they may carry a more nuanced message about the health and condition of the soil, crop, or animal. For example, rather than simply condemning weeds (regardless of their species) on the simple basis that they compete with the desired species for nutrients in the soil, two of the organic farmers in this study related that they now note the presence and prevalence of certain weed species, which will indicate to them the underlying availability of different nutrients and minerals. Learning to 'read' and understand their farm and to identify and address potential problems even before they develop becomes central to organic practice. The organic farmers liken this to moving towards a proactive rather than reactive or 'quick fix' approach, one that seeks to address the underlying causes of a problem rather than the superficial symptoms, as the following two quotes explain:

"In conventional farming, anytime someone tells you 'here's the quick fix', you're tempted. But once you get into organic, that kind of feeling just sort of goes. You just don't think that way anymore. And when people say to you 'what do you do if', I just sort of look at them and say 'well, I guess we'll cross that bridge when it comes but we haven't hit that yet." And so far by trying to do things in a systematic way, some of those problems are solved."

(Farmer, beef producer; female)

"It's just letting things be, letting things happen and working with it, not getting our knickers in a knot over it. What one would think of as a huge problem, is not really a problem. It's rethinking what is a problem. You know, people say it just takes a switch around in your head. And I know what they're talking about when they say that. You just start seeing things in a different way. You start seeing how things are working together and it changes your whole farming practice."

(Farmer, dairy farm; female) 
Rather than an approach which 'targets' a particular component of the agricultural system or a problem with that component through a single management intervention, then, organic farmers favour a methodologically plural approach, which requires that farmers learn or re-learn a series of new farming techniques, practices, and skills.

\section{$\underline{\text { Re-skilling Farming }}$}

The organic farmers in this study undertake a range of complex farming practices, including growing diversified crop rotations, growing green manure and cover crops, composting, maintaining mixed farms, and often growing heritage breeds of crops and/or raising rare breeds of animals. Farmers also contribute to the overall ecology of their farms by maintaining hedgerows and wooded areas on their properties. Many of the practices are primarily geared towards maintaining the fertility, structure and overall health of the soil, which the organic farmers understand as the foundation of the organic system. However, most of the practices in fact serve multiple purposes simultaneously, contributing variably to the maintenance of soil health and to weed, pest, and/or disease management, or in some cases to animal husbandry. For example, the farmers in this study grow a range of crops in a diversified rotation on their farms, a practice that contributes to a balanced nutrient profile in the soil (and so to soil fertility), works to interrupt weed cycles physically and biologically, helps control pest populations by alternating the 'hosts' available to them, and contributes to and preserves biodiversity on the farm. Similarly, maintaining hedge- and fence-rows provides valuable habitat for a variety of wildlife species including predators that help keep pests at bay, helps filter water into the surrounding soil, helps reduce soil erosion by breaking up the wind profile 
over the farm, and provides shade for livestock in the fields. Accordingly, the farmers understand most of the practices of organic farming as both multi-functional and highly interactive. (Appendix 1 provides a more detailed description of the specific goals and forms of these interactive practices as they are articulated and practiced by the farmers.)

Some of the practices, such as composting, are unique to organic farming. Others, such as crop rotations, were used more widely (if in different forms) by farmers before the advent of agrichemicals, which seemed to make their contributions to soil fertility and weed- and pest management unnecessary. Collectively, however, these practices make up a suite of techniques and skills which the participants in this study stressed that those new to organic farming must learn or re-learn-and the only way to learn them is through practice and the building of experience on the farm. The participants of this study were thus quick to assert that organic farming as they practice it on their farms is an active, multi-dimensional process that involves much more than merely avoiding certain practices common in conventional farming, such as the use of synthetic chemicals and pesticides in the fields or antibiotics in farm livestock, although learning to do without these also requires new skills. The farmers feel their practice makes positive contributions to the landscape, and works towards developing a form of agriculture that is both viable in the short term and sustainable in the long term. To this end, an approach which focused only on the avoidance of substances, rather than on building up the soil and nurturing the growing crops and animals was dismissed by the farmers as "shallow-" rather than "deep organics" (Farmer, diversified market garden; female), or as being "organic by neglect" (Farmer, grain farm; male). The farmers in this study liken the movement to a fuller definition of organic based on what it includes 
and the contributions it makes rather than on the practices it excludes to a shift "from a negative to a positive definition of organic" (Farmer, beef producer; male).

What the above discussion begins to make clear is that, while the organic farmers in this study grant increased agency to nature in food production processes, this does not mean that a farmer's contribution to the growing process is not also seen as significant. Indeed, as quotes in the earlier section suggested, the farmers stress that it takes a high degree of attention and an unhurried attitude to produce food the organic way. The farmers emphasize that it takes skill to understand and respond to nature, to find systematic solutions to problems rather than the quick-fix promised by pesticides or antibiotics, and generally to master the various complex practices that underpin organic farming. Most of the farmers who participated in this study consider themselves to be in a position of constant learning. While many of them consider that they are already 'good farmers', they almost always emphasized that they were becoming still more observant, still more practiced, still more familiar with the particular ecological conditions and requirements of their particular farm, and hence still 'better farmers' with each passing year in organic production, as described below:

"We were good farmers [when we switched to organic], but we're getting much better. We're becoming more observant. We can see things coming before they happen."

(Farmer, dairy farm; female)

"I think it's getting easier, as I'm getting experience. You have to learn a lot. It all comes through experience! There are not very many farmers experienced in raising sheep organically, I know some from Western Ontario, but you really have to make your own experiences. It's pretty hard at the beginning-you have lots of losses and problems, but you grow into it."

(Farmer, meat producer; male) 
Most of the farmers also suggested that they had seen both a steady reduction in management problems and steady improvements in the ecological conditions of their land and in the quality, taste, and nutrition of the food they produced as they gained more experience with organic techniques. For the farmers, this acts as the primary reinforcement of their organic practice.

However, the farmers' experience of organic farming as a skilled occupation also has deeper social implications. For the farmers in this study, participating in organic farming acknowledges, prioritizes, and harnesses the highly localized knowledge and experience that they build up on their farms. For example, when I asked one farmer about whether there were particular sources she relied on for information on organic techniques, she replied:

"We're members of COG, and EFAO, so we participate in their events. But you know, I've farmed my entire adult life, a lot of it is, you learn, you know, its knowledge that you learn, that you have. I teach seminars now. You can always learn, you get hints from other people about what worked for them, we use an organic handbook. We get Acres magazine and we're always reading the latest on what's going on in other parts of the world, what other countries are doing. We stay very, very current, but what's most valuable to us is our own knowledge."

(Farmer, mixed farm; female)

The improved results that the farmers attain through their own efforts and experimentation is tremendously validating for them, as are the opportunities they have to share their knowledge with other farmers in the local 'kitchen table' discussion groups organized in their areas through chapters of organic farming interest groups such as the Ecological Farmers Association of Ontario and the Canadian Organic Growers. Especially for the farmers who converted to organic farming from conventional production, the shift from farming under the productivist system, which tended to dismiss 
their knowledge as insignificant, to the organic system, where personal observations and experience are the primary basis for decision-making, was tremendously significant.

When they spoke about this shift in the interviews, it was evident that the experience had reinstalled a sense of confidence in their abilities as farmers and a stronger sense of self. One fifth-generation farmer who had been farming conventionally for much of his life explained that the welcoming, receptive attitude and the value attributed to his personal farming experience amongst an organic discussion group he attended while considering switching into organic production was one of the key factors that sold him on the transition.

Of course, the privilege that organic farming gives to locally derived agroecological knowledge is also politically significant to the farmers in this study, given that their perception that the conventional system has continually favoured the off-farm expertise of agrichemical company representatives. It is central to the notion of regaining control of their farms, as a number of farmers describe below:

"[Conventional] farmers are users of inputs, that's the way they know agriculture. They have their spray regime, their fertilizer regime, they have work contracted out, so that really, you know, we're just users of input. A lot of our knowledge base in agriculture has gone off the farm, and now we have all these other people telling us what we have to do. And for the conventional farmers-if they could only take all that back, that would be a huge. A lot of these farmers wouldn't agree with me, they would say 'Oh, no. I know what has to be done on my land.' Yeah, but you're basically a user of inputs...For me, I use the inputs that I want to use, I have more control over it."

(Farmer, mixed farm; female)

"I don't think [conventional] farmers see that! I don't think they see what they've lost. They're so proud they think that they're their own boss but they haven't been for a long time. And to do the type of work we do [as farmers], to take on the financial burden, there needs to be those other, you need to know that you're your own boss, that you have control over your destiny to some degree."

(Farmer, dairy farm; female) 
"Now that I'm farming organically, no one can tell me what to do on my land. I'm no longer a pawn to the system. I am the one that knows my land."

(Farmer, beef producer; male)

For these farmers, the increased sense of control that they have within the agricultural system as organic farmers also serves as a significant motivator for them to stay in organic practice.

\section{Contradictions and the Evolution of Organic Farming}

What emerges in this chapter, then, is that there is a relatively high degree of agreement amongst the discourses around nature and the relationship between organic farming and nature articulated by the farmers in this study. The farmers also employ, broadly, a similar range of organic farming practices (as described further in Appendix 2). This is perhaps not surprising given the historical importance of environmental concerns in the emergence of organic farming as a movement, concerns that were addressed by the development of a particular suite of agricultural practices. Of course, as I have shown, there are subtle differences in farmers' perspectives on the question of nature, for example in their understandings of the importance and validity of science in the context of their practice in nature, or in whether they present their practice as traditional or modern on the basis of its ecological approach. These differences are mainly articulated by farmers at the individual level, rather than being issues of widespread debate in the organic farming community.

In a similar way, a number of the farmers also identified contradictions within their own farming practices in the course of the interviews. For the most part, these 
contradictions seem to exist around certain practices, which, while commonly employed by many or even most organic farmers, some see as violating the movement's dual goal of minimizing ecological degradation and maximizing ecological capacity. These practices are mainly problematized by farmers at the individual, rather than a movementwide, level. For example, some of the farmers who raised livestock imported a portion of their feed onto their farms, a practice which some feel violates organic principles given the emphasis these place on running self-sufficient, self-contained farms. In almost all of these cases, the farmers had initially tried to supply all their feed from the resources of their own farms, but found that they lacked sufficient land base, labour power, or time to do so. As one farming couple related:

"We were trying to grow all our own feed but that was getting unfeasible, because we could never quite get the right kind of mix. Like you really need good, balanced rations for the chickens to grow properly in the time that you have... And we were spending all our time growing crops and trying to look after the animals, so we didn't really have time to be balancing all our feed rations. But we tried it for three years, didn't we [question directed to her husband]? And then, finally we decided we better start buying the commercial stuff."

(Farmer, beef producer; female)

Comments such as this were often related in a somewhat defensive tone of voice, indicating that the farmers acknowledged this practice as one that would be contested by some of their peers.

Another aspect of their practice which a number of the farmers in this study questioned pertained to the use on organic farms of farm machinery and vehicles which run off fossil fuels. These were seen by farmers to contribute to environmental degradation (both on the farm and more widely) and so to be in some senses 'unorganic' as evidenced by the quotes below: 
“The environmental aspect, it's so huge. I mean personally I'd like to see-and it's probably not realistic-but more horses doing the ploughing and that sort of thing. But oh, there has to be a lot of things that would have to change before that sort of thing would happen. And that may never happen, maybe we'll find some other way to keep it more sustainable that way, because we're really still very dependent on fossil fuels, and that's not sustainable, I don't care what anybody says."

(Farmer, dairy farm; female)

"For me, I always dreamed of having such a truck, since I was a little boy. But now I understand it's not really what I want, because it uses a lot of gas. It's totally the opposite of everything else that I'm doing right now, so I want to get rid of it...We can manage it with one car. It's maybe not convenient, but I can manage it."

(Farmer, meat producer; male)

Another participant in the study related her discomfort around the fact that organic farmers are sometimes criticized by their conventional farming peers for being "diesel fuel farmers," due to the fact that those who grow field crops sometimes rely on additional rounds of tilling before seeding or other types of mechanical interventions to help control weeds. In a similar vein, one farmer noted her discomfort around the horsebreeding business she runs as a way to subsidize her farm, worrying that it encourages people to travel extensive distances and so burn more fossil fuels. For the farmers, then, their participation in polluting activities both troubles them on an individual level, but they also worry that it will discredit their efforts in the eyes of the conventional community.

I point out these differences and contradictions here not to discredit organic farmers' broader efforts to farm in a more sustainable manner, but rather to highlight an interesting aspect of organic farming and how it evolves as a suite of practices. This centres on the fact that being involved in organic production seems to expose organic farmers to contradictions in their own practices. Indeed, as one farmer related: 
"Since I've been farming organically, well, you just really have a deeper feeling for a lot of different things. And at the same time you feel, like when I see all these cars going by, it bothers me-like I'm just as bad, I have to go to town and in the truck and everything - but it really makes a lot of contradictions, too, in your mind. Even though it definitely opens you up to all kinds of things and it makes you want to look into biodynamics, and be a better homeopath..."

(Farmer, dairy farm; female)

In a similar light, one farmer likened starting to farm organically to setting out on a path in which the destination keeps shifting through a process of evolution, as the farmers strive both to become better farmers vis-à-vis their techniques and to resolve the contradictions that inevitably arise in their farming practice.

\section{The Relationship between Nature and Society in Organic Farming}

For the organic farmers in this study, the fact that agriculture is based in and sustained by natural systems is perhaps its most fundamental characteristic. These farmers clearly understand nature as not only a condition of agricultural production, but as a quality of and an agent in production (and hence also as a product of production), such that they direct their activity to nurturing ecological health and nature's agency. This differs significantly from industrialist understandings, which objectify nature, seeing it as an external condition of production (Smith 1984), or as merely "a stock of resources for the accumulation of wealth" (Braun 2002: 2). However, if organic farmers understand their practice to be about nurturing the capacity of nature in agriculture, then this also requires a reworking of the notion of the act of production as it pertains in agriculture. 
As Tim Ingold (2000) has suggested, in contemporary Western societies the concept of production is typically understood to mean a sort of 'making by art' of nature into something that better serves human purposes, an "imprinting of prior conceptual design upon a raw material substrate. Human reason is supposed to provide the form, nature the substance in which it is realised" (ibid. 80). ${ }^{39}$ The industrialist conception of production understands human labour as the source of value in the production process. But this contrasts with the organic farmers' understandings which posit nature, by its status as a significant agent in the production of food, to be the source of the value, quality, and healthiness of organic food. As such, these farmers seek to enact a system, through their practice, which enhances nature's capacity to provide food and to imbue it with these desirable qualities. Indeed, as Ingold notes, applying an industrialist concept of production to the breeding and raising of crops and animals on a farm may imply something quite outside of the way many farming cultures from around the world understand what it is that farming does. He asks whether this concept of production is really suitable to agriculture: "But how can you 'make' a pig, a yam, or a crop of millet?" (ibid. 85) Rather, Ingold assesses, "the work of the farmer or herdsman does not make crops or livestock, but rather serves to set up certain conditions of development within which plants and animals take on their particular forms and behavioural dispositions. We are dealing, in a word, with processes of growth" (ibid.)

\footnotetext{
${ }^{39}$ Ingold (2000) shows that this conception of production has long been used to separate agrarian or pastoral cultures from those of hunter and gatherer groups. In drawing the applicability of the term 'production' into question, Ingold dissolves the boundaries between 'production'- and 'collection'-focussed cultures, arguing that they exist along a continuum of varying degrees of human intervention in establishing the conditions of growth.
} 
Ingold's conception of farmers as being concerned with the growth of crops and animals, rather than producing (making) them, resonates with the organic farmers' understanding of their practice as being centrally concerned with establishing the conditions under which life (and nature) can flourish rather than the machine-like production of plant or animal products. Because the farmers understand nature to be an agent in the production of and so a source of value in organic food, they understand their practice in this regard to be the basis of both the ecological and economic sustainability of the farm. Again, this contrasts with the approach in the industrialized agri-food system, which, insofar as it sees nature as a barrier or constraint to capitalist accumulation, works to reconfigure production processes so as to minimize their dependence on nature (Guthman 2000: 149). Against this, organic farmers understand nature as holding the opportunities for accumulation, rather than the constraints to it; accumulation happens through the naturalness of agriculture, not in spite of it. However, at the same time, the organic farmers' connection of their practice to the concept of sustainability belies a different notion of this concept than that mobilized by the Canadian government. For while the farmers' understandings of nature as a source of value in food shares some superficial similarities with government discourses of sustainability which increasingly frame nature as a site of accumulation (Escobar 1996), for the farmers the natural basis of agriculture is the very reason that profit must cease to be the first concern in how we produce our food. Rather, the organic farmers insist that the ecological health of the food-producing system must become the first concern, such that certain high profit modes of production that degrade the farm's natural basis—-but whose sustainability curiously never comes into question in current governmental discourses-must be ruled 
out. As I have suggested, this reflects an understanding of the economy as irretrievably embedded in ecology.

For the organic farmers, then, organic production requires a particular, dynamic relationship with nature, one based not around the idea of dominating, suppressing or overcoming nature, but rather on nurturing it and working with it in the production of food, and respecting the lessons to be learned therein. The farmers' efforts in this regard hinge on an understanding of their farms as natural systems that are highly complex, dynamic, and above-all, interconnected, a view common to agroecological perspectives, but which differs significantly from the reductionist postivist science of the conventional agri-food system (Hecht 1995). In turn, the dual emphasis on minimizing ecological degradation and maximizing ecological capacity that the farmers set out to achieve in their practice serves, as Terry Marsden (2000) has suggested, to reembed agricultural products in the ecological relations by which they are produced.

As I have shown, the organic farmers' desire to centralize nature in the agricultural production process is intricately interlinked with a parallel desire to recentre themselves as farmers within this process, as emerges through their emphasis on reskilling agriculture. Ironically, this emphasis may in part come about amongst the organic farmers as a correction to their own attempts to naturalize agriculture, (i.e., in that their portrayal of agriculture as 'natural' may make the organic farmers' work seem to be negligible and unimportant to outsiders' eyes). However, I believe that this emphasis also emerges in response to what the organic farmers perceive as a broader problem in the conventional agricultural system, which requires a consideration of the way that the industrialization of this system has proceeded. Unable to directly and uniformly 
transform the biological and biophysical processes on which agriculture relies, agricultural industrialization has taken a course that is distinct from that of the industrialization of other production systems (Goodman et al. 1987; Goodman and Redclift 1991). Processes of appropriationism have played a key role in the industrialization of agriculture, whereby the development of agricultural inputs that were once provided through natural processes on the farm has increasingly been moved off the farm and transformed into industrial processes under the control of agribusiness firms, such that the standardized inputs that result (such as seeds and agrichemicals) can be sold back to the farmer as a mechanism of accumulation. This has had important social implications for farmers in the conventional system. For, at the same time that it has worked to trivialize nature in the agricultural production process, it has in parallel trivialized the farmer.

As Jack Kloppenburg (1991) has pointed out, the conventional system of agriculture, by steadily increasing farmers' reliance on standardized agricultural inputs, has led to a loss of farmer knowledge. For example, conventional farmers know less and less about how to develop strong seed stock, manage soil fertility without the use of agrichemicals, choose the species that are best suited to their climate and location, differentially apply practices of stewardship and husbandry to local circumstances, and so on. They have lost a sort of 'local agroecological knowledge' and with it a whole set of farming skills. As one farmer participating in a public forum on genetically modified food that I attended during the course of this research commented, "the industrial transformation of agriculture has turned knowledge into information." (Public Forum, 'Genetically Modified Food: The Answer to World Hunger and Poverty?', Ottawa 
Congress Centre, March 9, 2005). Of course, what farmers have also lost in this process is a significant degree of control over the agri-food system. Mary Hendrickson and William Heffernan (2002) describe the grim reality of the contemporary conventional agri-food system for farmers, characterized as it is by transnational corporations who, in various assemblages or 'food chain clusters' increasingly control not just those portions of the agri-food system that are up- and down-stream of the farm, but in important ways, the farm itself:

"In food chain clusters, the food product is passed along from stage to stage, but ownership never changes, and neither does the location of the decisionmaking. Starting at the intellectual property rights that governments give to biotechnology firms, the food product always remains the property of a firm or a cluster of firms. The farmer becomes a grower, providing the labour and often some of the capital, but never owning the product as it moves through the food system and never making the major management decisions." (p. 350)

The significance of this process and its interlinkages to agro-industrialization's attempts to overcome the natural basis of agriculture must not be underestimated. It has effectively limited the control that farmers in the conventional system experience over their farms.

For the organic farmers in this study, and especially those who moved into organic production from conventional farming, farming organically offers significant redress to this situation. As the farmers stress, organic farming requires of the farmer an intimate knowledge or intense familiarity with the particular natural conditions and processes of their farms. As such, the new approaches and skills that organic farmers have to learn (indeed, that those interviewed for this study consider they are still learning) have tended-as Kevin Morgan and Jonathon Murdoch (2000: 159) have suggested is true of the conversion process amongst organic farmers more generally—to "redistribute 
knowledge back towards the farm and farmers." In the organic system, "farmers can once again become "knowing agents", able to exercise more autonomy and control over both their relations with other actors in the food chain and means of production on the farm" (ibid:: 171). This puts farmers' comments that "now that I'm farming organically, no one can tell me what to do on my land" in broader perspective. For the farmers in this study, then, naturalizing agricultural production gives not only nature but also the farmer greater agency in the process in agricultural production and the agricultural system in general.

With these insights in mind, it is worth returning to the question Timothy Vos (2000: 245) poses at the beginning of his paper on the organic farming movement in the U.S.: "what is the significance of organic agriculture", he asks, "in the context of the environmental/ecological imaginary of contemporary culture?" What emerges in this study is that, within their efforts to farm organically, organic farmers are placed at the centre of a struggle where different conceptions of nature, and how it relates to society within the context of agricultural production, are articulated. The farmers challenge the constructions of nature and the nature-society relationship inherent to conventional agricultural production, on the basis of the environmental degradation and the associated reduction in food quality that these have yielded, and on the basis of the way they undermine their own skill and knowledge as farmers. Against this, they posit a new construction which enables the kind of socio-natural world which the farmers find more desirable. At the heart of this is a new socioecological imaginary, premised not on the externalization of nature from society—as is the industrial imaginary of the naturesociety relationship—but rather on an acknowledgement of nature and society as 
overlapping and mutually sustained. In the organic farmers' practice, nature and society are relationally constituted, in that not only are they intricately interconnected, but that the possible expressions of each are shaped by the other (c.f. Whatmore 1997). Interestingly, it is this same understanding which makes organic farmers distance themselves from mainstream environmental groups, which also posit nature (at least in its purest form) as a site external to the productive processes of society (Castree 1995; Braun 2002), rather than as something that is alive and intact in the productive landscapes of organic farms. Indeed, from the farmers' perspectives, the discourses of the conventional agricultural system and those of the environmental groups share the same fault, in that they are each premised on the strict separation of nature and society, as against organic farmers' understanding that these may both be found within the spaces of organic farms and food.

This study, then, is in broad agreement with the suggestion of a number of agrifood scholars that organic farmers seek a different vision of the society-nature relationship than that which pertains in the conventional agricultural system and indeed in capitalist production more generally (e.g. Goodman 1999; Kaltoft 1999; Vos 2000; Kaltoft 2001; Mansfield 2004). Because food is envisaged as a co-production of nature and social (productive) activity, it becomes "a unifying material and symbolic linkage that bridges and binds the social and the natural together" (Goodman 1999: 33). As Becky Mansfield (2004: 222) suggests, for organic farmers, the system by which they produce food is "a hybrid system in which what is natural and what is social are not so easily separated." In these senses, organic farmers are struggling to move beyond a notion of nature and society as clear and unitary ontological categories (Kaltoft 1999, 
2001). As I have shown in this chapter, this process has both discursive dimensions, being wrapped up in revisionings not only of the nature-society relationship, but also of nature, as well as in a revaluing of farmers' knowledges, and also material dimensions, resulting in particular farming practices and the material control of the organic farm.

For the farmers, this new socioecological imaginary or vision of the societyrelationship is intimately tied up with the notion of stewardship and so with responsibility—since acknowledging nature and society as intimately interconnected is what encourages them to foreground these concerns. Indeed, it seems that amongst the organic farmers in this study, a new identity for the 'good farmer' is being posited. Rather than focussing narrowly on production and maximizing yields, as Rob Burton (2004) has suggested the productivist system encourages 'good farmers' to do, the organic farmers define a 'good farmer' as one who includes a concern for environmental protection within his or her productive activities and landscapes. Indeed, perhaps another significant aspect of organic farming is that it posits the possibility of social action that at once produces and protects nature-in the deepest sense, since farmers posit their practices as simultaneously producing food and protecting the farm environmentthereby avoiding the either/or mentality that can characterize the environmentalist discourses which are often the most obvious alternative to industrialism. For the organic farmers in this study, given the fundamental human need for food and so for agriculture, we cannot avoid producing nature. For them, then, as for Raymond Bryant (2001) and Braun (2002), the critical question thus becomes what kinds of nature we should produce, and in whose interests. The organic farmers interviewed in this study have articulated their answers to these questions in their desire to produce natural and lively landscapes 
that produce healthful food, sustainable livelihoods, and empowered farmers. In these senses, in a world which has few resources for thinking about how to responsibly inhabit our complex socioecological worlds (Braun 2002), perhaps organic farming movements hold insights into how a more ecologically and socially just possibility might be obtained. 


\section{Chapter 5: Organic farming and the localization of the agricultural economy}

\section{Introduction}

In recent decades, the dominant approaches in agro-food studies have tended to frame globalization and global political economic forces as the primary determinants of agri-food system change. Accounts have "focused on the rise and uniform reach of an industrial, capitalist, concentrated, and globally integrated agro-food system" (Hinrichs 2003: 34), and have seemed both to presume and to predict that local agro-food systems would undergo a gradual process of homogenization under the unbridled intrusion of global capitalism. These approaches have been undeniably useful: they have helped us to understand, for example, that the increased liberalization of the international agricultural economy (and the associated restructuring of national agricultural economies to reflect neoliberal perspectives) has had significant consequences for local agricultural livelihoods and communities. However, against the apparent predictions of such approaches, it has become increasingly evident that heterogeneity at the local level remains less the exception than the rule in agro-food systems. As a result, theorists have increasingly turned to a consideration of the roles that local cultures and histories play in shaping agricultural change (Hinrichs 2003, Winter 2003b).

The local, it seems, is back on the agro-food agenda, and scholars are engaged in renewed efforts to understand the intersection of globalization with the local scale in agro-food systems. To this end, a number of theorists have engaged with ideas around embeddedness. As Michael Winter (2003b: 24) notes "[a]t the heart of the notion of embeddedness is the emphasis laid on the necessity of social relations to all economic transactions." Such approaches argue that the global economic system is rooted through 
its transactions in local places and contexts. This can go some distance towards countering the notion that the globalization of agri-food systems is inevitable: it suggests, to paraphrase Mary Hendrickson and William Heffernan (2002: 365, but see McMichael $2000 \mathrm{a}$, on whom they are drawing), that perhaps the greatest certainty in the globalization process is its inherent uncertainty.

At the same time, agro-food system localization seems to be emerging as a key strategy amongst agriculture and food-related social movements, as evidenced by the rise of buy- and eat-local campaigns, and of local labelling projects in many regions in both North America and Europe. This has encouraged scholars to focus on the opportunities that the local might hold for resisting ongoing processes of globalization in the agri-food sector, and for building alternatives to the industrial, capitalist system of food provisioning that has rapidly come to dominate in most highly industrialized countries (Hendrickson and Heffernan 2002; Hinrichs 2003; Winter 2003b; DuPuis and Goodman 2005). Here, agri-food system localization appears to emerge as a challenge to globalization, as its antithesis or even as a 'solution' to the globalization 'problem' (Hinrichs 2003; DuPuis and Goodman 2005). Investigations of the politics of such localization efforts are becoming more common, and have revealed that these efforts may also harbour potential dangers. These include the possibility that localization initiatives may articulate a kind of 'defensive localism' that works to make "localities responsible only for the problems that occur within them", and hence to "reduce the lens of who we care about" by excluding non-local others and pitting communities against each other (Allen 1999: 122) ${ }^{40}$. In this sense, the "valorization of the local" may become implicated

\footnotetext{
${ }^{40}$ More recently still, theorists have been concerned to point out that agro-food localization efforts that hinge on a 'defence' of the local may also exclude various local populations, that is, they may homogenize
} 
in "the production of...parochialism or nationalism" (Holloway and Kneafsey 2000: 294)—what has elsewhere been referred to as 'food patriotism' (Bell and Valentine 1997). Increasingly, these analyses of the politics of agro-food system localization recognize the local as a socio-political construction, then, with particular effects and consequences (c.f. Hinrichs 2003).

Organic farming movements are one of a number of alternative food movements which often exhibit a tendency towards localism. Indeed, Clare Hinrichs (2003) suggests that "interest in local food—whether academic or applied—has been the stepchild of sustainable agriculture", particularly organic and low-input farming approaches. The roots of localism's popularity amongst organic farming movements are difficult to pinpoint. While no work has yet set out to address this question expressly, it seems likely that the firm establishment of and emphasis on localism amongst organic farming movements may originate from a number of related sources. These might include a strong motivation amongst organic farmers towards models of self-sufficiency on a variety of scales, which themselves might be tied to post-war discourses around food security. The popularity of localism was likely re-emphasized by the back-to-the-land movement, which hinged both on a rejection of consumerism and a desire to get back in touch with the 'basics', but perhaps most importantly (in this context) to build local communities (Grant 2005).

With these thoughts in mind, this chapter explores how organic farmers in Southeastern Ontario construct, mobilize and draw on concepts of the local in their organic farming practice. I reflect on how the farmers understand the relationship between the 
local and the global as it pertains in agri-food systems, and on how their understandings can support and enhance current theorizations around the intersection of the local and the global. I argue that localizing the agricultural economy emerges as a central goal amongst the organic farmers who participated in this study. Their efforts in this regard are fuelled by a desire to internalize a concern for local (social) interests, values, and needs into the way that food is produced and exchanged, something that they see as missing from the conventional agriculture system. I suggest that this desire becomes reflected in farmers' efforts to build local production-consumption networks, and in their establishment of a range of new economic practices, which broadly serve to rework the process of exchange so as to ensure that it better reflects local concerns and experiences. Further, I contend that this effort to establish a local agricultural economy enables the farmers to see the local as a site of agency in local-global relations, and that this is central to a project of regaining a say in how agri-food systems play out, and in their outcomes and repercussions for both individual farmers and local communities. In all of this, the farmers' efforts to localize agricultural economies also serve to problematize the notion of the local and the global as ontologically distinct and mutually exclusive realms.

\section{Building Local Agricultural Economies}

Amongst the organic farmers in this study, it was common to see organic farming as the only way to survive as a farmer amidst the ongoing financial crises of the Canadian agricultural sector. While only one farmer listed economic concerns as her primary reason for switching over to organic production, many of the farmers clearly suggested that organic farming was a more economically tenable and sustainable system of 
agriculture, particularly for small-scale farmers. In part, the economic benefits of organic farming are tied to the organic farmers' decreased input costs once agrichemicals are removed from the farming equation, or to the price premiums organic farmers receive for their goods. However, the increased economic sustainability of organic farming is also seen by farmers to be tied to the engagement of organic farming systems with local agricultural economies. These are seen not only as central to resolving the financial crises of farming on a personal scale, i.e., by increasing farmer's incomes, but also as central to the sustenance of local communities and cultures:

"In my eyes the only way to survive as a farmer is to go organic. Because you don't have these input costs. Farming conventionally, you'd find after a couple of years your harvest goes down and down and you have more and more inputs until you barely get something back. So a lot of farmers are forced into organics because of the economics. But some they just understand that it's more sustainable, and you are more independent. And I believe that the key for the future and for a healthy local economy, is in independent farms. Because farmers, they are very important for local communities. I see what we do: I need parts for the tractor, I go to the local tractor supplier, I buy different things here and use different services around this area. Until now I've spent more money here than I've made here."

(Farmer, meat producer; male)

"Being organic-it can help small farmers survive, like family farmers. And that's so important for a lot of different reasons. For cultural reasons, for social reasons, for the towns and the local economies. People say it's not sustainable right now to be a family farmer. Well, one of the reasons we are not sustainable is because we've been incorporating all of these ideas and technologies into our farms and we've developed lifestyles that don't work with what agriculture really should be."

(Farmer, dairy farm; female)

The organic farmers' mobilization of a discourse of localizing the agricultural economy, then, emerges as a critique of the conventional agricultural system and its heavy (and increasing) reliance on a global economy which the farmers experience as placeless or ungrounded - an economy which, as one farmer put it, "does not seem to be 
based on anything, anywhere" (Farmer, diversified market garden; male). Certainly, in its prioritization of global markets and its deferral to "the global price" (Farmer, orchard; female), this economy is seen not to have given much accord to the true costs of food production as experienced by the farmer. Nor has it given much accord to local interests and values, or to the local consequences of global exchange. Rather, it has decimated local farming livelihoods, communities, and cultures. Against this, the farmers are engaged in a struggle to build an economy which will actively support and sustain farmers, and through farmers, local communities.

\section{Localizing Production-Consumption Networks}

For the farmers in this study, the central strategy for revitalizing local economies lies not — as the Canadian government would have it—in an increased engagement with global markets. Just the opposite: it lies in the prioritization of local markets, through the development of local production-consumption networks. To this end, the majority of the farmers in this study strive to sell a significant portion of their product into local markets through a range of practices, which I describe in some detail below. In addition, as one of the farmers in the opening to this section points out, many of the farmers also strive to be local consumers themselves: turning to local businesses to buy their farm inputs and services and for their families' personal consumption needs. Together, this localization of production (on the part of the farmer) and consumption (on the parts of both the farmer and the consumer) serves to contain as much as possible the circulation of financial capital within local communities. It acts as a rural development strategy, ensuring that any dollar generated instils the maximum possible value to the community before its 
'escape' into the global economy. However, it also ensures that the 'development' that is brought about through their farming activities is geared to local priorities and interests, and not merely to the logic of global capitalism. In short, it is seen by farmers to protect the local interest.

This being said, it is important to note that in their efforts to localize productionconsumption networks, the organic farmers who participated in this study have in mind a transformation of the food system that stretches beyond the local scale. Like many proponents of localism, the farmers' motivations to develop these networks are based in their belief that the localization of production and consumption will also protect the interests of other farmers in other locales. In this respect, the organic farmers are motivated by a desire that is similar to that expressed in models of 'food sovereignty', which draw on human rights discourses to assert the rights of populations everywhere to grow and eat the kinds of food that they desire, and to be able to provide for their own development needs while doing so ${ }^{41}$. Indeed, three of the farmers are very actively

\footnotetext{
${ }^{41}$ Here, I use the term "food sovereignty" to specify a model of food provisioning that I feel more accurately reflects organic farmers' aspirations in this regard. In their 'Statement on People's Food Sovereignty, the People's Food Sovereignty Network' (a loose international coalition of farmer organizations and NGOs working on food and agriculture issues) define food sovereignty as "the right of peoples to define their own food and agriculture; to protect and regulate domestic agricultural production and trade in order to achieve sustainable development objectives; to determine the extent to which they want to be self reliant; to restrict the dumping of products in their markets; and, to provide local fisheriesbased communities the priority in managing the use of and the rights to aquatic resources"

(http://www.peoplesfoodsovereignty.org/index.php?option=com_content\&task=view\&id=32\&Itemid=26). Placing priority on production for domestic and local markets is thus only one dimension of food sovereignty, albeit an important one. As I will suggest of the organic farming movement more generally at the end of this chapter, "food sovereignty" is less centered on an exclusive notion of locality than is "food nationalism", being motivated more by a desire for the mutual preservation of farming ways of life around the globe, rather than by a simple desire of protecting only farmers' resident locale against the global. Further, as the People's Network points out, "[f]lood sovereignty does not negate trade, but rather, it promotes the formulation of trade policies and practices that serve the rights of peoples to safe, healthy and ecologically sustainable production." Thus conceptualized, the intersection of the organic farming movement (and likely a range of other alternative food movements) with notions of food sovereignty is a rich area for future analyses.
} 
involved with national and international organizations that fight for the rights of farmers and/or for the establishment of local food movements everywhere, such as the National Farmers' Union, Via Campesina, Oxfam International and the International Slow Food movement.

Within their efforts to build local production-consumption networks, organic farmers in South-eastern Ontario engage in a variety of economic practices that depend to varying degrees on traditional market mechanisms and on alternative economic structures, but which together share a common goal of incorporating local context into the exchange process. To this end, the farmers participate in direct marketing initiatives in which they can play a central role in setting the price for their products to ensure that it reflects the true cost of producing that food as the farmer experienced it. The farmers have also, however, established a range of new types of economic institutions which seek to address shortcomings or problems associated with more traditional exchange relationships. Below, I detail both the direct marketing relationships and the new types of economic relationships that the participants in this study are involved in, and the benefits that each of these offer.

\section{Direct Marketing: Setting a 'Sustainable Price'}

Central to the localized production-consumption networks that organic farmers in South-eastern Ontario are building is an emphasis on more direct marketing connections between the farmer and the consumer. For a number of the farmers, direct marketing is the key feature of the organic farming economy. They are seen, as one farmer notes in the quote below, to hold great promise for transforming the agri-food system: 
"I'm very supportive of all direct marketing initiatives. I just feel that they hold some way forward. That's the way to transform the food system-it's the only way to make sure the real cost of food production is internalized."

(Farmer, diversified market garden; male)

To this end, the farmers in this study regularly participate in farmers' markets in communities near their farms, and many sell their products through farm gate sales, whether through a formal booth or a store on their farms, or by word of mouth. A few of the farmers are currently involved in (or have been at one point) regular supply relationships with local restaurants, or sell their products to local butcher shops or health food stores. Such direct marketing initiatives reduce or eliminate the intermediaries in the food chain between the farmers and consumers, thus shortening the food supply chain. These initiatives offer the farmer two main economic advantages. The first is that the farmer can actively participate in setting the price for their product, a situation that differs markedly from that of conventional farmers who, as one farmer put it, "having produced according to the [global] system, have little choice but to take what that system offers" (Farmer, mixed farm; female). Organic goods often receive a price premium, ostensibly to support the increased labour costs associated with their production; however, direct marketing allows the organic farmers to ensure that this premium reflects their particular experience of production. As one farmer explained:

"I price things according to the labour, to how much it hurts my back. Beans are expensive...If it's started in the greenhouse, and then it's transplanted, and then you have to weed it, and mulch it, and sometimes do some mechanical pest control-you know, I look at the trail of that food, the journey that it has taken, from seed right through to consumer, and I decide how much I'll charge, what it's cost me on labour."

(Farmer, mixed farm; female) 
When the farmers get to set the price, they can also factor in the ecological services that organic farming offers. Included here is the healthfulness and quality of the food that results from a farm that is maintained in a well-balanced form, ecologically speaking. For, as one farmer noted, it is not merely carrots she is selling, but carrots that were produced on her farm in a particular way, the organic way, which respects and nurtures nature, and which have especially healthful qualities because of this. For the farmers, being better able to 'internalize' these costs is a significant benefit-it allows the farmers to set what another participant called a "sustainable price" (Farmer, diversified market gardener; female), one that sustains both the ecological aspects of organic production as well as the social relations of small-scale farming.

The second economic benefit of localizing (and concurrently shortening) the chain between the producer and the consumer is that it usually increases the share of the food dollar that the farmer receives. This increase can be significant given that the valuation of food in the open marketplace is slanted to favour the post-farm parts of food networks, notably distributors and retailers (c.f. Marsden 1997). In this sense, direct marketing can go some distance to improving and stabilizing farmers' incomes directly. For example, one farmer noted that he had significant increases in his financial returns at each step when he moved from selling his cattle to auction houses, to selling to a local butcher, to his current practice of selling the cut meat directly to customers through word of mouth.

Direct selling via markets or farm-gate sales is a time consuming process and a heavy draw on labour: the farmer may have to go to several markets every week to sell all of their product, which takes them away from the work they need to do on the farm. 
Many farmers simply cannot afford to hire additional labourers to fill the labour gap this approach creates. In addition, there are a number of shortcomings to the traditional economic relationship on which even direct selling continues to rely to some degree. In an effort to overcome these challenges, the organic farmers in this study also participated in a range of economic practices that served to refigure the structure of the exchange relationships more deeply. These practices have led to the emergence of a number of new economic institutions which serve to aid in the broader goal of building local agricultural economies.

\section{The New Economic Institutions of Organic Farming}

In some cases, the organic farmers' efforts to build a local agricultural economy have also led to the emergence of new types of economic institutions in the region. Typically, these have been developed to address some of the challenges that local farmers encounter when they rely exclusively on more traditional variations of the exchange relationship. These include shortages of labour, time, and capital. The new economic institutions can also mediate the financial risks inherent in farming's basis in natural systems, and hence the farmers' financial vulnerability in the face of poor yields, poor weather, pest or disease outbreaks or other problems.

As an example, one of the organic farmers in this study has joined together with other farmers in his region to form the Quinte Organic Farmers Cooperative, a marketing cooperative that has also served as a local bartering economy amongst its members. This initiative has resulted in significant savings of time, labour and capital for its members, 
and better coordinated them so that they could both avoid glutting local markets with the same product and gain access to new markets, as he describes below:

"Eleven of us here, we decided to market together. Our problem is that we spend a lot of time marketing our products. So if we work together we can supply more markets. Like, if I go to the market I'm supplying only one market, but in a co-op I can send my products with the other farmers, so that I have, in the same amount of time and work, 5 to 6 times the amount of products going to market...As a farmers coop we can also supply larger quantities, as a single farm I can produce only certain amounts and if you want to go into retailers you have to have a steady supply and be able to supply more, so this is a way of working together and coordinating. And especially we can concentrate on what we can produce best, because here it makes no sense for me to produce potatoes because my soil is not good for that, so other farmers can do that and I can concentrate on my lambs. It's already working pretty well, despite the fact that last year we were only in the Belleville and Kingston markets, and we didn't have enough stuff and it wasn't coordinated at all. Along with this, the exchanging of things and experience and helping together within the coop, it really helps things for the farmers a lot. You see, I'm short on hay and I've just changed whatever straw I had for hay with another farmer, and otherwise I would have to buy it...Now there is a small network of different things, being bartered. It helps us to not have to spend money on these things."

(Farmer, meat producer; male)

This initiative is seen as so successful by farmers in the region that a similar initiative is being planned in Kingston.

In a similar way, two other types of initiatives undertaken by organic farmers who participated in this study also serve to make working capital more available to farmers. A number of the farms and gardens are running community-supported agriculture (CSA) programs, in which consumers buy shares in part or all of the farm's annual production at the beginning of the season. This gives the farmers funds for inputs such as seed purchases and to live on in the period before they have appreciable funds coming in from product sales. Similarly, a second farm is formulating a plan to become a cooperative with both on- and off-farm members, where each member may contribute varying 
amounts of labour and capital in exchange for shares of the food and any profit that is made. These arrangements also play a key role in mediating the financial risk inherent in farming because of its dependence on natural factors. They act to spread the costs of a production failure in a particular crop or season between producers and consumers, minimizing the risk of a serious financial crisis for the farmer.

Of course, as these new economic initiatives develop, they may offer still other benefits to farmers: for example, the organizers of the Kingston marketing cooperative have noted that they may coordinate rotating work bees to help members undertake bigger projects on their farms that require significant amounts of labour. As such, these new initiatives often contribute to the development of new types of social relationships between farmers. However, they also serve to install new types of relationships between farmers and consumers, that is, social relationships with new qualities.

\section{Challenges to Local Production-Consumption Networks}

The organic farmers who participated in this study face a number of challenges in their effort to build local economies through the development of local productionconsumption networks. First, the farmers are constrained from selling through some local channels by the recent changes in municipal, provincial and national regulation around food safety and quality. This constrains their ability to sell at farmers' markets, where a number of the farmers have felt targeted by inspectors over their sale of ungraded eggs and their handling procedures for organic meats. Significantly, a number of local agro-food businesses such as butchers also face an uncertain future because of this increasingly stringent regulation, and these small businesses may disappear causing 
further shrinking of the local markets on which organic farmers depend. Related to this point, the farmers are also constrained by the regulation that has sought to open farmers' markets to large-scale distributors of non-local food, subjecting local farmers to intense competition and price undercutting, essentially squeezing them out of this venue. These changes affect the local organic farmers just as they would any other small farmer who wished to sell locally.

A second constraint to the farmers' efforts to develop local productionconsumption networks has been poor demand amongst local consumers in some regions. Consumer demand for local food in the region seems still to be localized to cities. Most farmers in the study are located close to mid-size cities such as Perth or Kingston, or to Ottawa, such that these cities can serve as the consumption points of their local networks. But the farmers in more rural regions such as Quinte or Prince Edward County are having a harder time finding sufficient local markets for their products. This is ironic because Prince Edward County is perhaps the region best known in the study area for its efforts to develop a distinct regional food culture. However, one of the farmers from this area noted that this food culture so far seems to be more attractive to cottagers and weekend visitors to the region, while the permanent residents continued to purchase foods from outside the region from the local supermarket.

A third constraint to the development of local production-consumption networks is the lack of local processing facilities, particularly those prepared to deal with the diverse nature of organic farming products. For example, a number of the farmers who produce organic meat noted a lack of local processing facilities in their local area that could knowledgeably handle more unusual types of livestock such as geese, or rabbits. 
As one of these farmers describes, these facilities also often lack the skill to prepare

organic products in a way that is in keeping with their high quality as products:

“There are factors I can't influence, like in processing. I can't influence how the local processor cuts up the meat, I have no influence because if I were to cut up the meat it's on farm processing and I would have to get into the CFIA issues. I have to rely on local processing places and they don't always do a good job. They don't cut the fat out of the meat, and everything there is fast paced, they have to make a living, so what they do is they just cut meat however it comes...If I demand better cutting I don't get it because they don't have the knowledge and they don't have the facility to do it. So these things play a role in quality."

(Farmer, meat producer; male)

This lack of infrastructure often forces organic farmers to ship their products out of the local area for processing, increasing their costs.

There are also challenges to farmers' efforts to set 'sustainable prices'-i.e., prices that internalize the true costs of food production—for their products, such as through direct marketing. Even as direct marketing replaces the open market with one geared specifically towards supporting local farming livelihoods and communities, most of the organic farmers in this study feel constrained in what they can charge for their products, feeling that consumers will only pay a certain percentage more for organic products relative to conventionally produced goods. Therefore, organic goods produced in the region continue to be priced by the farmers in relation to their conventional counterparts. The farmers suggested that their products thus remained in some senses underpriced—not relative to conventional goods, since almost all of the farmers were generally satisfied with the price premiums they received—but rather because all food in Canada is underpriced relative to its true cost of production and distribution. In this case, "the problem", as one farm couple pointed out, "is really cheap food" (Farmer, beef producer; male). The farmers noted that there was significant resistance amongst 
consumers to increases in prices in the farmers' products, despite the fact that these merely reflected the farmers' increasing production costs, as another farmer notes below:

"I think we get a fair price for our product, but what we have to spend, that makes a big difference... The price for food stays pretty stable, but gas prices go up, the property taxes go up, services go up, but if I go up 50 cents on the price of my meat, then there is a big upset because food has to stay cheap. And that comes because government says food is one of the basic important things in life and it has to be affordable for everybody. But having it affordable doesn't mean that the people producing it shouldn't make a living."

(Farmer, beef producer; male)

This is not to say that local production-consumption networks do not hold important financial benefits for farmers. Indeed, all of the organic farmers who moved into organic farming from conventional production felt that they were doing better financially since the transition, and all of the farmers also felt that they were doing better than their conventional neighbours. It is merely to point out that there are larger political economic constraints that are not resolved by direct marketing relationships, and which hence continue to affect the organic farmers in this study in similar ways as they do any small farmer in the region. These constraints make the goal of building local economies a very challenging task.

\section{Social Dimensions of Building the Local Economy}

In addition to the economic benefits that local agricultural economies provide for the farmers, these economies also create important opportunities both to socialize and politicize exchange relationships. They allow for a type of interaction between producers and consumers that is more direct and personal than that which farmers find in the economic relationships of the global market. This interaction provides space for 
discussion and consideration of concepts such as respect and justice, which are important to many organic farmers as well as to many consumers of organic products. This interaction also serves as an important site to mobilize consumers to think reflectively about the predominating (conventional) food system and, as discussed below, to socialize and politicize the exchange process.

The participation of the organic farmers in local production-consumption networks - whether they depend on traditional market mechanisms, or on some of the new economic forms highlighted above-serves to develop new types of social relations between producers and consumers. Many of the farmers who participated in this study characterize the exchange relationships that they participate in within these networks as based on principles of mutual respect. This is especially true for those who can develop ongoing relationships with regular customers. For organic farmers, these are personal relationships, rather than the "faceless" relationships of the global marketplace. One farmer spoke of his relationship with the owner of a local restaurant who buys his organic meat on a regular basis as follows:

"I have one restaurant [that I sell to], and he is really into local, he only buys from outside sources if it's not available [locally]. And for him it's something about relationships too. I don't always get what I want from him, but I know he's reliable and he's honest. Like if he can't pay what I want for it, he says to me "Listen, I can't make a living." And we work something out."

(Farmer, meat producer; male)

In these situations, the interaction becomes something more than a simple exchange of money for food products. Rather, exchange becomes an important site for social interaction and discussion between farmers and consumers. For the farmers, this discussion is important because it serves to maintain a balance between their needs as 
farmers and those of their consumers, addressing the fact that in the conventional system it is usually the farmers' needs that are compromised. As one farmer noted, localizing exchange relations seeks to institutionalize something like the international trade movement at the local level:

"This is like fair trade, bringing the principles of the international fair trade movement to your own farm. It's true that we have to market our products to the consumer, but it has to be sustainable for the farmer too."

(Farmer, market garden; female)

In this sense, these local exchange relationships have an important social justice dimension.

In addition, a number of the farmers saw local production-consumption networks as offering unique opportunities for receiving valuable feedback from consumers about their needs, likes and dislikes, and on the taste, quality and affordability of the products the farmers produce. This information helps the producer adapt what they grow according to local demand. Interestingly, this interactive relationship feeds both ways, since some of the farmers went to great lengths to encourage consumers to try new varieties or types of products, for example by including recipes for less common vegetables in their CSA deliveries or vegetable boxes, or by cooking up a dish featuring their product to take to the market in order to introduce it to potential consumers as part of their marketing strategy.

For the organic farmers, the more personal nature of these relationships seems also to go some distance to addressing the basic discomfort that many farmers have around the idea and process of marketing and selling their products. Many of the participants in this study related that they felt guilty charging money for something which serves such a very basic need of human society. As one farmer woefully related: "I don't 
go to market. I'm not allowed to go to market, my wife goes. I'm no good at selling things; I'm only good at giving them away." (Farmer, mixed farm; male). For these farmers, relying on local economic relationships-and especially with a regular customer-seems to 'frame' the practice of exchange in a way that better honours the work and skill that goes into farming. In a sense, it goes some distance towards recognizing organic food as a service and not merely a commodity.

The organic farmers who participated in this study also understand these new types of exchange relationships as playing an important educational role, suggesting that local production-consumption networks help consumers to develop a clearer idea of where their food comes from and how it is produced. They assert that direct interaction with the grower is what puts meaning to the term 'organic' in the sense that it is the site where the principles and practices of the organic system are communicated to the consumer. Some of the farmers felt that without this interaction, the term organic becomes meaningless. As one farmer explained:

"Organic doesn't mean shit-all. It doesn't mean anything!! You have to talk to the farmer, get to know them, know what they're doing on their land...That's the only way."

(Farmer, market garden; female)

The personal interaction involved in "knowing the hand that feeds you' ${ }^{42}$ communicates knowledge that two of these farmers felt could not be captured in any kind of certification process or standard. This is an important point given that many advocates of the certification process (including some of the other farmers in this study) see as its primary benefit its role in guaranteeing that food was produced in a particular, 'organic', way. As

\footnotetext{
${ }^{42}$ I have borrowed the concept of knowing the hand that feeds you from a recent calendar put out by a coalition of farmers in Marin County, California, the region often acknowledged as the 'heartland' of the American organic farming movement. See: http://www.marinorganic.com/about.html
} 
one organic farmer suggested, the higher price of organic products is one of the main sites where the 'uneducated' customer first encounters organic practice, such that she referred to her endeavours to set a fair price for her product and to explain what was behind it as "educational pricing". Direct and personal interaction means that a farmer can encourage consumers to think critically about the conventional food system and its effects for both farmers and consumers alike. One farmer describes her 'guerrilla' tactics in educating consumers:

"One day, two women were walking by the stall, and I heard that they were griping about the cost of my produce...Now, as a seller you could let that opportunity get away on you, but I wasn't about to. I...hopped right in front of them and started to explain all that went into this food, and all the costs that get externalized in the food at the other stalls...I mean, I think I took them by surprise, but they listened. I think of this as a kind of guerrilla warfare, it's like taking a sort of sniper shot at the system."

(Farmer, diversified market garden; female)

For farmers such as this one, local exchange relationships contribute directly to farmers' broader efforts both to develop the local organic sector, and to problematize the conventional farming system. All too often, as the farmers point out, the true costs of the conventional and global agricultural system are invisible to consumers. This is a frustrating experience for the farmers, for whom the effects of this system are all too evident. Indeed, as discussed in the following section, in their efforts to build a local agricultural economy, the farmers continually struggle with the effects of a globalized agricultural system. 


\section{Local Encounters with the Global Economy}

\section{Local Farmers and the Global Organic Industry}

While organic farmers in South-eastern Ontario prioritize the creation of local agricultural economies, they repeatedly butt up against a globalized agricultural system, which they see as continually undermining local economies and communities.

Interestingly, what emerges in conversations with these farmers is a picture of challenges posed by an emerging international organic agriculture system-the very system in which the Canadian government is so eager to participate in as a competitive opportunity. Under this emerging system, some types of markets such as health food stores or meat markets in South-eastern Ontario have increasingly turned to imported organic goods, often produced in the U.S. or in Mexico, to meet the increasing local demand. Local organic growers, then, are increasingly forced to compete with these imported products and with the relatively low prices that these products sell for. Indeed, local organic farmers also face indirect competition from these products as some of the larger food retailers in the region, such as the major supermarket chains- to which the farmers would not normally sell but which still compete with the farmers for consumers-are also increasingly developing extensive organic sections, stocked almost exclusively with these imported products. In this way, the price of organic products at the local level is set by this emerging global organic industry, and this has negative repercussions for local organic farmers.

For many of the farmers, the emerging global organic sector is a very uncomfortable reality, not least because they question whether the goods produced for the international system should really count as organic. Of central concern here are the 
different standards by which organic production is defined in different countries. Many farmers consider the American National Standard for organic production to be much less stringent than either the certification standard that they subscribe to, or than the way they personally choose to practice organic production. Further, many of the organic farmers also question whether goods that are produced organically but then transported great distances run against the movement's commitment to minimizing ecological degradation, given the air pollution that may be generated in their transport:

"One of the obstacles for the development of organic is from the marketing side. From marketing side is that everyone wants to adapt the conventional food system into organic. Like doing everything globally, importing exporting, adapting whatever is going on in conventional into organic. That means for example, most of the products we can buy as organic, that consumers can buy, they come from outside of the country because they are cheaper there, the distribution system is adapted to the conventional so you don't have to learn anew, you just copy whatever was there. But it doesn't make sense. It doesn't make sense to eat certified organic product which came from $10,000 \mathrm{~km}$ away. So that's very-the understanding of the people as to why local food is important and understanding that externalizing costs happens also to organic, and we have to prevent that. We don't gain anything by [externalizing costs]."

(Farmer, mixed farm; male)

Similarly, another farmer related that he wasn't sure that organic food produced in California or Argentina should really 'count' as organic.

The farmers also problematize the increasing domination of the international organic sector by large, vertically-integrated firms, with questionable commitments to good labour practices and social responsibility, which the farmers understand as central to their personal definition of what is organic. Of course, underlying all of this is the farmers' worry that because of its basis in the same neoliberal ideas that characterize the conventional system (i.e., an emphasis on export-oriented production and international trade, a favouring of capital-intensive agribusinesses, and a seeking to lower labour 
costs), the internationalization of organics will only lead to a direct decline in local organic farmers' incomes, returning them to the very state of economic crises which organic farming was supposed to help them overcome.

For all of these reasons, farmers are deeply frustrated at the increasing frequency with which they directly or indirectly encounter goods produced by this system. For example, one of the farmers who has a good-sized horticultural practice at her farm, and who sells her produce to a number of health food stores in Ottawa, describes below her encounters with 'the American price list' at a number of these stores, much to her dismay:

"There are some stores in Ottawa that I refuse to sell to simply because they insist that I compete with imported agriculture, with imported organics from California. Even though my stuff was picked an hour before it was delivered, and it was delivered by the farmer. You know, they don't understand the politics of food. And I try to convince them that if people are going out of their way to buy organic, to shop at this store, they probably also want to know that it comes from a local farm. But, they're more concerned about the bottom line, so I've had to boycott them. I can't afford to drive to Ottawa [at a cost of] \$30, and they pull out their American price list!...I mean one time they ordered three dozen cobs of corn from me. Three dozen cobs of corn [repeated slowly]. They said they were going to pay me $\$ 8$ a dozen. I said I don't want $\$ 8$ a dozen, pay me $\$ 3$ a dozen and buy 50 dozen, or a hundred dozen! How dare you!! I really am a farmer, I can't afford to drive to Ottawa for 15 bucks."

(Farmer, mixed farm; female)

She argues that local farmers cannot and should not be expected to compete with imported American goods, which are able to take advantage of high domestic subsidies (which apply to organic and conventional farmers alike) and 'watered down' national organic standards, and which may be produced predominantly using underpaid Mexican migrant labour. For this farmer, the types of players and practices that free trade agreements such as NAFTA favour are, again, questionably organic. Like many of the 
other farmers in the study, she worries that the proliferation of international organic products will confuse consumers, who may think that they are supporting a more ecologically and socially just form of agriculture even as they continue to perpetuate many of the same injustices existing in the conventional food system, hence constraining the development of and potentially undermining the local organic sector.

All of this is not to suggest that the farmers involved in this study feel that they are already subsumed to the 'grip' of global competition. Indeed, as did the above farmer, many feel that they can avoid those stores or customers that insisted that organic farmers compete with imported products, especially since there is healthy demand for local organic products at other stores with buying policies that favour local growers. Further, the farmers pointed out that there are venues or mechanisms by which they can sell the majority of their products that remain 'safe' from imported competition and that simultaneously enjoy the favour of customers, such as local producer-focused farmers markets and farm gate sales. However, the farmers' responses were nonetheless permeated with a strong sense of worry that, with the internationalization of organic production it might soon become quite difficult for small organic farmers to survive financially.

Given organic farmers' broad critiques of the internationalization of organic markets, it is not surprising that most of them choose to sell the majority of their products locally. However, despite these critiques, almost all of the organic farmers in this study do sell some of their products into global markets. Indeed, this element of local organic practice has become a conflict-ridden topic for the farmers in this study at both a personal and collective level. The next section of this chapter explores this in more detail. 


\section{Globalizing Local Organic Production}

So far in this chapter, I have argued that organic farmers in South-eastern Ontario are trying to build local agricultural economies, but that they feel that they are increasingly encountering and under pressure from the globalization of the organic sector. For these farmers, selling into global markets is problematized on the basis of its impact on local communities and ecologies. Yet even while establishing local productionconsumption networks emerges as a prominent goal and practice amongst organic farmers in this study, the same farmers are also selling at least some of their products via the global economy. Indeed, amongst the organic farmers who participated in this research, certain types of products—including organic meats, eggs and horticultural crops, as well as seasonal products such as maple syrup and value added products-were sold almost exclusively through direct marketing relationships at the local level, while others-including the milk produced by the organic dairy farms and the cash crops produced by almost all of the farmers in the study—were sold almost exclusively into markets that reach far beyond the local scale. Some sectors of organic production in South-eastern Ontario, it seems, are currently more globalized than others ${ }^{43}$.

The dairy farmers in this study sell their milk to a province-wide organic dairy cooperative (OntarBio), which processes the milk locally but sells its products in stores across the country. Even though farmers appreciated that both the cooperative and

\footnotetext{
${ }^{43}$ The question of why different sectors of organic production are unevenly globalized is a difficult one and a rich area for future research. Working in California, Guthman (1998) has shown that the historical forms of agricultural production in a region have a significant impact on the types of organic systems that develop in those regions. Similarly, Hinrichs (2003) has shown that how "local food" is defined, produced and consumed in Iowa is also shaped by the legacy of conventional commodity agriculture. Future research would thus do well to investigate in more detail the history of grain and oilseed and dairy production in the region relative to the production of other commodities, and how the history of organic production in these sectors have interfaced with infrastructure from the conventional system.
} 
supply-management arrangements acted to stabilize milk producers' incomes, at least one of them admitted that she wished that the region could return to a system of local dairies. She feels that the increased engagement of local organic farmers with markets beyond the local or even provincial levels is sub-optimal at best, and potentially a worrying development:

"I have very mixed feelings about this. I definitely see how we're beingwell, I guess sometimes I think we're like a big flock of sheep that's headed down the wrong chute...I would certainly like to see milk in glass jars, to go back to local dairies again. To me that is what we need-we need to have local dairies."

(Farmer, dairy farm; female)

The organic farmers in this region also sell the vast majority of the cash-crops (typically soybeans, grain, or oilseeds) they produce into the international market, although two were having their flour and hempseed processed to sell directly from their farms. This practice is very common amongst farmers in the study, with almost all of the farmers producing at least one cash crop for international markets. Primarily, the farmers engage in this practice because it has excellent financial returns, and so can subsidize farm incomes. This is largely because demand on the global market for organic cash crops far outstrips supply_indeed, so much so that farmers are often able to play potential buyers off each other to maximize their financial returns.

However, this practice does not go unproblematized amongst farmers. In fact, considering that the farmers are only selling a small portion of their products through this channel, it raised a surprising amount of controversy and self-questioning during the interviews. Like the dairy farmer above, many farmers were interested in extending the 
local production-consumption networks to include cash crops, but were not sure how, and if, this could be achieved.

What emerges in discussions with farmers around these topics is that the organic farmers in this study are uncomfortable with their own participation in the global economy for many of the same reasons that they are uncomfortable with the globalization of organic systems more generally. They worry that such activity will contribute to the global environmental problems associated with pollution. The farmers are also wary that while such global activity now works to sustain the local, too much engagement with it may lead local organic farmers into the same socio-economic catastrophes that descended on the conventional farming system, or will implicate them in the demise of other localities in the global farming community. However, here the farmers are also motivated by a more basic concern, and that is that their participation in the global economy serves to establish a system that might one day soon threaten the food security of local communities given that the global economy seems increasingly to be controlled by transnational, corporate agri-business firms, which increasingly determine not only the prices of food, but the types that are available in the farmers' home communities.

What the above discussion reveals is that organic farmers in South-eastern Ontario are currently faced with a series of difficult and rather paradoxical questions. Primarily, these concern whether and to what degree organic production systems should become globalized, whether it is possible and desirable to re-localize the more globalized portions of these systems, and how relocalization might be achieved. However, implicated in this first set of questions are further questions around where the division between the local and global lies, and whether it lies in the same location for all 
foodstuffs ${ }^{44}$. Further, each of these questions is entangled with concerns around whether and to what degree the organic system should rely on the structures and ideas of the conventional food production system. For while organic farming production systems in the region continue to serve as alternatives to the conventional system, it is evident that the organic farmers have relied on this (conventional) system for their processing, distribution and marketing needs for at least some of their products. Some of the farmers argue that the movement needs to move towards alternative distribution and marketing structures and ideas, and to further develop and protect local production systems. In all of this, farmers note that there are practical barriers to the development of local production-consumption networks (encompassing everything from limits on farmers' capital, labour power and time, to poorly developed local processing infrastructure, to underdeveloped local markets), and that, at present, there are real financial benefits to participating in global organic markets. As one farmer noted:

"Well, I guess there is a conflict in a way in that one of the objectives of the organic movement is to limit the transportation of products and yet I know that a lot if not all of my soybeans end up in Japan, because that is where the market is. And if they're prepared to pay top price for it, who am I to say no, you can't have my soybeans. And the buckwheat too, a lot of it goes to Europe. I don't know where the spelt ends up. I think most of it stays in North America. But if we're growing more here than we can use, who am I to say no, it shouldn't be shipped south. I think that's kind of silly, I mean it would be nice to grow our own local markets, but they're growing too slowly to take all of the product."

(Farmer, mixed farm; male)

Given all of these questions, it is easy to see why questions about 'the local' and 'the global' are a central focus of debate amongst organic farmers in the study region.

\footnotetext{
${ }^{44}$ At least one farmer pointed out that the global marketing of grains, which by their lower moisture content are lighter and thus less environmentally degrading to ship, and which also store better and with less nutrient decay, made more sense to him than the transport of vegetables, "which are basically little bags of water".
} 
Even as the Canadian government is developing a regulatory regime that will encourage the development of a more highly globalized Canadian organic sector, for the small-scale farmers who participated in this study questions around globalization and the future of the organic sector are far from settled. These are questions without easy answers, and many of the farmers are able to see both sides of each part of the debate. Indeed, with no obvious answers to these questions in sight, the movement seems to be exhibiting both localization and globalization tendencies at once, and to what extent a farmer follows either approach is more a matter of personal conviction and financial need than a matter of agreement-however provisional—amongst the farmers in the region.

\section{Globalization and Localization of Organic Farming in South-Eastern Ontario}

The organic farmers in this study make a direct link between the increasing integration of local systems of agricultural production and exchange into the global economy and the increasingly difficult conditions facing local farmers and local communities. As farmers have become increasingly dependent on this global economy for their livelihoods, so have their incomes decreased. Further, the farmers feel that local food security (for farmers and consumers alike) is increasingly out of their reach and control, to the extent that they now worry that we are headed for a food security crisis. Just as many theorists have suggested that globalization processes effect a deterritorialization of the local as an important space and scale of human activity, this is precisely how the farmers understand and experience the global economy in which they have become increasingly entangled: as placeless and ungrounded. 
While viewing the global as an overwhelming and displacing force has fallen out of favour amongst many theorists—-who argue that it must be recognized that all social activities, regardless of their degree of mobility, require some degree of spatial fixedness or of 'embeddness' in the local scale in order to function (Winter 2003b) -it is apparently still an accurate descriptor of how at least some local populations experience globalization. While the global economy may indeed touch down in (and so be constituted through) the farmers' physical locale-embodied in agrochemical and crop dealers, transnational processors and mega-retailers, but also in the farms of their neighbours who remain, as the organic farmers see it, subjects to the productivist system - this does not mean that this economy necessarily takes local farmers' production experiences, values and needs to heart. Indeed, for the farmers in this study, the global agri-food economy seems to proceed by a logic of agribusiness profits and multinational control, not by one which supports the small scale farms, healthy rural environments, and high-quality foods that they see as the hallmarks of the world they desire. Thus, the organic farmers suggest that if an increasingly open engagement with the global economy continues to be supported by their conventional neighboursalthough the recent spate of farmer protests in the province may suggest that this is less and less the case-this is only because a key part of the way globalization proceeds is by producing subjects that think there is no other alternative. As J.K. Gibson-Graham (2003: 49) suggests: "Perhaps a global regime is consolidating itself...through subjects who experience themselves as increasingly subsumed to a global order...Becoming part of the imagined global community involves our subjection to this order, our 
(re)constitution not primarily as national citizens but as economic subjects-productive or less so, competitive or not, winning or losing on the economic terrain."

The organic farmers, then, are struggling to get free of this subject position and the suppositions it makes about the local, in part by creating new economic identities (Gibson-Graham 2002, 2003). Their efforts to ground the organic system in the creation of alternative local economies emerge as a way of regrounding agricultural production and exchange in the vision of the local that they favour, one where small farmers and local communities alike flourish. They are trying to create a system that works towards producing and sustaining this vision as a reality. As such, their efforts are oriented less towards recovering a sense of the local as particular or different from other locales (and as against globalization as a homogenizing process) and more towards ensuring that the experiences and interests of small-scale farmers (both near and far) are reflected in how agricultural development happens.

Thus, the organic farming movement in South-eastern Ontario, like many other food localization efforts (organic and otherwise) elsewhere in the world, problematizes the notion of globalization as an inexorable, virtually unstoppable force that can only be accommodated, rather than resisted. Counter to this message, the organic farmers in this study posit the local as a scale of significance, as the scale of important social activity through which the world is (at least in part) constituted. This is a vision of the local as powerful, as the site of a kind of power that proceeds not by domination (as global power seems to do), but rather through an embodiment in constitutive processes (GibsonGraham 2002, 2003). Here, the enactment of a range of new economic structures and relationships by the organic farmers - the building of a diverse local economy which they 
experience as more reflective of local farming realities and of local farmers' needs-is significant, because it creates new options for economic identity beyond global capitalism (ibid.). These act on some of what Mary Hendrickson and William Heffernan (2002: 360) have identified as weaknesses of the global food system, that is, the difficulty globally networked firms have in responding to dynamic, differentiated markets, in establishing trust amongst consumers, and in resolving the social and environmental problems associated with conventional agriculture-all things that organic farmers excel at. Indeed, as this chapter has shown, the local economy that organic farmers build facilitates the kind of face-to-face contact and social and cultural interaction that Ash Amin and Nigel Thrift (1994: 13) have identified as the drivers of a continued progression towards localization. Together, these act to establish and reinforce the increased sense of local agency that Clare Hinrichs (2003) identifies as common to food localization projects, such that the farmers identify themselves as actors in shaping their futures rather than merely as subjects who are acted upon.

Clearly, the efforts of organic farmers in South-eastern Ontario emerge as a prioritization of an increased engagement with the local economy over the global economy. However, a reading of this as a type of "defensive localism" which would be apt to exclude global others from its sense of responsibility (c.f. Allen 1999) seems problematic. For, what emerges from the organic farmers' efforts to localize productionconsumption networks is a sense that this is the socially responsible and just thing to do on a global scale: that is, that focusing on local markets will also serve to protect (local) farmers both near and far, with whom the participants in this study are variably networked both through a shared identification as small-scale farmers, and through more 
formal structures such as international NGOs. Rather than exonerating the local of its role in producing the global (c.f. Massey 2004), they understand that their actions in the local constitute the global, and so seek to act accordingly and responsibly, which they see as turning towards local markets. Nonetheless, the farmers' mobilization of a discourse of localizing the agricultural economy marks an interesting contrast to the discourses of "feeding the world" which so often dominate in agricultural areas, and which articulate a concern with social justice to production for global markets.

While localist perspectives similar to those of the organic farmers have been critiqued in other fields for their apparent depoliticization of the international exchange process (see, for example, Monbiot 2004), the farmers' efforts to localize the agricultural economy is their attempt to resolve what Patricia Allen (1999) has suggested is a pressing question for food system activists everywhere: how, in our attempts to resolve the crises of the conventional agri-food system, can we avoid merely relocating them elsewhere such that they become somebody else's problem. In this sense, the organic farmers conceptualize their movement as following a model based on minimizing impact by noninterference, and are motivated by sentiments similar to those expressed in common social change slogans such as "think globally, act locally" or "be the change you want to see in the world". Here, the personal is political—a sentiment which Tovey (1997) has also noted is also common amongst farmers in the Irish organic farming movement. Also, as Mustafa Koc (1994) has suggested might usefully become the case for all of us working on and in agri-food systems, globalization has become not a succumbing to an inexorable global process or force, but rather the understanding that we all share the same world. This reframing of globalization carries with it a requirement for the establishment 
of a caring relationship amongst members of the world community, or 'caring at a distance' (Allen et al.: 1999). It is this understanding which the organic farmers who participate in this study self-consciously practice.

Indeed, it is the organic farmers' understanding of local-global interconnectedness (i.e., the local consequences of integration at the global scale) that first led them to develop an engagement with the local economy as a cornerstone of the organic system. In this sense, the organic farmers' understandings undermine the idea of the local and the global as ontologically distinct realms, seeing them instead as mutually constituted. Thus, it can be argued that, the organic farmers exhibit something akin to what economic geographer Doreen Massey (1997) has called "a global sense of the local." Here, the local and the global are understood as relationally constituted, and as each existing in the other such that local processes and structures are themselves deeply embedded within globalizing processes and structures (Massey 1991). Similarly, both Arjun Appadurai (1996) and Erik Swyngedouw (1997) have argued that the local is constituted through practices operating at a range of scales, which Swyngedouw has further noted are intricately interwoven, simultaneous, and nested, an intermingling that he describes as 'glocalization'. This is an accurate descriptor of the organic farming movement in Southeastern Ontario, where the local and the global are highly intertangled.

Like the understandings of organic farmers, such conceptualizations do not neglect the impacts of global processes on the local. Indeed, in the context of the local organic farming movement, this chapter has shown that organic farmers continue to be impacted by global political-economic forces (albeit sometimes to greater or lesser degrees than farmers in the conventional system), even when they choose a minimal 
engagement with the global economy. Rather, a relational sense of the local problematizes the notion that the forms it takes on are determined by the global, positing the relationship or dialectic between the local and the global as complex rather than unidirectional, and any boundary between them as porous, rather than strong (Massey 1997, Swyngedouw 1997). Such a logic understands that local places may continue to exhibit heterogeneity rather than assuming that they will slowly move towards homogeneity.

At the same time, organic farmers do make some distinctions from, and so close themselves off to or draw "strong" boundaries against, some translocal (in the symbolic sense) interests and imaginings of place. But this is to be expected from a movement that has developed as an alternative to and indeed in opposition to elements of a global conventional system. There are two things that are important to note here. The first is that this does not mean that farmers are denying that translocal relations help to constitute the places they call local. Rather, theirs is a struggle to articulate a new vision of the local and so to participate in setting how agriculture development happens, rather than having it set for them. This necessitates ruling out some (capitalist, exploitative, environmentally degrading, etc.) translocal relations while ruling in others. However, the degree to which specific translocal relations are ruled out is very much specific even to the individual farmer-as we have seen, the very issue of to what extent certain "global" structures should be allowed into a "local" is the very much an open and contested question. The second point regarding organic farmers' 'boundary-making' projects, and which is inherent in the first, is that it is crucial to remember the point of these projects, that is, that it's not something inherent in the transcendence of the local (or, conversely, 
the ascendance of the global) that farmers are reacting against. As Patricia Allen (1999; 122) usefully asks "Is globalization, as a concept and practice, the problem or is the problem the specific economic forms embedded in the global economy?" The crucial question here for the organic farmers is what is being globalized and what its effects are for farmers, environments and food. In this sense, it is more a particular type of social relationship - a particular way in which the global integrates and intervenes in the localthat farmers are resisting rather than the global scale itself.

Of course, through all of this, organic farmers still participate in the exchange relationships of the global market, a fact that some might argue seriously detracts from (if not nullifies) the movement's ability to act as a critique of this system. Certainly, this concern has characterized some of the debate over the power of organic agriculture as an alternative movement and the many ways that its 'alternativeness' might become compromised. However, it is surely too much to expect that new systems, or alternatives, will emerge from the ground intact, instantaneously and fully formed. Rather, organic farming is about the struggle to build such a new system: it is an ongoing project or "a bumpy road", as one farmer put it, "that we must go down one step at a time" (Farmer, market garden; male). Further, when organic farmers participate in these markets, most do so self-consciously, and while exercising reflexivity towards the potential consequences of this action, and to how these consequences might interface with different concepts of the organic project.

There is some question as to whether localist movements (and their analysts) have tended to objectify the local (and simultaneously the global), that is, to presume its ontological existence as pre-given or inherent structures, entities or things, rather than as 
"a category to be explicated in terms of societal processes" (DuPuis and Goodman 2005: 368). A more accurate conceptualization, they argue, would be one that recognizes the scales and sites of the local and global as social constructions, as 'interpretive frames' (Gibson-Graham 2003). Interestingly, despite their heavy reliance on the local as a trope, organic farmers do, to some extent, recognize that the local is not a pre-given space. Of central concern here to farmers is where the boundary of the local lies for different communities and for different foodstuffs. Just as an acknowledgement of nature as socially constructed has exposed as political the terms under which such constructions come to exist and be accepted, so the first consequence of recognizing the local as a social construct has been a concern with the role that politics plays in delineating what counts as local.

The idea that the local is socially produced and inscribed with meaning rather than existing pre-made 'out there' serves to de-homogenize and de-essentialize these concepts: that is, it problematizes the assumption that the local is a purified, conflict-free zone (DuPuis and Goodman 2005). Rather, the local is "always provisional, always in the process of being made, always contested" (Massey 1993: 149), and this process is one in which many different people, each with different ideas of what the local is and should be, participate. This offers important insight into the situation amongst the organic farmers in this study, who despite their status as a community of interest with some degree of coherence on a number of topics, are struggling with questions around the degree to which their more locally-focused system should look like the global system it arose in reaction to, and around where the local 'stops' and whether it stops at the same 
location for different communities and different food products ${ }^{45}$. For the farmers in this study, these are both pressing and contentious questions, especially as they are increasingly encountering and entering into global circuits. These questions are, for the most part, not addressed by organic certification standards. Nor are they considered in the developing regulatory regime around organics, which is more interested in facilitating a global trade in organic products. At present, the farmers are thus very much in the thick of struggles around the politics of agri-food system localization and the complex relationship between the concepts of organic, the local and the global.

\footnotetext{
${ }^{45}$ Clare Hinrichs' (2003) study of food localization efforts in Iowa shows that this lack of fixity or clear boundedness of the local can sometimes be problematic. She documents how the boundary of the local has been discursively stretched in the course of food localization efforts to correspond with that of Iowa as a state, but asks whether we can really consider such a large area (56,000 square miles) 'local'.
} 


\section{Chapter 6: Conclusion}

The productivist system of agriculture that was established in Canada following the Second World War institutionalized both the mass production of inexpensive food and a strong system of farm and agricultural commodity support programs. While crises of overproduction in this system occurred early on, subsidy programs provided farmers a measure of protection from their socio-economic effects until the mid 1970s. However, over the past 30 years, the Canadian agricultural sector has been dramatically restructured as the federal and provincial governments increasingly shift national agricultural policies to reflect neoliberal models of economic development which prioritize export-oriented production and the removal of barriers to trade. Agricultural subsidies have been rapidly rescinded, leading to a deepening farm income crisis associated with overproduction and low overall commodity prices. This restructuring has also yielded a situation of oligopolistic control where a small number of transnational agribusiness corporations control both the production and supply of agricultural inputs and the processing and distribution of agricultural outputs, further squeezing small-scale farmers. At the same time, the environmental consequences of the productivist system are rapidly becoming clear, with the emergence of both on- and off-farm pollution and a decline in farm production capacities, even as health concerns associated with the use of agrichemicals and a spate of recent food scares have also drawn the production methods of the conventional agricultural system into question. These socio-economic, environmental, and food crises have been experienced most directly by small-scale farmers, who have been faced with the loss of their incomes and, increasingly, their farms, the collapse of 
local farm economies and communities, and deteriorating farm environments. As a result, some of these farmers have joined with other members of the public to establish a number of different types of "alternative food movements", which seek to establish new ways of provisioning food that are more economically viable, ecologically sustainable, and socially just.

Organic farming, which is increasingly framed by agri-food scholars as one of this group of alternative food movements, originally emerged in Canada in the 1950s in response to the declines in soil fertility and food quality associated with the industrialization of agriculture in the productivist system. The organic farming movement has grown steadily over the past five decades, encouraged first by the back-tothe-land movement and later by a growing public concern with environmental and foodrelated health issues, but it has been developing especially rapidly for the last decade. Agri-food scholars have characterized such burgeoning organic farming movements not only as a critique of both the environmental consequences of productivist agriculture, but also as a response to the socio-economic difficulties experienced by small-scale farmers amidst the globalization, industrialization and corporatization of the agrifood system. At the same time, the significant domestic and international markets that have developed for organic products have increasingly drawn the attention of the Canadian government which has sought to insert itself into what has hitherto been a grassroots, independent, and self-regulated movement. Primarily, this has occurred through the ongoing development of a national standard for organic production, and an associated regulatory regime, both of which may come into effect in late 2006. These impending regulatory changes, the significant diversity observed by recent empirical studies of organic farming 
movements, and the significant symbolic content of these movements make enquiries into local organic farming movements timely and important.

This thesis has focused in particular on the local organic farming movement in South-eastern Ontario, drawing primarily on interviews conducted with 23 organic farmers in the region. In it, I have used a theoretical framework which draws on political ecology and on literature around social nature and the social construction of place to investigate how organic farmers in this region mobilize two key discourses: that of naturalizing agricultural production and that of localizing agricultural economies. These discourses describe two of the primary goals of the organic farmers who participated in this research, and they underlie both the farmers' personal farming practices as well as their understandings of the local organic farming movement as a whole.

In this thesis, I have suggested that the efforts of the organic farmers to mobilize a discourse of naturalizing the agricultural production process emerges out of a critique of the conventional industrialized agriculture system, based on the environmental degradation it has generated and its efforts to minimize the role of nature in agricultural production. Against this, the organic farmers draw on particular conceptions of sustainability and agrarian stewardship to instead posit their practice as geared towards minimizing ecological degradation and maximizing the agency of nature in agricultural production. These farmers understand their farms as dynamic, complex, and interconnected natural systems, and so also contest the positivist discourses around nature inherent to the conventional farming system. They direct their farming practices towards mobilizing these interconnections, thereby enabling nature to play out in its fullest on their farms and so producing the best quality food. This requires a process-focused or 
whole-systems approach which hinges on a reworked notion of the concept of agricultural production, whereby it is seen less as a process of making a particular product, and more as nurturing the conditions by which that product comes to exist. For organic farmers, each potential practice and activity is evaluated based on the agroecological benefits they provide to the farming system as a whole. Beginning to farm organically hence requires that the farmers learn a host of complex farming practices. This, in conjunction with the priority organic farming gives to the farmers' highly localized knowledge and to the grounded experience that they build up on their farms enables the farmers to see themselves as knowledgeable and as skilled. This is central to a broader project whereby the farmers regain an increased sense of agency and control over their farms and the processes and outcomes of agricultural development.

Similarly to studies of organic agriculture in other locales, this thesis suggests that the discourses and practices of organic farmers in South-eastern Ontario work to problematize the boundary between what is considered natural and what is considered social. The farmers conceptualize their farms as sites where nature is present and active despite these also being spaces of production. Thus, the farmers posit a new socioecological imaginary that sees nature and society as overlapping, as mutually sustaining, and as relationally constituted. This results in the formulation of a new identity and sense of responsibility regarding how to live in nature, one that moves beyond the problematic conceptions of nature presented by conventional industrial and environmental discourses.

In addition to their concerns about the environmental degradation associated with the conventional agricultural system, the participants of this study also feel that the 
privileging of and dependence of this system on global markets has led to the demise of local farm livelihoods, economies, and communities. Against this, the farmers articulate a discourse of localizing the agricultural economy, by which they seek to internalize a concern for local priorities and values into the way that food is produced and exchanged. The local agricultural economy that the farmers seek to build is grounded in local production-consumption networks, which rely on a range of new economic institutions. Most of the farmers prioritize selling into local markets via direct marketing mechanisms, which allow them to internalize the true cost of producing food as they experience it on their farm. The farmers also participate in a range of less traditional economic relationships which allow them to mediate both the shortages of labour, time and capital that can be associated with production for traditional economic relationships as well as the production-associated risks inherent to farming. The farmers' participation in these diverse local agricultural economies also have an important social dimension, in that they encourage the development of exchange relationships based on principles of mutual respect and social justice, and also provide significant educational opportunities for farmers and consumers alike.

At the same time as they prioritize selling their products to local markets, most of the organic farmers in this study do sell some of their products into the developing global economy for organic products, a practice that is highly contested amongst them. Nevertheless, I contend that the farmers' prioritization of local exchange relations serves an important function, in that it encourages farmers to formulate new economic identities and to posit the local as a site of agency as against the disempowering discourses of globalization. Like farmers' efforts to naturalize the agricultural production process, 
localization efforts are central to a project whereby farmers regain a say in how agricultural development plays out and in the outcomes of this development for both individual farmers and local communities. Further, the efforts of the participants in this study to localize the agricultural economy should not be mistaken for a case of the 'defensive localism' that some agri-food scholars have recently suggested might be operating in food localization projects. Rather, organic farmers prioritize local markets out of a concern for social responsibility and justice that stretches beyond the boundaries of the local to include farmers and consumers in other locales around the globe. In this way, the organic farming movement in South-eastern Ontario problematizes any easy distinction between the local and the global, illustrating instead that these are connected, interdependent, and relationally constituted realms.

This thesis contributes important nuance and detail to our understandings of how organic farming movements construct, draw on, and mobilize concepts of the natural and the local, concepts which a number of theorists have suggested are central to alternative food movements, but which remain somewhat vaguely theorized within this context. However, it can also contribute to broader discussions in human geography on two counts: first, by contributing to discussions around social movements and the connections and/or boundaries between the realms of the natural and the social, the local and the global, and second, by informing future approaches to political ecology. I describe these contributions in the next two sections of this chapter, before returning at the end of this chapter to a consideration of the impending institutional and regulatory changes in the Canadian organic sector in light of the main findings of this thesis. 


\section{Towards a Differential Geography of Organic Farming in South-eastern Ontario}

In this thesis, I have argued that the efforts of the organic farmers who participated in this study to naturalize the agricultural production process and to localize agricultural economies are part of a larger project by which they seek to regain a sense of agency within and control over how agriculture and agricultural development happens and its outcomes and repercussions for farmers, farm communities, and farming environments. In a recent article exploring the global indigenous movement, a social movement which is significantly different from the organic farming movement yet which shares with it certain characteristics in that both movements are at once territorially grounded and translocally connected, Noel Castree (2004: 136) suggested that many indigenous communities are engaged in a struggle for what he calls "differential geographies: that is, the right to make their own places, rather than have them made for them." I find Castree's terminology powerful, and so I want to borrow it while concurrently stretching its ambit in order to suggest that organic farmers in South-eastern Ontario are engaged in a similar struggle: they, too, are struggling to set differential geographies, though not merely to participate in making their own places, but, more broadly, in setting their own futures. As I have shown in this thesis, the farmers undertake this in such a way as to render problematic the idea that nature and society, and, concurrently, the local and the global are ontologically distinct and mutually independent realms. Rather, organic farmers forward views which problematize the boundary between the natural and the social, the local and the global, recognizing these rather as mutually dependent, relationally constituted, and entangled concepts and realms. 
As such, the approaches of the organic farmers and the analysis of them that I have presented herein both contribute to a broader effort amongst social scientists to problematize boundaries, and, particularly, the binaries that often underpin them. This binarized view often serves, as Doreen Massey (1999: 280) has put it, to "channel thinking down particular, and not particularly helpful, pathways." However, what becomes clear in the previous chapters is that at the same time that organic farmers problematize the boundaries between the natural and the social, they also participate in acts of boundary making, most notably, in setting organic farming off as distinct from conventional farming. Of course, a closer examination of the findings of this thesis shows that even this boundary is troublesome, or rather, as David Goodman (2000: 215) has suggested, it is 'porous', 'poorly demarcated', 'contested' and 'in flux'. For example, as I have shown, organic farmers continue to rely to some extent on the distribution and retailing systems of conventional agriculture and on the globalized capitalist markets which underpin the conventional system. However, the systems overlap in more insidious ways, too, for example in that many organic farmers set the prices of their products relative to the price of similar, conventionally produced goods. Indeed, the distinction between the organic farmers and many of their neighbours producing in the conventional system is also blurred by their shared identity as small-scale farmers, who are each struggling — albeit sometimes to different degrees-with the recent regulatory changes in the national agricultural sector, with the production risks inherent in any type of farming, with the effects of the loss of government subsidies, with problem of cheap food, and indeed with any number of other challenges which affect all small farmers today. By all of this, I do not mean to suggest that the local organic farming movement 
does not maintain important distinctions from the conventional farming movement vis-àvis their practices and structures, but only that organic farmers might simultaneously share commonalities with conventional farmers and bound themselves off from them.

This research suggests, then, that both acts of boundary elision and acts of boundary marking can be central to the attempts of social movements to delineate their own geographies and futures. Indeed amongst the organic farmers in this study, the disturbance of the boundaries between the natural and the social, and, correspondingly, the local and the global is made to interface and entangle with the installation of a boundary between organic practice and conventional farming ${ }^{46}$. Thus, my research suggests that acts of boundary elision and boundary marking can be related and implicated in each other in complex ways. It suggests a need for more nuanced approaches to studies of social movements which consider how and where boundaries are created and disturbed by these movements, and for what purposes.

\section{Organic Farming in South-eastern Ontario and the Political Ecology Approach}

This research can also make broader contributions to human geography research by informing future political ecology approaches. My work, like that of McCarthy (2002) and Walker (2003), suggests that political ecology is a fitting framework for investigating ecological issues and social movements in highly industrialized ('First World') settings. I have shown that organic farming, as it is conceptualized and practiced by farmers in South-eastern Ontario, is fundamentally bound up with a struggle for access to and control over resources, a theme central to many political ecology analyses. By

\footnotetext{
${ }^{46}$ Castree (2004) has shown indigenous movements to be embedded in a similarly mixed and complex experience of both boundary-making and boundary-elision.
} 
way of this struggle, organic farmers articulate solutions towards making agriculture more ecologically sustainable, economically viable for small-scale farmers, and socially just—solutions that differ from those put forth by the Canadian government and the industrialized, globalized model of productivist agriculture that the government promotes. This struggle, articulated in key discourses around naturalizing agricultural production and localizing agricultural economies, has both material and symbolic dimensions, such that organic farming is not only about the control of farms and the material resources of production, but also of livelihoods, identities, cultures, and ways of life. Indeed, although organic farming is understood by the public to be mainly an environmental movement, this study reveals how thoroughly this 'environmental' struggle is intricately entangled with broader social concerns. This research thus simultaneously supports recent conceptualizations of organic farming which understand it as encompassing a concern for socioeconomic issues as well as environmental sustainability, and contributes to recent efforts in political ecology to investigate the liberatory potential of social movements around environmental issues (e.g. Peet and Watts 1996).

In my analysis, and in response to recent critiques of political ecology approaches, I have also sought to integrate an increased concern for both questions of ecology and of politics. In the first case, I have sought to incorporate a concern for nature as an agent in agricultural production, which indeed is central to how organic farmers understand the production process. While questions of ecology in political ecology have not been typically framed in terms of a desire to acknowledge the 'agency' of nature, this has certainly been central to the efforts of agri-food scholars in recent years (see, for 
example, Murdoch and Marsden 1995; Murdoch 1998; Goodman 1999; Whatmore 2002). With regards to politics, I have shown that questions of what counts as nature and as local are central to organic farmers' efforts to operationalize an alternative system of food provisioning. This suggests a need to continue to engage political ecology with poststructuralist theory which demands that even those entities which appear to be selfevident or pre-given be seen as important sites of politics. My work suggests that the bodies of literature on social nature and social construction of place hold particularly rich insights for geographers and other social scientists working under the political ecology rubric; these provide ways for deepening our conception of what it is that is contended in environmental struggles, revealing organic farming to be not just a matter of differing interests between organic farmers and the conventional system, but, more fundamentally, of different conceptions of agriculture, nature, society, the local, and the global, and the interrelations between these processes and realms. At the same time, I have sought to engage with a broader conception of the possible forms of politics, including the everyday production and economic practices that together make up functioning organic farming systems in South-eastern Ontario. My work in these regards suggests that political ecology approaches will be enriched by keeping both questions of ecology and politics central to their analyses.

\section{Whither Organic Farming?}

Even as the organic farmers in this study articulate discourses which prioritize naturalizing the agricultural production process and localizing agricultural economy as two key goals of their practices and movement, the Canadian government, with the 
support of some representatives of the organic sector (including some organic farmers), is attempting to codify a particular definition of organic production in the drafting of a new national standard and regulatory regime. This initiative has advanced rapidly in the 12 months since the interviews for this thesis were completed. At the time of these interviews, some of the participating farmers were unaware of the developing regulatory regime-indeed, many of its details had not, at that point, been worked out. However, with its impending installation likely to come at the end of this year in order to meet the third party equivalent dates set by the EU, it is likely that these farmers are more aware of the development of the regulatory initiative today. Given these impending changes, a key question emerges: are the priorities of the farmers who participated in this research reflected in this institutionalization process?

A thorough review of the process of drafting the standard and designing the regulatory regime is a considerable project, and, while it would be a worthy endeavour for future research, is well beyond the scope of this thesis. Instead, I want to draw attention to a few key issues around the standardization and regulation of organic production. First, it is notoriously difficult to codify the process-focus of organic farming in any kind of standard, but particularly one that is to be applied at the national scale. As I have shown, organic farming relies on a series of complex, interrelated, agroecological practices to maintain and enhance soil fertility, and to manage weeds, diseases, pests, and livestock health. The mix of these practices that is put into effect on any given farm is derived from the farmers' grounded experience in the specific ecologies of that farm. The organic farming approach is therefore inherently non-standard: it is not a single model that could be uniformly applied across the diverse natures of farming 
environments in a single region, never mind across a nation as large and diverse as Canada. The possible effects of trying to codify such a non-standard approach become clear when looking at particular management goals and practices. For example, organic standards can insist that soil fertility be maintained in part through crop rotations-as do each of the EU, US, and current draft Canadian national standards. However, they could not codify the specific types or numbers of crops that should be incorporated into a rotation, since these would vary tremendously across farms. As such, the current Canadian draft merely states that crop rotations "shall be as varied as possible and include plough-down, legume, catch crops and deep rooting plants., ${ }^{, 47}$ This is just one of many possible examples which reveal the possible agroecological effects of the fact that standards necessarily simplify organic production.

Furthermore, and as both Guthman (2004) and Coombes and Campbell (1998) have suggested, the difficulties of codifying the complexities of organic management practices can mean that standardization processes encourage a drift in local organic farming movements from a focus on processes to a focus on allowable inputs to organic farming systems (such as natural fertilizers, minerals, etc., delineated in organic standards by an 'allowable materials list'), which is reminiscent of a conventional approach to agriculture. Guthman (2004) shows that while the institution of the national standard in California and the shift to an input-oriented approach has effectively set a 'floor' for organic production in that state (by ensuring that large agribusinesses do not use inputs beyond those on the allowable materials list), it also sets a ceiling, insofar as growers are

\footnotetext{
${ }^{47}$ This is actually a significant improvement over the EU and US standards, which make no such statements. However, it contrasts with the standards set by some independent certifying bodies, such as OCPP, which the farmers in this study suggested was among the most stringent, suggests a minimum of three crops in a crop rotation, and provides more extensive guidelines as to what rotation plans should include.
} 
not encouraged to strive for anything beyond the minimum acceptable practices. As such, it is possible that the Canadian national standard, once implemented, may effectively blunt the ability of the South-eastern Ontario organic farming movement to fully transform the processes by which food is produced in this region, and the effects of these processes for farming environments.

However, if standards for organic production have at least attempted to incorporate organic farmers' concerns pertaining to naturalizing the production process, they have never incorporated farmers' focus on localizing agricultural economies, or their interest in creating more equitable and socially just exchange relationships therein. Indeed, the latest revision of the Canadian national standard has been undertaken specifically to ensure that organic farmers retain access the burgeoning international market for organic products, and to encourage production for this market, which the federal government sees as a significant competitive opportunity for the national agricultural sector. In part, the lack of incorporation of local and less traditional economic institutions into the national standard in Canada is due to differences in the structure of the organic farming sector in different regions of the country-for example, larger farms focusing primarily or exclusively on grains and oilseeds are more common on the prairies, and local markets for these products, as in Ontario, are more difficult to find. However, as I have shown, production for global markets is a contested issue even amongst organic farmers in the region of this study, where farms are smaller and tend to be mixed operations. While the prioritization of selling to local markets remains highly important to some of the farmers, it seems that those who are interested in codifying or formalizing this emphasis on local economies as part of the organic commitment will 
need to look to new mechanisms of institutionalization. Alternately, they may choose to continue to ally themselves with the range of independent buy and eat local campaigns in the study region, which are not always limited to organic producers, but which still allow the farmers to emphasize their commitment to what they understand as more environmentally sustainable and socially just exchange.

It is difficult to predict whether the failure of the new organic regulatory regime to fully incorporate the environmental and social justice concerns of the farmers who participated in this study may encourage some degree of 'conventionalization' of the organic farming sector in South-eastern Ontario. To date, agribusiness has made limited entries into organic farming in the study region, and was not perceived as an imminent threat to the local organic farming movement by the farmers in this study. Rather, the farmers were more concerned about the entry of 'profit-oriented individuals' into the local sector. Indeed, the assertion that from now on those farmers who take up organic farming will be doing it for the money, rather than out of a concern the agroecological and social values that have traditionally been associated with organic farming, is commonplace. This is a pessimistic assessment and one with which I personally disagree. However, it is worth noting that the draft standard and the new regulatory regime that is being planned seems as though it may only act to encourage this 'profitoriented' effect. On the one hand, the institutionalization of organic farming may prevent opportunistic cheating by conventional producers who wish to benefit from the price premium of organic goods without truly adopting organic production methods. On the other hand, it may 'water down' organic farming practice to a level that attracts farmers less motivated by social and ecological concerns, and more exclusively interested in 
maximizing their income. Thus, assessing the costs and benefits of institutionalization is not an easy task.

Finally, what about those farmers who adamantly disagree with the standardization and regulatory process on the basis of their personal understandings of and values within organic farming? A number of the farmers in this study opposed any institutionalization of their practice, whether by independent certifiers or by a national standard. The common assessment is that, because the new regime will make it illegal for them to call their products organic (if they refuse to be certified), they will have to devise new terminology by which to differentiate their products from those produced by conventional methods and those codified as organic under the Canadian national standard. In the U.S., this has resulted in a new, non-profit certification system for those who do not wish or cannot afford to partake in the national standard in that country, and who so can not call their products organic: 'Certified Naturally Grown' (see CNG 2002).

\section{Directions for Future Research}

If the research in this thesis can be considered a snapshot of the organic farming movement before the installation of the new standard and regulatory regime, future research would do well to look at the 'after' picture, and to investigate whether this has changed the key discourses that organic farmers in South-eastern Ontario draw on and mobilize in their practice of organic farming. Of course, this thesis has also only investigated two of the discourses mobilized by organic farmers in the region, and there are certainly others which could be investigated both now and in the future. For example, in the course of my interviews it became clear that organic farmers are increasingly 
mobilizing discourses around the rural and the relationship between rural and urban areas-an interesting theme given Michael Woods' (2003: 309) suggestion that we are witnessing the emergence of set of social movements whose central motivating force is a defence of the rural. Similarly, discourses of the 'public' and the public good and the relationship of this to private interests also figure very prominently in the local organic movement, even as the rising prevalence of contract farming and the growing of genetically modified organisms challenge traditional notions of private property and control. Clearly, these have significant overlaps with the discourses presented herein, but they are each complex enough to yield their own independent considerations. Finally, given the significant differences that have been observed in empirical studies of organic farming movements in other countries, as well as the diversity of the organic agriculture sector in Canada, future researchers would do well to investigate organic farming as it is understood and practiced in other regions of the province and the country. 


\section{References}

AAFC (Agriculture and Agri-Food Canada). 2001. Centre set to bolster Canada's organic expertise. News Release (July 12, 2001). Available on-line at: http://www.agr.gc.ca/cb/index_e.php?s1=n\&s2=2001\&page=n10712a

Abu-Lughod, Lila. 1993. Writing Women's Worlds: Bedouin Stories. Berkeley: University of California Press.

Allen, Patricia. 1999. Reweaving the food security safety net: Mediating entitlement and entrepreneurship. Agriculture and Human Values 16: 177-129.

Allen, Patricia, Margaret FitzSimmons, Michael Goodman, and Keith Warner. 2003. Shifting plates in the agrifood landscape: The tectonics of alternative food initiatives in California. Journal of Rural Studies 19: 61-75.

Allen, Patricia and Martin Kovach. 2000. The capitalist composition of organic: The potential of markets in fulfilling the promise of organic agriculture. Agriculture and Human Values 17(3): 221-32.

Altieri, Miguel. 2000. Ecological impacts of industrial agriculture and the possibilities for truly sustainable farming. In Fred Magdoff, John Bellamy Foster and Frederick H. Buttel (eds.), Hungry for Profit: The agribusiness threat to farmers, food, and the environment. New York: Monthly Review Press.

Amin, Ash and Nigel Thrift. 1994. Living in the global. In Ash Amin and Nigel Thrift (eds.), Globalization, institutions and regional development in Europe. Oxford: Oxford University Press.

Appadurai, Arjun. 1996. Modernity at large: Cultural dimensions of globalization. Minneapolis, Minn.: University of Minnesota Press.

ATS (Agricultural Trade Service). 2005. Canada's agriculture, food, and beverage industry: Canada's organic industry. Fact Sheet. Available on-line at: http://atssea.agr.gc.ca/supply/3313_e.htm

Balfour, Lady Eve. 1948. The living soil. London: Faber and Faber. Available online from the Soil and Health Library: http://www.soilandhealth.org/

Balfour, Lady Eve. 1977. Towards a sustainable agriculture-the living soil. (Transcript of a talk given at an IFOAM conference in Switzerland, 1977). Available online from the Soil and Health Library: http://www.soilandhealth.org/ 
Banks, Jo and Terry Marsden. 2001. The nature of rural development: The organic potential. Journal of Environmental Policy and Planning 3(2): 103-21.

Barrett, H.R., B.W. Ilbery, A.W. Browne, and T. Binns. 1999. Globalization and the changing networks of food supply: The importation of fresh horticultural produce from Kenya into the UK. Transactions of the Institute of British Geographers NS 24: 159-74.

Barron, Jennifer. 2000. In the name of solidarity: The politics of representation and articulation in support of the Labrador Innu." Capitalism, Nature, Socialism 11(3): 87112.

Bell, David and Gill Valentine. 1997. Consuming geographies: We are where we eat. London: Routledge.

Blaikie, Piers. 1985. The political economy of soil erosion in developing countries. London: Longman Development Series.

Blaikie, Piers and Harold C. Brookfield (ed.). 1987. Land degradation and society. London: Methuen.

Braun, Bruce. 2002. The intemperate rainforest: Nature, culture and power on Canada's west coast. Minneapolis, MN: University of Minnesota Press.

Braun, Bruce and Joel Wainwright. 2001. Nature, poststructuralism, and politics. In Noel Castree, and Bruce Braun (eds.), Social nature: Theory, practice, and politics. Malden, MA: Blackwell.

Bryant, Raymond L. 2001. Political ecology: A critical agenda for change? In: Castree, Noel and Bruce Braun (eds.). Social nature: Theory, practice, and politics. Malden, MA: Blackwell.

Bryant, Raymond L. 1998. Power, knowledge and political ecology in the Third World: A review. Progress in Human Geography 22(1): 79-94.

Bryant, Raymond L. 1992. Political ecology: An emerging research agenda in ThirdWorld studies. Political Geography 11(1): 12-36.

Bryant, Raymond and David Goodman. 2004. Consuming narratives: The political ecology of 'alternative' consumption. Transactions of the Institute of British Geographers NS 29: 344-66.

Buck, Daniel, Christina Getz, and Julie Guthman. 1997. From farm to table: The organic vegetable commodity chain of northern California. Sociologia Ruralis 37(1): 3-20. 
Burton, Rob J.F. 2004. Seeing through the 'good farmer's' eyes: Towards developing an understanding of the social symbolic value of 'productivist' behaviour. Sociologia Ruralis 44(2): 195-215.

Butler, Judith. 1992. Contingent foundations: Feminism and the question of "postmodernism". In Judith Butler and Joan Scott (eds.), Feminists theorize the political. New York: Routledge.

Buttel, Frederick H. 1997. Some observations on agro-food change and the future of agricultural sustainability movements. In David Goodman and Michael Watts (eds.), Globalising food: Agrarian questions and global restructuring. London and New York: Routledge

Buttel, Frederick H. 1996. Theoretical issues in global agrifood restructuring. In David Burch, Roy E. Rickson, and Geoffrey Lawrence (eds.), Globalization and agri-food restructuring: Perspectives from the Australasia region. Sydney: Avebury Press.

Campbell, Hugh and Ruth Liepins. 2001. Naming organics: Understanding organic standards in New Zealand as a discursive field. Sociologia Ruralis 41(1): 21-39.

Canadian Business. 2005. Q\&A-WTO meeting: Jim Peterson on crippling agricultural subsidies and Canada's trade policy. (December 5-25 Issue of Canadian Business Magazine.) Available online at:

http://www.canadianbusiness.com/after_hours/opinion/article.jsp?content=20051230_1 55114_4640

Castree, Noel. 2004. Differential geographies: place, indigenous rights and 'local' resources. Political Geography 23: 133-167.

Castree, Noel. 2001. Socializing nature: Theory, practice, and politics. In Noel Castree and Bruce Braun (eds.), Social nature: theory, practice, and politics. Malden, MA: Blackwell.

Castree, Noel and Bruce Braun (eds.). 2001. Social nature: Theory, practice, and politics. Malden, MA: Blackwell.

CGSB (Canadian General Standards Board). 2005. National Standard of Canada for Organic Agriculture (CAN/CGSB-32.310). Available on-line at: http://www.pwgsc.gc.ca/cgsb/on_the_net/032_0310/032_0310_1999-e.pdf

City of Ottawa. 2001. Food security in Ottawa: A community profile. Report by People Services Department and Ottawa Food Security Group, City of Ottawa (March 2001). Available on-line at: http://www.perc.ca/library/resources/food/food-security/index.en.html 
Coombes, Brad and Hugh Campbell. 1998. Dependent reproduction of alternative modes of agriculture: Organic farming in New Zealand. Sociologia Ruralis 38(2): 127-45.

Cotterill. Pamela. 1992. Interviewing women: Issues of friendship, vulnerability, and power. Women's Studies International Forum 5/6: 593-606.

Cronon, William. 1995. The trouble with wilderness; Or, getting back to the wrong nature. In William Cronon (ed.), Uncommon ground: Remaking the human place in nature. New York: Norton.

Daly, Brian. 2003. Lower farm subsidies urged. The Canadian Press, July 29, 2003. Available on-line at: http://www.geocities.com/ericsquire/articles/wto/cp030729c.htm

Darnhofer, Ika. 2005. Organic farming and rural development: Some evidence from Austria. Sociologia Ruralis 45(4): 308-23.

Demeritt. David. 2002. What is the 'social construction of nature'? A typology and sympathetic critique. Progress in human geography 26(6): 767-790.

Demeritt, David. 2001. Being constructive about nature. In Noel Castree and Bruce Braun (eds.), Social nature: Theory, practice, and politics. Malden, MA: Blackwell.

DuPuis, E. Melanie. 2002. Not in my body: rBGH and the rise of organic milk. Agriculture and Human Values 17: 285-95.

DuPuis, E. Melanie and David Goodman. 2005. Should we go "home" to eat?: Toward a reflexive politics of localism. Journal of Rural Studies 21: 359-71.

DuPuis, E. Melanie and David Goodman. 2002. Knowing food and growing food: Beyond the production-consumption debate in the sociology of agriculture. Sociologia Ruralis 42(1): 5-22.

EAP (Ecological Agricultural Projects). 1995. Evolution of the organic movement in Canada. Available online at: http://eap.mcgill.ca/MagRack/COG/COG_A_95_04.htm

EFAO (Ecological Farmers' Association of Ontario). 2004. EFAO Requests Quota Exemption for Small-Scale, Direct Marketed Chicken. Media Release, November 8, 2004. Ecological Farmers Association of Ontario (EFAO). Available online at: http://www.efao.ca/press_chicken_quota.shtml

Environics, International Ltd. 2001. Food issues monitor survey 2000. Survey results summarized at: http://www1.agric.gov.ab.ca/\$department/deptdocs.nsf/all/sis8434 
Escobar, Arturo. 1996. Constructing nature: Elements for a poststructuralist political ecology. In: Peet, Richard and Michael Watts (eds.). Liberation ecologies:

Environment, development, social Movements. London and New York: Routledge.

Escobar, Arturo. 1999. After nature: Steps to an antiessentialist political ecology. Current Anthropology 40(1): 1-30.

Escobar, Arturo. 2001. Culture sits in places: Reflections on globalism and subaltern strategies of localization. Political Geography 20: 139-174.

Evans, Nick, Carol Morris, and Michael Winter. 2002. Conceptualising agriculture: A critique of post-productivism as the new orthodoxy. Progress in Human Geography 26: 313-32.

Evans, Nick and Brian Ilberry. 1993. The pluriactivity, part-time farming, and farm diversification debate. Environment and Planning A 25: 945-59.

Ontario Farmers' Markets Food Safety Working Group. 2005. Recommendations to ensure food safety at Ontario's Farmers' markets. (Report released December 29, 2005). Available online at: http://www.farmersmarketsontario.com/foodsafety.pdf

Flax, Jane. 1992. The end of innocence. In Judith Butler and Joan Scott (eds.), Feminists theorize the political. New York: Routledge.

Foucault, Michel. 1980. Two Lectures. In Colin Gordon (ed.), Power/knowledge: Selected interviews and other writings. Brighton: Harvester Press.

Friedland, William. 1997. Commentary of part III: 'Creating space for food' and 'agroindustrial just-in-time'. In David Goodman and Michael Watts (eds.), Globalising food: Agrarian questions and global restructuring. London and New York: Routledge.

Friedmann, Harriet. 1993. The political economy of food. New Left Review. 197: 29-57.

Gezon, Lisa L. and Susan Paulson. 2005. Place, power, difference: Multiscale research at the dawn of the twenty-first century. In: Paulson, Susan and Lisa L. Gezon (eds.). 2005. Political ecology across spaces, scales, and social groups. New Brunswick, New Jersey and London: Rutgers University Press.

Gibson-Graham, J.K. 2003. An ethics of the local. Rethinking Marxism 15(1): 49-74.

Gibson-Graham, J.K. 2002. Beyond global vs. local: Economic politics outside the binary frame. In Andrew Herod and Melissa Wright (eds.)., Geographies of power: Placing scale. Oxford: Blackwell.

Gibson-Graham, J.K. 1994. 'Stuffed if I know': Reflections on post-modern feminist social research. Gender, Place and Culture 1(2): 205-24. 
Goodman, David. 2004. Rural Europe redux? Reflections on alternative agro-food networks and paradigm change. Sociologia Ruralis 44(1): 3-16.

Goodman, David. 2002. Rethinking food production-consumption: Integrative perspectives. Sociologia Ruralis 42(4): 271-77.

Goodman, David. 2001. Ontology matters: The relational materiality of nature and agrofood studies. Sociologia Ruralis 41(2): 182-200.

Goodman, David. 2000. Organic and conventional agriculture: Materializing discourse and agro-ecological managerialism. Agriculture and Human Values 17: 215-19.

Goodman, David. 1999. Agro-food studies in the "age of ecology": Nature, corporeality, bio-politics. Sociologia Ruralis 39(1): 17-38.

Goodman, David and Michael Redclift. 1991. Refashioning nature. London: Routledge.

Goodman, David and Michael Watts (eds.). 1997. Globalising food: Agrarian questions and global restructuring. London and New York: Routledge.

Goodman, David, Berbardo Sorj and John Wilkinson. 1987. From farming to biotechnology. Oxford: Basil Blackwell.

Grant, Brian. 2005. Surveying the back-to-the-land movement in the 70s. Published online at: www.mcn.com/backtotheland/

Gregory, Derek. 2001. (Post)colonialism and the production of nature. In Noel Castree and Bruce Braun (eds.), Social nature: Theory, practice, and politics. Malden, MA: Blackwell.

Gregory, Derek. 2000. Discourse. In: Johnston, R.J., Derek Gregory, Geraldine Pratt, and Michael Watts. (eds.). The dictionary of human geography. (Fourth Edition). Malden, MA: Blackwell.

Guthman, Julie. 2004a. The trouble with 'organic lite' in California: A rejoinder to the 'conventionalisation' debate. Sociologia Ruralis 44(3): 301-316.

Guthman, Julie. 2004b. Agrarian dreams: The paradox of organic farming in California. Berkeley: University of California Press.

Guthman, Julie. 2000. Raising organic: An agro-ecological assessment of grower practices in California. Agriculture and Human Values 17: 257-266.

Guthman, Julie. 1998. Regulating meaning, appropriating nature: The codification of California organic agriculture. Antipode 30(2): 135-154. 
Hall, Alan. 2003. Canadian agricultural policy: Liberal, global, and sustainable. In Jane Adams (ed.), Fighting for the farm: Rural America transformed. Philadelphia: University of Pennsylvania Press.

Hall, Alan and Veronika Mogyorody. 2001. Organic farmers in Ontario: An examination of the conventionalization argument. Sociologia Ruralis 41(4): 399-422.

Haraway, Donna. 1991. Simians, cyborgs, and women: The reinvention of nature. New York: Routledge.

Hecht, Susanna. 1995. The evolution of agroecological thought. In Miguel Altieri (ed.), Agroecology: The science of sustainable agriculture. Boulder: Westview Press.

Hecht, Susanna and Alexander Cockburn. 1989. The fate of the forest: Developers, destroyers and defenders of the Amazon. London: Penguin.

Hendrickson, Mary and William Heffernan. 2002. Opening spaces through relocalization: Locating potential resistance in the weaknesses of the global food system. Sociologia Ruralis 42(4): 347-69.

Hill, Stuart B. and Rod J. MacRae. 1992. Organic Farming in Canada. Agriculture, Ecosystems and Environment 39: 71-84.

Hinrichs, C. Claire. 2003. The practice and politics of food system localization. Journal of Rural Studies 19: 33-45.

Hoggart, Keith, Loretta Lees, and Anna Davies. 2002. Researching human geography. London: Arnold.

Holden, Patrick. 2004. A revolution in sustainable agriculture. Interview with Patrick Holden, Director of Soil Association. Available online at: http://www.bigpicture.tv/index.php?id $=4 \&$ cat $=\& a=4$

Holloway, Lewis and Moya Kneafsey 2000. Reading the space of the farmers' market: A preliminary investigation from the UK. Sociologia Ruralis 40(3): 285-99.

Howard, Sir Albert. 1947. Farming and gardening for health or disease (the soil and health). London: Faber and Faber. Available online at: http://journeytoforever.org/farm_library/howardSH/SHtoc.html

Huff, H. Bruce. 1997. The changing role of public policy in Canadian agriculture. American Journal of Agricultural Economics 79(5): 1401-1409.

IFOAM (International Federation of Organic Agriculture Movements) 2004. The role of organic agriculture in mitigating climate change. Report released June 1, 2004. 
Available online at: www.ifoam.org/press/positions/Climate_study_green_housegases.html

Ilbery, Brian and I. Bowler. 1998. From agricultural productivism to post-productivism. In Brian Ilbery (ed.), The geography of rural change. London: Longman.

Ingold, Tim. 2000. The perception of the environment: Essays on livelihood, dwelling and skill. New York and London: Routledge.

Donald, Betsy and Alison Blay-Palmer. (forthcoming). The urban creative food economy: Producing food for the urban elite or social inclusion opportunity. Environment and Planning $A$.

Kaltoft, Pernille. 2001. Organic farming in late modernity: At the frontier of modernity or opposing modernity. Sociologia Ruralis 41(1): 146-58.

Kaltoft, Pernille. 1999. Values about nature in organic farming practice and knowledge. Sociologia Ruralis 39(1): 39-53.

Kloppenburg, Jack. 1991. Social theory and de/reconstruction of agricultural science: Local knowledge for an alternative agriculture. Rural Sociology 56: 519-48.

Knickel, Karlheinz and Henk Renting. 2000. Methodological and conceptual issues in the study of multifunctionality and rural development. Sociologia Ruralis 40(4): 512-28.

Kobayashi, Audrey. 2001. Negotiating the personal and the political in critical qualitative research. In Melanie Limb and Claire Dwyer (eds.), Qualitative methodologies for geographers: Issues and debates. London: Arnold.

Koc, Mustafa. 1994. Globalization as a discourse. In Alessandro Bonano, Lawrence Busch, William Friedland, Lourdes Gouveia, and Enzo Mingione (eds.), From Columbus to ConAgra: The globalization of agriculture and food. Lawrence, Kansas: University of Kansas Press.

Lockie, Stewart. 2002. 'The invisible mouth': Mobilizing 'the consumer' in food production-consumption networks. Sociologia Ruralis 42(4): 278-94.

Lockie, Stewart, Kristen Lyons, and Geoffrey Lawrence. 2000. Constructing "green" foods: Corporate capital, risk, and organic farming in Australia and New Zealand. Agriculture and Human Values 17: 315-22.

Lowe, Philip, Jonathan Murdoch, Terry Marsden, Richard Munto, and Andrew Flynn. 1993. Regulating the new rural spaces: The uneven development of land. Journal of Rural Studies 9: 205-22. 
MacRae, Roderick J. 1990. Strategies to overcome institutional barriers to the transition from conventional to sustainable agriculture in Canada: The role of government, research institutions and agribusiness. Montreal: $\mathrm{PhD}$ thesis, Department of Renewable Resources, McGill University. Available online at: http://www.eap.mcgill.ca/rod_thesis/rod_toc1.htm

Macey, Ann. 2004. 'Certified organic': the status of the Canadian organic market in 2003. Report to Agriculture and Agri-Food Canada. Available on-line at: http://www.agr.gc.ca/misb/hort/org-bio/pdf/OrganicsREPORT2003_e.pdf

Mann, Susan A. 1989. Agrarian capitalism in theory and practice. Chapel Hill: University of North Carolina Press.

Mansfield, Becky. 2004. Organic views of nature: The debate over organic certification for aquatic animals. Sociologia Ruralis 44(2): 216-33.

Marsden, Terry. 2000. Food matters and the matter of food: Towards a new food governance? Sociologia Ruralis 40(1): 20-29.

Marsden, Terry. 1998. Agriculture beyond the treadmill? Issues for policy, theory and research practice. Progress in Human Geography 22(2): 265-75.

Marsden, Terry. 1997. Creating space for food: The distinctiveness of recent agrarian development. In David Goodman and Michael Watts (eds.), Globalising food: Agrarian questions and global restructuring. London and New York: Routledge.

Marsden, Terry, Jonathan Murdoch, Philip Lowe, Richard Munton, and Andrew Flynn. 1993. Constructing the Countryside. Boulder: Westview Press.

McCarthy, James. 2002. First World political ecology: Lessons from the wise use movement. Environment and Planning A 34: 1281-1302.

McMahon, Naoimh. 2005. Biodynamic farmers in Ireland: Transforming society through purity, solitude and bearing witness? Sociologia Ruralis 45(1-2): 98-114.

McMichael, Philip. 2000a. Global food politics. In Fred Magdoff, John Bellamy Foster and Frederick H. Buttel (eds.), Hungry for Profit: The agribusiness threat to farmers, food, and the environment. New York: Monthly Review Press.

McMichael, Philip. 2000b. The power of food. Agriculture and Human Values. 17: 2133.

McMichael, Philip (ed.). 1994. The global restructuring of agro-food systems. Ithaca: Cornell University Press. 
Massey, Doreen. 2004. Geographies of responsibility. Geografiska annaler 86 B (1): 518.

Massey, Doreen. 1999. Spaces of politics. In Doreen Massey, John Allen, and Philip Sarre (eds.), Human geography today. Malden, Mass.: Polity Press.

Massey, Doreen. 1997. A global sense of place. In Trevor Barnes and Derek Gregory (eds.), Reading human geography: The poetics and politics of enquiry. London: Arnold.

Massey, Doreen. 1994. Space, place and gender. Minneapolis: University of Minnesota Press.

Massey, Doreen. 1993. Questions of locality. Geography 78(2): 142-49.

Massey, Doreen. 1984. Spatial divisions of labour: Social structures and the geography of production. London: Macmillan.

Merrigan, K.A. 1997. Government pathways to true food security. In W. Lockeretz (ed.), Visions of American Agriculture. Ames, Iowa: Iowa State University Press.

Mohammad, R. 2001. 'Insiders' and/or 'outsiders': Positionality, theory and praxis. In: Limb, M. and C. Dwyer (eds.). Qualitative methodologies for geographers: Issues and debates. London: Arnold.

Monbiot, George. 2004. Manifesto for a new world order. New York: New Press.

Morgan, Kevin and Jonathan Murdoch. 2000. Organic vs. conventional agriculture: Knowledge, power, and innovation in the food chain. Geoforum 31(2): 159-73.

Murdoch, J. 1998, 'The Spaces of Actor-Network Theory.' Geoforum. 29: 357-374.

Murdoch, J. and Marsden, T. 1995, 'The Spatialization of politics: local and national actor-spaces in environmental conflict.' Transactions of the Institute of British Geographers. 20: 368-380.

MPAC (Municipal Property Assessment Corporation). 2004. MPAC News (May 2004, Issue 1). http://www.mpac.ca/pdf/mpac_news_spring_2004.pdf

Murdoch, Jonathan and Mara Miele. 1999. 'Back to nature': changing 'worlds of production' in the food sector. Sociologia Ruralis 39(4): 465-83.

NFU (National Farmers' Union). 2003. The farm crisis, bigger farms, and the myths of "competition" and "efficiency". Saskatoon: National Farmers Union (Canada).

Neumann, Roderick. 1998. Imposing wilderness: Struggles over livelihood and nature preservation in Africa. Berkeley: University of California Press. 
Northbourn, W.E.C.J. 4th Baron. 1940. Look to the Land. London: Dent.

OMAFRA (Ontario Ministry of Agriculture and Food and Rural Affairs). 2001. Organic Farming: Challenges and Opportunities. Available on-line at:

www.gov.on.ca/OMAFRA/english/crops/field/news/croptalk/2001/ct_1101a3.htm Published: November 2001.

OMAFRA (Ontario Ministry of Agriculture and Food and Rural Affairs). 2003. Organic Farming in Ontario. Available on-line at: www.gov.on.ca/OMAFRA/english/crops/facts/03-063.htm. Published: July 2003.

OMAFRA (Ontario Ministry of Agriculture and Food and Rural Affairs). 2004. Organic Farming: Frequently Asked Questions. Available on-line at: www.gov.on.ca/OMAFRA/english/crops/organic/faq.htm. Published: December 2, 2004.

OTF (Organic Production System Task Force). 2006. Organic Production System Task Force $(O T F)$. Available on-line at: http://www.inspection.gc.ca/english/fssa/orgbio/otfgtspbe.shtml

OTF. 2005a. Government of Canada Establishes Production System Task Force. Update on the OTF, February 2005. Available on-line at:

http://www.inspection.gc.ca/english/fssa/orgbio/newnou/2005/2005-02e.shtml

OTF. 2005b. Phase One for Organic Production System Task Force. Update on the OTF, March 2005. Available on-line at: http://www.inspection.gc.ca/english/fssa/orgbio/newnou/2005/2005-03e.shtml

Padel, Susanne. 2001. Conversion to organic farming: A typical example of the diffusion of an innovation. Sociologia Ruralis 41(1): 40-61.

Paulson, Susan and Lisa L. Gezon (eds.). 2005. Political ecology across spaces, scales, and social groups. New Brunswick, New Jersey and London: Rutgers University Press.

Pedersen, Kirsten Bransholm and Bente Kjaergard. 2004. Do we have room for shining eyes and cows as comrades? Gender perspectives on organic farming in Denmark. Sociologia Ruralis 44(4): 373-94.

Peet, Richard and Michael Watts. 1996. Liberation ecology: Development, sustainability, and environment in an age of market triumphalism. In: Peet, Richard and Michael Watts (eds.). Liberation ecologies: Environment, development, social Movements. London and New York: Routledge. 
Potter, Clive and Mark Tilzey. 2005. Agricultural policy discourses in the European postFordist transition: Neoliberalism, neomercantilism and multifunctionality. Progress in Human Geography 29(5): 581-600

Pugliese, Patrizia. 2001. Organic farming and sustainable rural development: A multifaceted and promising convergence. Sociologia Ruralis 41(1): 112-30.

Raynolds, Laura T. 2000. Re-embedding global agriculture: The international organic and fair trade movements. Agriculture and Human Values 17: 297-309.

Reed, Matthew. 2001. Fight the future! How the contemporary campaigns of the UK organic movement have arisen from their composting of the past. Sociologia Ruralis 41(1): 131-45.

Rocheleau, Dianne, Barbara Thomas-Slayter, and Esther Wangari (eds.). 1996.

Feminist political ecology: Global issues and local experiences. London and New York: Routledge.

Rodale Institute n.d. Who we are. Available online at: http://www.rodaleinstitute.org/about/who_set.html

Rose, Gillian. 2001. Visual methodologies: an introduction to the interpretation of visual materials. London: Sage.

Rose, Gillian. 1997. Situating knowledges: Positionality, reflexivities and other tactics." Progress in Human Geography 21(3): 305-320.

Scott, James. 1985. Weapons of the weak: Everyday forms of peasant resistance: Hidden transcripts. New Haven: Yale University Press.

Sharma, R. 2000. Agriculture in the GATT: A historical account. Technical Cooperation Division, United Nations Food and Agriculture Organization (FAO). Available online at:

http://www.fao.org/documents/show_cdr.asp?url_file=/docrep/003/x7352e/x7352e04.ht $\mathrm{m}$

Smith, Neil. 1984. Uneven development: Nature, capital, and the production of space. New York: Blackwell.

Soil Association n.d. About us. Available online at:

http://www.soilassociation.org/web/sa/saweb.nsf/aboutus/index.html

Steiner, Rudolf. 1924. Unpublished series of lectures on agriculture. Translation available online at: http://www.garudabd.org/Agriccourse/contents.html 
Stott, Philip and Sian Sullivan. 2000. Introduction. In Philip Stott and Sian Sullivan (eds.), Political ecology: Science, myth, and power. London: Arnold.

Swyngedouw, Erik. 1997. Neither global nor local: 'Glocalization' and the politics of scale. In K.R. Cox (ed.), Spaces of globalization: Reasserting the power of the local. New York: Guilford.

Thompson, Paul B. 1995. The spirit of the soil: Agriculture and environmental ethics. London and New York: Routledge.

Tovey, Hilary. 1997. Food environmentalism and rural sociology: On the organic movement in Ireland. Sociologia Ruralis 37(1): 21-37.

UNESCO (United Nations Educational, Scientific, and Cultural Organization. n.d. UN decade for education for sustainable development (2005-2014). Available on-line at: http://portal.unesco.org/education/en/ev.phpURL_ID=23279\&URL_DO=DO_TOPIC\&URL_SECTION=201.html

van der Ploeg, Jan Douwe and Henk Renting. 2004. Beyond the 'redux': A rejoinder to David Goodman. Sociologia Ruralis 44(2): 233-42.

Vayda, Andrew P. and Bradley B. Walters. 1999. Against political ecology. Human Ecology 27(1): 167-179.

Vos, Timothy. 2000. Visions of the middle landscape: Organic farming and the politics of nature. Agriculture and Human Values 17(3): 245-56.

Walker, Peter. 2003. Reconsidering 'regional' political ecology: Towards a political ecology of the American West. Progress in Human Geography 27(1): 7-24.

Walker, Peter A. 2005. Political ecology: Where is the ecology? Progress in Human Geography 29(1): 73-82.

Watts, Michael. 2004. Enclosure: A modern spatiality of nature. In Paul Cloke, Philip Crang, and Mark Goodwin (eds.), Envisioning human geographies. New York: Oxford University Press.

Watts, Michael. 2000. Political ecology. In: Johnston, R.J., Derek Gregory, Geraldine Pratt, and Michael Watts. (eds.). The dictionary of human geography. (Fourth Edition). Malden, MA: Blackwell.

Watts, Michael. 1983. Silent violence: Food, famine and peasantry in northern Nigeria. Berkeley: University of California Press.

Whatmore, Sarah. 2002. Hybrid geographies: Natures cultures spaces. London: Sage. 
Whatmore, Sarah. 1997. Dissecting the autonomous self: Hybrid cartographies for a relational ethics. Environment and Planning D: Society and Space. 15: 37-53.

Whatmore, Sarah. 1995. From farming to agro-business. In R.J. Johnston, Peter J. Taylor, and Michael Watts (eds.), Geographies of global change: Remapping the world in the late twentieth century. London: Blackwell.

Whatmore, Sarah, Pierre Stassart, and Henk Renting. 2003. Guest editorial. Environment and Planning A 35: 389-91.

Wilson, Geoff A. 2001. From productivism to post-productivism...and back again? Exploring the (un)changed natural and mental landscapes of European agriculture. Transactions of the Institute of British Geographers NS 26: 77-102.

Winter, Michael. 2004. Geographies of food: Agro-food geographies-farming, food, and politics. Progress in Human Geography 28(5): 664-70.

Winter, Michael. 2003a. Geographies of food: agro-food geographies-making reconnections. Progress in Human Geography 27(4): 505-13.

Winter, Michael. 2003b. Embeddedness, the new food economy and defensive localism. Journal of Rural Studies 19: 23-32.

Woods, Michael. 2003. Deconstructing rural protest: the emergence of a new social movement. Journal of Rural Studies 19: 309-325 


\section{Appendix 1: Guide for Semi-Structured Interviews with Participating Organic}

\section{Farmers}

Name:

Farm:

Date of Interview:

\section{History of participation in organic farming}

(1) How long have you been farming organically? Do you farm full time?

(2) Have you always farmed?

$\rightarrow$ Did you have a different career prior to becoming an organic farmer?

$\rightarrow$ Did you farm conventionally before becoming an organic farmer?

\section{Background information on the farm}

(3) How large is your farm? How many acres are in organic production? Do you have any acreage in conventional production? Was this the original size of the farm, or have you expanded?

(4) What crops do you grow? Organically? Conventionally? Why these crops?

Motivation/ideology of farming organically

(5) Can you tell me about the process of starting to farm organically?

$\rightarrow$ Did you switch crops when you switched to organic farming? If so, why?

$\rightarrow$ Did you convert the entire farm to organic at once, or by crop, or section of the farm? What factors affected how the transition was undertaken?

(6) Why did you start farming organically? 
(7) What does organic farming mean to you?

$\rightarrow$ What principles and/or practices do you consider central to organic farming?

(8) Have your reasons for farming organically changed over time?

\section{On conventional farming}

(9) How/why do you think we became so dependent on chemical/synthetic input use in farming?

\section{Land}

(10) Has your land historically been used for farming? What was it used for before?

(11) Would you consider the quality of your land good for agricultural purposes?

(excellent, good, medium, poor or marginal soil)

$\rightarrow$ How would you describe your soil quality?

$\rightarrow$ Did you/do you undertake special activities to boost the quality of your land or soil?

\section{Research and training}

(12) Did you undertake any on- or off-farm training before starting to train organically? (training on the family farm, university or college courses, internship programs, etc.)

Practical training, or was it focused on principles as well?

(13) What sources do you use to get information on crops and farming practices? Where do you think the most important research into organic agriculture occurs?

(14) Do you conduct any on-farm research? What kind? Why? 
(15) Do government ministry research and training initiatives reflect your needs as an organic farmer? Do the initiatives of private bodies? How or why not?

(16) What types of research are most useful to you? What would you like to see more research on?

\section{Biodiversity and crop selection}

(17) How do you decide which varieties of a crop to grow? What kinds of things do you consider? (ecological/economic/social considerations)

\section{Biotechnology}

(18) Do you undertake any plant breeding activities on your farm? What kinds of characteristics do you breed for?

$\rightarrow$ Are there any kinds of plant breeding activities that you would consider contradictory to the principles of organic farming?

(19) What is your view on genetic engineering? How would you define genetic engineering? Is there a place for it in organic agriculture?

\section{Seed Control}

(20) What type of seeds do you use and where do you get them? (saved, purchased, exchanged, organic, conventional, treated)

(21) What do you think are the main issues around seed control for organic farmers?

(22) How do you think the seed sector review will affect organic farmers? 


\section{Agroecological principles}

(23) Are there agroecological principles that you consider central to farming organically?

Biodiversified cropping patterns: Does the farm use annual crop rotation systems, or are more than type of crop produced on the same section of land over the course of the year? If the former, is the same crop produced more than once on the same section? If the latter, how many different types of crops, on average, are produced on the same piece of land over the course of a year? Are two or more crops ever planted concurrently on the same section of land? Are any non-crop plants incorporated into the ecosystem?

Fertility management: Does the farm compost? Does the farm rely on off-farm compost? What is the source of this compost and where does it come from? Does the farm grow any cover crops? Does the farm use other on or off-farm soil amendments?

Pest and disease management: How does the farm manage insects and disease? Does the farm rely on any allowable insecticides or substances used to prevent disease? Does the farm rely on design mechanisms such as the presence/creation of habitat for predator populations or diversified cropping practices? On physical mechanisms such as bug traps? On biological mechanisms such as the release of biological predators?

Weed control: How tolerant is the farm of weeds? What mechanisms of weed control does the farm use? Pre-irrigation, cover crops, mulches, hand weeding, technologies?

Use of legally restricted/controversial materials: Does the farm rely on any substances which are not on the permitted substances list in Canada's National Standard? On any substances whose use is controversial amongst the organic community?

Other agroecological 


\section{Agriculture, agroecosystems, and surrounding ecosystems}

(24) Do you have naturalized areas on the farm that are not directly involved in crop production (e.g., woodlots, wetlands, naturalizing fields)? Do you use naturalized areas in amongst the planted areas (e.g., windbreaks, buffer strips, riparian protection strips on streams etc.)?

(25) Do you manage or maintain these areas in any way? Have you ever created more naturalized areas on your farm?

$\rightarrow$ Do you participate in any farm stewardship activities or programs?

(26) Why do you keep these areas: why not convert them to additional fields? Have you noticed any evidence of the naturalized areas benefiting the farm or crop production?

\section{Future of the organic sector}

(27) What's it like for you today, financially speaking? Has this changed since you started farming organically?

(28) What are the major barriers or obstacles to organic producers today? Is this different from conventional farmers? How?

(29) What prevents new farmers from moving into organic farming, or conventional farmers from making the transition?

(30) What changes are needed to improve social and economic conditions for organic farmers, and to allow organic farming to continue to develop and thrive?

(31) Will you pass this farm on to children or others in your family? 


\section{The Farm Crisis, conventionalization, and the organic sector}

(32) As an independent farmer, do you feel pressure to compete with larger scale enterprises or those with a higher productivity level? How does this affect your practice (increase in intensity of farming, area farmed, specialization or diversification of crops)

$\rightarrow$ How important is participating in 'economies of scale' to farmers' social and economic survival?

(33) Have you been affected by any agricultural restructuring or deregulation policies initiated by the government? (dropping of price supports for crops or farm inputs, centralization of processing and retailing bodies, etc.). Which ones?

(34) Do you feel that organic farming is becoming more conventional/ 'conventionalized'? What are the causes of this? What effects is this having on the principles and practices of organic farming? How is it affecting you? (increasing presence and role of multinational corporations, of certification standards and bodies, by the need for small scale farmers to become increasingly competitive due to economic globalization, etc.)

(35) Do you think there is significant entry of corporations and large-scale private bodies into the organic sector? Where have you felt the most effects? (gene/seed development, input development, crop processing and storage, crop marketing and retailing)

(36)In your experience, what has been the effect of increased competition, agricultural restructuring and conventionalization pressures in farming ecosystems?

\section{Markets and consumption in the organic sector}

(37) Do you have trouble obtaining what you feel is a reasonable price for your products? Do the prices you receive reflect your labour? 
(38) Have you made changes in what you farm because of market changes or because of market obstacles or opportunities for a particular crop? Have you changed how you farm because of market changes or other market factors?

\section{Food and environmental politics}

(39) How much of the food you eat comes from your own farm? How much of it is organic?

(40) Would you consider yourself active in politics surrounding food and environmental issues?

$\rightarrow$ Do you see organic farming as a political activity?

$\rightarrow$ Are there other political activities around food and environmental issues in which you are active?

(41) Other food politics issues: 


\section{Appendix 2: Socio-Economic Characteristics of Participating Farms and Farmers}

\begin{tabular}{|c|c|c|c|c|c|c|c|c|c|}
\hline \multirow[t]{2}{*}{ Farmer } & \multirow[t]{2}{*}{ Products } & \multicolumn{2}{|l|}{ Land } & \multirow[t]{2}{*}{ Livestock } & \multirow{2}{*}{$\begin{array}{l}\text { History in } \\
\text { Conventional } \\
\text { Production? }\end{array}$} & \multirow{2}{*}{$\begin{array}{l}\text { Years Farming } \\
\text { Organically }\end{array}$} & \multirow{2}{*}{$\begin{array}{l}\text { People } \\
\text { Employed } \\
\text { on Farm } \\
\end{array}$} & \multirow{2}{*}{$\begin{array}{l}\text { Off Farm } \\
\text { Employment }\end{array}$} & \multirow{2}{*}{ Point of Sales } \\
\hline & & Owned & Rented & & & & & & \\
\hline \multicolumn{10}{|l|}{ Farms } \\
\hline (F01) & $\begin{array}{l}\text { Small grains, } \\
\text { buckwheat, } \\
\text { hay, straw, } \\
\text { soybeans, } \\
\text { pasture. } \\
\text { Also keeps } \\
\text { horses and } \\
\text { runs a horse } \\
\text { riding school } \\
\text { on the } \\
\text { property. }\end{array}$ & $\begin{array}{l}210(80 \text { in } \\
\text { production })\end{array}$ & 60 & Sheep (60). & $\begin{array}{l}\text { Yes. Farmer's } \\
\text { family has } \\
\text { historically } \\
\text { farmed in } \\
\text { Manitoba, } \\
\text { where they ran } \\
\text { a conventional } \\
\text { operation. He } \\
\text { farmed his } \\
\text { current } \\
\text { property } \\
\text { conventionally } \\
\text { for } 9 \text { years } \\
\text { prior to } \\
\text { converting to } \\
\text { organic. }\end{array}$ & 22 & $\begin{array}{l}1 \\
\text { ( } 2 \text { adults } \\
\text { in the } \\
\text { family) }\end{array}$ & $\begin{array}{l}\text { Farmer is } \\
\text { also an } \\
\text { antique } \\
\text { dealer, owns } \\
\text { an art } \\
\text { gallery, is } \\
\text { trained as an } \\
\text { engineer, } \\
\text { and serves } \\
\text { as a } \\
\text { coordinator } \\
\text { for various } \\
\text { community } \\
\text { events. Also } \\
\text { describes } \\
\text { himself as a } \\
\text { quasi-social } \\
\text { activist. }\end{array}$ & $\begin{array}{l}\text { Crop dealer } \\
\text { (crops). } \\
\text { Word of mouth } \\
\text { (lamb). }\end{array}$ \\
\hline (F02) & $\begin{array}{l}\text { Pasture. } \\
\text { Vegetables } \\
\text { (sold through } \\
\text { a box } \\
\text { delivery } \\
\text { program and } \\
\text { through } \\
\text { markets), cut }\end{array}$ & $\begin{array}{l}70 \text { acres } \\
4500 \text { square } \\
\text { foot } \\
\text { Greenhouse }\end{array}$ & None & $\begin{array}{l}\text { Sheep, beef } \\
\text { cattle }\end{array}$ & $\begin{array}{l}\text { Yes. Farmer } \\
\text { was involved } \\
\text { in } \\
\text { conventional } \\
\text { operations for } \\
15-20 \text { years in } \\
\text { Southern } \\
\text { Africa. On his } \\
\text { property here }\end{array}$ & $\begin{array}{l}10-15 \\
\text { ( } 3 \text { in Canada). }\end{array}$ & $\begin{array}{l}2 \text { adults, } 2 \\
\text { teenagers } \\
\text { ( } 2 \text { adults, } \\
2 \\
\text { teenagers } \\
\text { in family. } \\
\text { One of the } \\
\text { teenager's }\end{array}$ & $\begin{array}{l}\text { Both adults } \\
\text { have part- } \\
\text { time jobs to } \\
\text { support the } \\
\text { farm. The } \\
\text { children are } \\
\text { still in } \\
\text { university } \\
\text { and }\end{array}$ & $\begin{array}{l}\text { Vegetable box } \\
\text { delivery } \\
\text { program. Sales } \\
\text { at market } \\
\text { (veggies, } \\
\text { flowers and } \\
\text { meat, prepared } \\
\text { food products). } \\
\text { Farm store }\end{array}$ \\
\hline
\end{tabular}




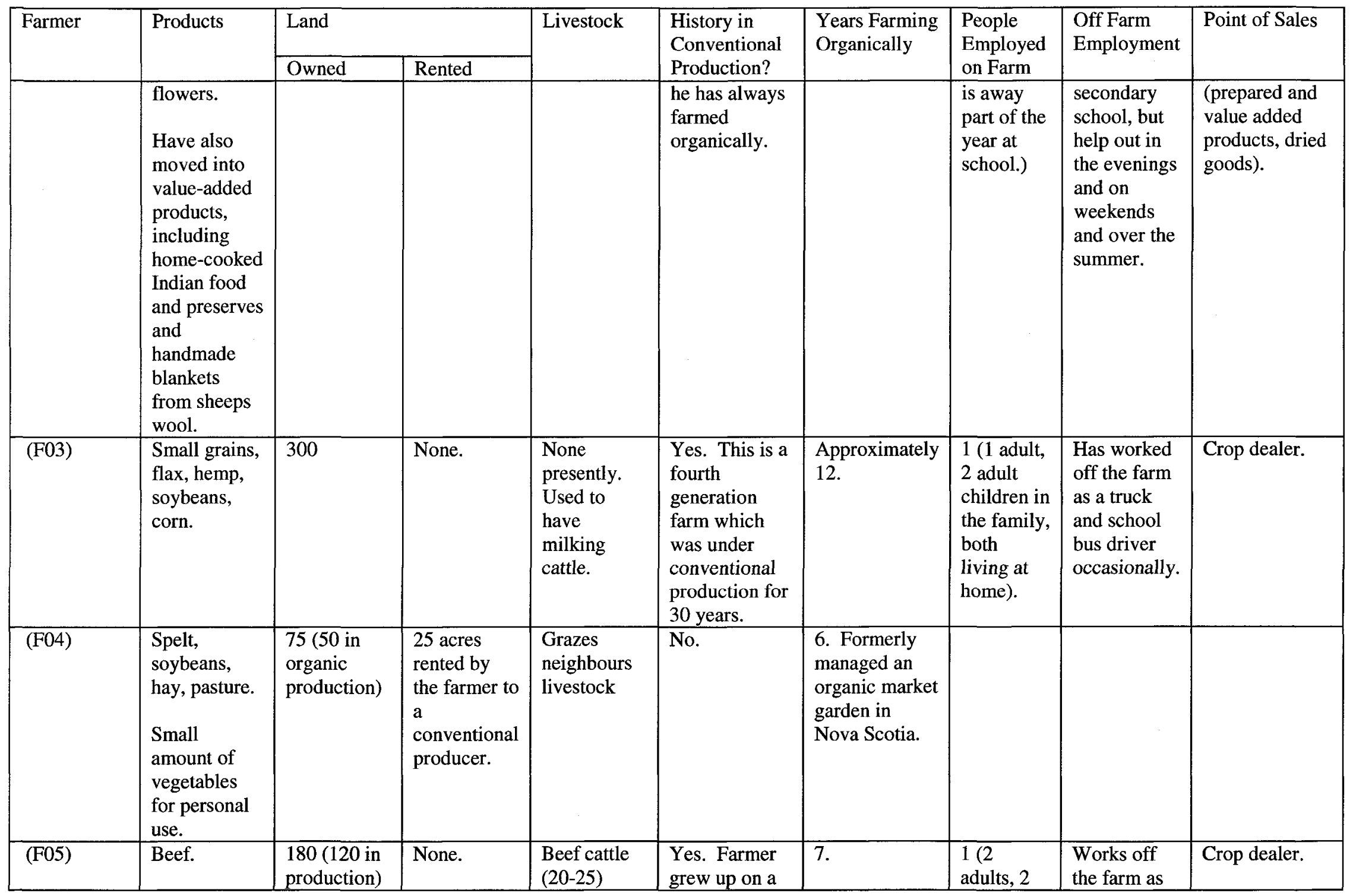




\begin{tabular}{|c|c|c|c|c|c|c|c|c|c|}
\hline \multirow[t]{2}{*}{ Farmer } & \multirow[t]{2}{*}{ Products } & \multicolumn{2}{|l|}{ Land } & \multirow[t]{2}{*}{ Livestock } & \multirow{2}{*}{$\begin{array}{l}\text { History in } \\
\text { Conventional } \\
\text { Production? }\end{array}$} & \multirow{2}{*}{$\begin{array}{l}\text { Years Farming } \\
\text { Organically }\end{array}$} & \multirow{2}{*}{$\begin{array}{l}\text { People } \\
\text { Employed } \\
\text { on Farm }\end{array}$} & \multirow{2}{*}{$\begin{array}{l}\text { Off Farm } \\
\text { Employment }\end{array}$} & \multirow[t]{2}{*}{ Point of Sales } \\
\hline & & Owned & Rented & & & & & & \\
\hline & $\begin{array}{l}\text { Spelt, } \\
\text { buckwheat, } \\
\text { soybeans, } \\
\text { pasture. }\end{array}$ & $\begin{array}{l}\text { (Partly } \\
\text { under joint } \\
\text { ownership) }\end{array}$ & & & $\begin{array}{l}\text { conventional } \\
\text { farm, then left } \\
\text { farming for } 25 \\
\text { years. When } \\
\text { he returned, } \\
\text { he farmed the } \\
\text { current } \\
\text { property } \\
\text { conventional } \\
\text { for } 10 \text { years. }\end{array}$ & & $\begin{array}{l}\text { adult } \\
\text { children } \\
\text { living } \\
\text { away from } \\
\text { home.) }\end{array}$ & $\begin{array}{l}\text { an } \\
\text { agricultural } \\
\text { consultant } \\
\text { on water and } \\
\text { climate } \\
\text { change } \\
\text { issues. }\end{array}$ & $\begin{array}{l}\text { Word of } \\
\text { mouth. }\end{array}$ \\
\hline (F06) & $\begin{array}{l}\text { Dairy, eggs, } \\
\text { beef, pork, } \\
\text { chicken. } \\
\text { Rye, spelt, } \\
\text { barley, oats, } \\
\text { sweet corn, } \\
\text { hay, pasture. } \\
\text { A few } \\
\text { vegetable } \\
\text { crops } \\
\text { (potatoes to } \\
\text { Desert Lake } \\
\text { Gardens) } \\
\text { Maple syrup. }\end{array}$ & $\begin{array}{l}600 \text { acres } \\
\text { ( } 400 \text { acres } \\
\text { arable and } \\
\text { in } \\
\text { production) }\end{array}$ & None. & $\begin{array}{l}\text { Milking } \\
\text { cattle (40), } \\
\text { beef cattle, } \\
\text { chicken, } \\
\text { pigs. }\end{array}$ & $\begin{array}{l}\text { Yes. This is } \\
\text { the family } \\
\text { farm of one of } \\
\text { the operators, } \\
\text { and was } \\
\text { farmed } \\
\text { conventionally } \\
\text { for many } \\
\text { years until it } \\
\text { was } \\
\text { converted. } \\
\text { The other } \\
\text { active } \\
\text { operator } \\
\text { comes from a } \\
\text { non-farming } \\
\text { background. }\end{array}$ & 6. & $\begin{array}{l}2(2 \\
\text { adults, } 1 \\
\text { teenager } \\
\text { living at } \\
\text { home) }\end{array}$ & & $\begin{array}{l}\text { One of the } \\
\text { operators does } \\
\text { extensive } \\
\text { volunteer work } \\
\text { for the NFU. } \\
\text { Teenager is in } \\
\text { high-school but } \\
\text { is very } \\
\text { involved in the } \\
\text { farm, starting } \\
\text { the sugarbush } \\
\text { operation and } \\
\text { running it } \\
\text { single- } \\
\text { handedly, for } \\
\text { example. }\end{array}$ \\
\hline (F07) & $\begin{array}{l}\text { Beef, pork. } \\
\text { Spring and } \\
\text { fall wheat, } \\
\text { spelt, oats, } \\
\text { barley, } \\
\text { soybeans. }\end{array}$ & 250 & $\begin{array}{l}200 \\
\text { Operators } \\
\text { have rented } \\
\text { significant } \\
\text { land in } \\
\text { addition to }\end{array}$ & $\begin{array}{l}\text { Beef cattle } \\
(120), \text { pigs } \\
(10) .\end{array}$ & $\begin{array}{l}\text { Yes. This is a } \\
\text { fifth } \\
\text { generation } \\
\text { farm, and it } \\
\text { was farmed } \\
\text { conventionally } \\
\text { by one of the }\end{array}$ & 10 . & $\begin{array}{l}2(2 \\
\text { adults, } 2 \\
\text { adult } \\
\text { children } \\
\text { living } \\
\text { away from } \\
\text { home). } \\
\end{array}$ & & $\begin{array}{l}\text { Both operators } \\
\text { work short- } \\
\text { term jobs at } \\
\text { points through } \\
\text { the year, such } \\
\text { as polling } \\
\text { clerks for }\end{array}$ \\
\hline
\end{tabular}




\begin{tabular}{|c|c|c|c|c|c|c|c|c|c|}
\hline \multirow[t]{2}{*}{ Farmer } & \multirow[t]{2}{*}{ Products } & \multicolumn{2}{|l|}{ Land } & \multirow[t]{2}{*}{ Livestock } & \multirow{2}{*}{$\begin{array}{l}\text { History in } \\
\text { Conventional } \\
\text { Production? }\end{array}$} & \multirow{2}{*}{$\begin{array}{l}\text { Years Farming } \\
\text { Organically }\end{array}$} & \multirow{2}{*}{$\begin{array}{l}\text { People } \\
\text { Employed } \\
\text { on Farm }\end{array}$} & \multirow{2}{*}{$\begin{array}{l}\text { Off Farm } \\
\text { Employment }\end{array}$} & \multirow[t]{2}{*}{ Point of Sales } \\
\hline & & Owned & Rented & & & & & & \\
\hline & & & $\begin{array}{l}\text { that farmed } \\
\text { currently, } \\
\text { but have cut } \\
\text { back in } \\
\text { recent years. } \\
\text { For three } \\
\text { years they } \\
\text { let a small } \\
\text { area of land } \\
\text { to a woman } \\
\text { to run a } \\
\text { vegetable } \\
\text { CSA project } \\
\text { and plan to } \\
\text { return to this } \\
\text { next year. }\end{array}$ & & $\begin{array}{l}\text { operators and } \\
\text { his father for } \\
30 \text { years until } \\
\text { they } \\
\text { converted. }\end{array}$ & & & & $\begin{array}{l}\text { Elections } \\
\text { Canada. }\end{array}$ \\
\hline (F08) & $\begin{array}{l}\text { Dairy. } \\
\text { Pork, } \\
\text { chicken, } \\
\text { turkey. } \\
\text { Hay, barley, } \\
\text { pasture, } \\
\text { sometimes } \\
\text { corn (field } \\
\text { crops are } \\
\text { used } \\
\text { exclusively } \\
\text { for animal } \\
\text { feed). } \\
\\
\text { Operators } \\
\text { also breed }\end{array}$ & 150 & $\begin{array}{l}\text { Approx. } \\
100 .\end{array}$ & $\begin{array}{l}\text { Milking } \\
\text { cattle (30- } \\
40 \text { ), pigs for } \\
\text { personal } \\
\text { consumption } \\
(3-4)\end{array}$ & $\begin{array}{l}\text { Yes. This is } \\
\text { the family } \\
\text { farm of one of } \\
\text { the operators, } \\
\text { and was } \\
\text { farmed } \\
\text { conventionally } \\
\text { until the } \\
\text { conversion. } \\
\text { The other } \\
\text { operators } \\
\text { parents ran a } \\
\text { small } \\
\text { conventional } \\
\text { dairy while } \\
\text { working full } \\
\text { time at other } \\
\text { jobs. }\end{array}$ & 7. & $\begin{array}{l}2(2 \\
\text { adults, } 2 \\
\text { children })\end{array}$ & & None. \\
\hline
\end{tabular}




\begin{tabular}{|c|c|c|c|c|c|c|c|c|c|}
\hline \multirow[t]{2}{*}{ Farmer } & \multirow[t]{2}{*}{ Products } & \multicolumn{2}{|l|}{ Land } & \multirow[t]{2}{*}{ Livestock } & \multirow{2}{*}{$\begin{array}{l}\text { History in } \\
\text { Conventional } \\
\text { Production? }\end{array}$} & \multirow{2}{*}{$\begin{array}{l}\text { Years Farming } \\
\text { Organically }\end{array}$} & \multirow{2}{*}{$\begin{array}{l}\text { People } \\
\text { Employed } \\
\text { on Farm }\end{array}$} & \multirow{2}{*}{$\begin{array}{l}\text { Off Farm } \\
\text { Employment }\end{array}$} & \multirow[t]{2}{*}{ Point of Sales } \\
\hline & & Owned & Rented & & & & & & \\
\hline & $\begin{array}{l}\text { and raise } \\
\text { horses at the } \\
\text { farm. }\end{array}$ & & & & & & & & \\
\hline (F09) & $\begin{array}{l}\text { Spelt, } \\
\text { buckwheat, } \\
\text { barley, red } \\
\text { clover, corn, } \\
\text { soybeans. }\end{array}$ & 230 & None. & None. & $\begin{array}{l}\text { Yes. This is } \\
\text { the family } \\
\text { farm of the } \\
\text { operator, but } \\
\text { was run as a } \\
\text { dairy } \\
\text { operation until } \\
1997 \text {. }\end{array}$ & 5 & $\begin{array}{l}1 \text { ( } 2 \\
\text { adults, } 1 \\
\text { adult child } \\
\text { living } \\
\text { away from } \\
\text { home). }\end{array}$ & & None. \\
\hline (F10) & $\begin{array}{l}\text { Oats, } \\
\text { buckwheat, } \\
\text { spelt, hard } \\
\text { wheat, hay. } \\
\text { Operator } \\
\text { started an } \\
\text { organic } \\
\text { milling } \\
\text { business that } \\
\text { was } \\
\text { successful in } \\
\text { getting a } \\
\text { number of } \\
\text { local farmers } \\
\text { to convert to } \\
\text { growing } \\
\text { organic } \\
\text { grains. He } \\
\text { runs a supply } \\
\text { business } \\
\text { providing }\end{array}$ & $\begin{array}{l}138(60 \text { in } \\
\text { production })\end{array}$ & None. & None. & No. & 21. & $\begin{array}{l}1 \text { ( } 2 \\
\text { adults, } 3 \\
\text { children) }\end{array}$ & & $\begin{array}{l}\text { Operator works } \\
\text { full time as a } \\
\text { professor at a } \\
\text { university. }\end{array}$ \\
\hline
\end{tabular}




\begin{tabular}{|c|c|c|c|c|c|c|c|c|c|}
\hline \multirow[t]{2}{*}{ Farmer } & \multirow[t]{2}{*}{ Products } & \multicolumn{2}{|l|}{ Land } & \multirow[t]{2}{*}{ Livestock } & \multirow{2}{*}{$\begin{array}{l}\text { History in } \\
\text { Conventional } \\
\text { Production? }\end{array}$} & \multirow{2}{*}{$\begin{array}{l}\text { Years Farming } \\
\text { Organically }\end{array}$} & \multirow{2}{*}{\begin{tabular}{|l} 
People \\
Employed \\
on Farm \\
\end{tabular}} & \multirow{2}{*}{$\begin{array}{l}\text { Off Farm } \\
\text { Employment }\end{array}$} & \multirow[t]{2}{*}{ Point of Sales } \\
\hline & & Owned & Rented & & & & & & \\
\hline & $\begin{array}{l}\text { restaurants } \\
\text { with his } \\
\text { products and } \\
\text { other } \\
\text { imported } \\
\text { organic } \\
\text { products }\end{array}$ & & & & & & & & \\
\hline (F11) & $\begin{array}{l}\text { Dairy. } \\
\text { Feed crops. }\end{array}$ & $\begin{array}{l}340 \text { (320 in } \\
\text { production) }\end{array}$ & & Dairy cattle & $\begin{array}{l}\text { Yes. The } \\
\text { operator is a } \\
2^{\text {nd }} \text { generation } \\
\text { farmer and } \\
\text { grew up on a } \\
\text { conventional } \\
\text { farm. His } \\
\text { present farm } \\
\text { was operated } \\
\text { as a } \\
\text { conventional } \\
\text { operation for } \\
12 \text { years } \\
\text { before the } \\
\text { conversion. }\end{array}$ & 7 & $\begin{array}{l}1 \text { (2 } \\
\text { adults, } 9 \\
\text { children). }\end{array}$ & & $\begin{array}{l}\text { The children } \\
\text { are home- } \\
\text { schooled, and } \\
\text { help out around } \\
\text { the farm } \\
\text { outside of class } \\
\text { hours. }\end{array}$ \\
\hline (F12) & 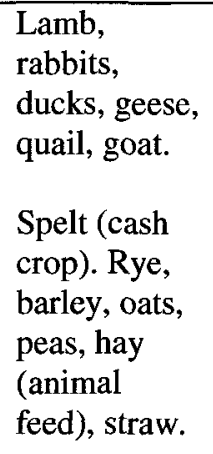 & 140 & $\begin{array}{l}110(50-60 \\
\text { in } \\
\text { production) }\end{array}$ & $\begin{array}{l}\text { Sheep (60), } \\
\text { goats, } \\
\text { rabbits, } \\
\text { ducks, } \\
\text { geese, quail. }\end{array}$ & $\begin{array}{l}\text { No. Operator } \\
\text { has a history } \\
\text { as a } \\
\text { landscaper } \\
\text { and has } \\
\text { worked in } \\
\text { conventional } \\
\text { landscaping } \\
\text { businesses in } \\
\text { Germany and } \\
\text { in Canada. }\end{array}$ & 3 & $\begin{array}{l}2(2 \\
\text { adults, } 2 \\
\text { young } \\
\text { children })\end{array}$ & & \\
\hline
\end{tabular}




\begin{tabular}{|c|c|c|c|c|c|c|c|c|c|}
\hline \multirow[t]{2}{*}{ Farmer } & \multirow[t]{2}{*}{ Products } & \multicolumn{2}{|l|}{ Land } & \multirow[t]{2}{*}{ Livestock } & \multirow{2}{*}{$\begin{array}{l}\text { History in } \\
\text { Conventional } \\
\text { Production? }\end{array}$} & \multirow{2}{*}{$\begin{array}{l}\text { Years Farming } \\
\text { Organically }\end{array}$} & \multirow{2}{*}{$\begin{array}{l}\text { People } \\
\text { Employed } \\
\text { on Farm }\end{array}$} & \multirow{2}{*}{$\begin{array}{l}\text { Off Farm } \\
\text { Employment }\end{array}$} & \multirow[t]{2}{*}{ Point of Sales } \\
\hline & & Owned & Rented & & & & & & \\
\hline & $\begin{array}{l}\text { Vegetables, } \\
\text { herbs. }\end{array}$ & & & & & & & & \\
\hline (F13) & $\begin{array}{l}\text { Wheat, } \\
\text { soybeans, } \\
\text { buckwheat, } \\
\text { alfalfa. }\end{array}$ & $\begin{array}{l}100(75 \text { in } \\
\text { production })\end{array}$ & 125 & None. & $\begin{array}{l}\text { Yes. Prior to } \\
\text { moving to } \\
\text { Ontario, the } \\
\text { operator ran a } \\
\text { mixed farm in } \\
\text { Quebec by } \\
\text { conventional } \\
\text { methods. The } \\
\text { current farm } \\
\text { was farmed } \\
\text { conventionally } \\
\text { for } 10 \text { years } \\
\text { before the } \\
\text { conversion }\end{array}$ & 17. & $\begin{array}{l}1(2 \\
\text { adults, } 2 \\
\text { adult } \\
\text { children } \\
\text { living } \\
\text { away from } \\
\text { home). }\end{array}$ & & None. \\
\hline (F15) & $\begin{array}{l}\text { Sheep, beef } \\
\text { cattle. } \\
\text { Small grains, } \\
\text { hay, } \\
\text { soybeans. }\end{array}$ & $\begin{array}{l}200(190 \text { in } \\
\text { production })\end{array}$ & None. & $\begin{array}{l}\text { Beef cattle, } \\
\text { sheep. }\end{array}$ & $\begin{array}{l}\text { Yes. Prior to } \\
\text { buying this } \\
\text { farm, the } \\
\text { operators } \\
\text { lived on and } \\
\text { farmed } \\
\text { conventionally }\end{array}$ & 9 & $\begin{array}{l}2, \text { with } \\
\text { seasonal } \\
\text { workers } \\
\text { for the } \\
\text { vegetable } \\
\text { production } \\
\text { ( } 2 \text { adults, }\end{array}$ & & $\begin{array}{l}\text { One of the } \\
\text { operators does } \\
\text { paid contract } \\
\text { work for the } \\
\text { NFU, Oxfam, } \\
\text { etc. }\end{array}$ \\
\hline
\end{tabular}




\begin{tabular}{|c|c|c|c|c|c|c|c|c|c|}
\hline \multirow[t]{2}{*}{ Farmer } & \multirow[t]{2}{*}{ Products } & \multicolumn{2}{|l|}{ Land } & \multirow[t]{2}{*}{ Livestock } & \multirow{2}{*}{$\begin{array}{l}\text { History in } \\
\text { Conventional } \\
\text { Production? }\end{array}$} & \multirow{2}{*}{$\begin{array}{l}\text { Years Farming } \\
\text { Organically }\end{array}$} & \multirow{2}{*}{$\begin{array}{l}\text { People } \\
\text { Employed } \\
\text { on Farm }\end{array}$} & \multirow{2}{*}{$\begin{array}{l}\text { Off Farm } \\
\text { Employment }\end{array}$} & \multirow[t]{2}{*}{ Point of Sales } \\
\hline & & Owned & Rented & & & & & & \\
\hline & Vegetables. & & & & $\begin{array}{l}\text { in Australia. } \\
\text { They worked } \\
\text { on the family } \\
\text { farm of one of } \\
\text { the operators. }\end{array}$ & & $\begin{array}{l}\text { with two } \\
\text { older } \\
\text { children } \\
\text { living } \\
\text { away from } \\
\text { home and } \\
\text { one } \\
\text { younger } \\
\text { child } \\
\text { living at } \\
\text { home) }\end{array}$ & & \\
\hline (F16) & $\begin{array}{l}\text { Beef, pork, } \\
\text { eggs. } \\
\text { Small grains, } \\
\text { spelt, corn, } \\
\text { soybean, } \\
\text { clover. } \\
\text { Berries, } \\
\text { veggies. }\end{array}$ & $\begin{array}{l}100 \text { (around } \\
50 \\
\text { workable) }\end{array}$ & 150 & $\begin{array}{l}\text { Beef cattle, } \\
\text { pigs, laying } \\
\text { hens. }\end{array}$ & $\begin{array}{l}\text { Yes. The field } \\
\text { crops on the } \\
\text { farm. The } \\
\text { operator used } \\
\text { to run a } \\
\text { conventional } \\
\text { dairy } \\
\text { operation, but } \\
\text { has since } \\
\text { gotten out of } \\
\text { dairy. }\end{array}$ & 17. & $\begin{array}{l}1(2 \\
\text { adults, } 2 \\
\text { adult } \\
\text { living } \\
\text { away from } \\
\text { home) }\end{array}$ & & $\begin{array}{l}\text { Operator drives } \\
\text { a school bus } \\
\text { during the } \\
\text { school year. }\end{array}$ \\
\hline \multicolumn{10}{|c|}{ Diversified Market Gardens } \\
\hline$(\mathrm{F} 17)$ & $\begin{array}{l}\text { Garlic, } \\
\text { vegetables. } \\
\text { Maple syrup. } \\
\text { Christmas } \\
\text { trees. }\end{array}$ & 30 & None. & None. & $\begin{array}{l}\text { No. The } \\
\text { operator grew } \\
\text { up on a farm, } \\
\text { but it was } \\
\text { farmed } \\
\text { organically. }\end{array}$ & Approx. 15. & $\begin{array}{l}1(2 \\
\text { adults })\end{array}$ & & $\begin{array}{l}\text { Operator took } \\
\text { up farming } \\
\text { approximately } \\
10 \text { years before } \\
\text { his retirement; } \\
\text { he is now } \\
\text { retired and runs } \\
\text { the farm full } \\
\text { time. }\end{array}$ \\
\hline
\end{tabular}




\begin{tabular}{|c|c|c|c|c|c|c|c|c|c|}
\hline \multirow[t]{2}{*}{$\overline{\text { Farmer }}$} & \multirow[t]{2}{*}{ Products } & \multicolumn{2}{|l|}{ Land } & \multirow[t]{2}{*}{ Livestock } & \multirow{2}{*}{$\begin{array}{l}\text { History in } \\
\text { Conventional } \\
\text { Production? }\end{array}$} & \multirow[t]{2}{*}{$\begin{array}{l}\text { Years Farming } \\
\text { Organically }\end{array}$} & \multirow{2}{*}{$\begin{array}{l}\text { People } \\
\text { Employed } \\
\text { on Farm }\end{array}$} & \multirow[t]{2}{*}{$\begin{array}{l}\text { Off Farm } \\
\text { Employment }\end{array}$} & \multirow[t]{2}{*}{ Point of Sales } \\
\hline & & Owned & Rented & & & & & & \\
\hline (F18) & $\begin{array}{l}\text { Pork, goat's } \\
\text { milk (for } \\
\text { personal } \\
\text { consumption) } \\
\text { Vegetables. } \\
\text { Maple syrup }\end{array}$ & $\begin{array}{l}200 \text { ( } 80 \text { in } \\
\text { production?) }\end{array}$ & & $\begin{array}{l}\text { Pigs, goats, } \\
\text { horses. }\end{array}$ & No. & 25. & 1 & & \\
\hline \multicolumn{10}{|c|}{ Market Gardens } \\
\hline (F19) & $\begin{array}{l}\text { Vegetables. } \\
\text { The } \\
\text { operators } \\
\text { have started a } \\
\text { distribution } \\
\text { and supply } \\
\text { business. } \\
\text { They buy } \\
\text { products } \\
\text { from local } \\
\text { organic } \\
\text { farmers but } \\
\text { also stock } \\
\text { some } \\
\text { imported } \\
\text { organic } \\
\text { goods. They } \\
\text { are opening a } \\
\text { store selling } \\
\text { their goods } \\
\text { this season }\end{array}$ & 2 & None. & None & No. & 16 & $\begin{array}{l}2 \text { plus } \\
\text { seasonal } \\
\text { workers (2 } \\
\text { adults, } 2 \\
\text { children) }\end{array}$ & & $\begin{array}{l}\text { The operators } \\
\text { run a } \\
\text { distribution } \\
\text { and supply } \\
\text { business } \\
\text { related to the } \\
\text { garden. }\end{array}$ \\
\hline$\overline{(F 20)}$ & Vegetables. & $\begin{array}{l}130(80 \\
\text { arable })\end{array}$ & $\begin{array}{l}\text { Rents land } \\
\text { to a farmer }\end{array}$ & None. & No. & 2 & $\begin{array}{l}2(2 \\
\text { adults })\end{array}$ & & $\begin{array}{l}\text { Works } \\
\text { seasonally as a }\end{array}$ \\
\hline
\end{tabular}




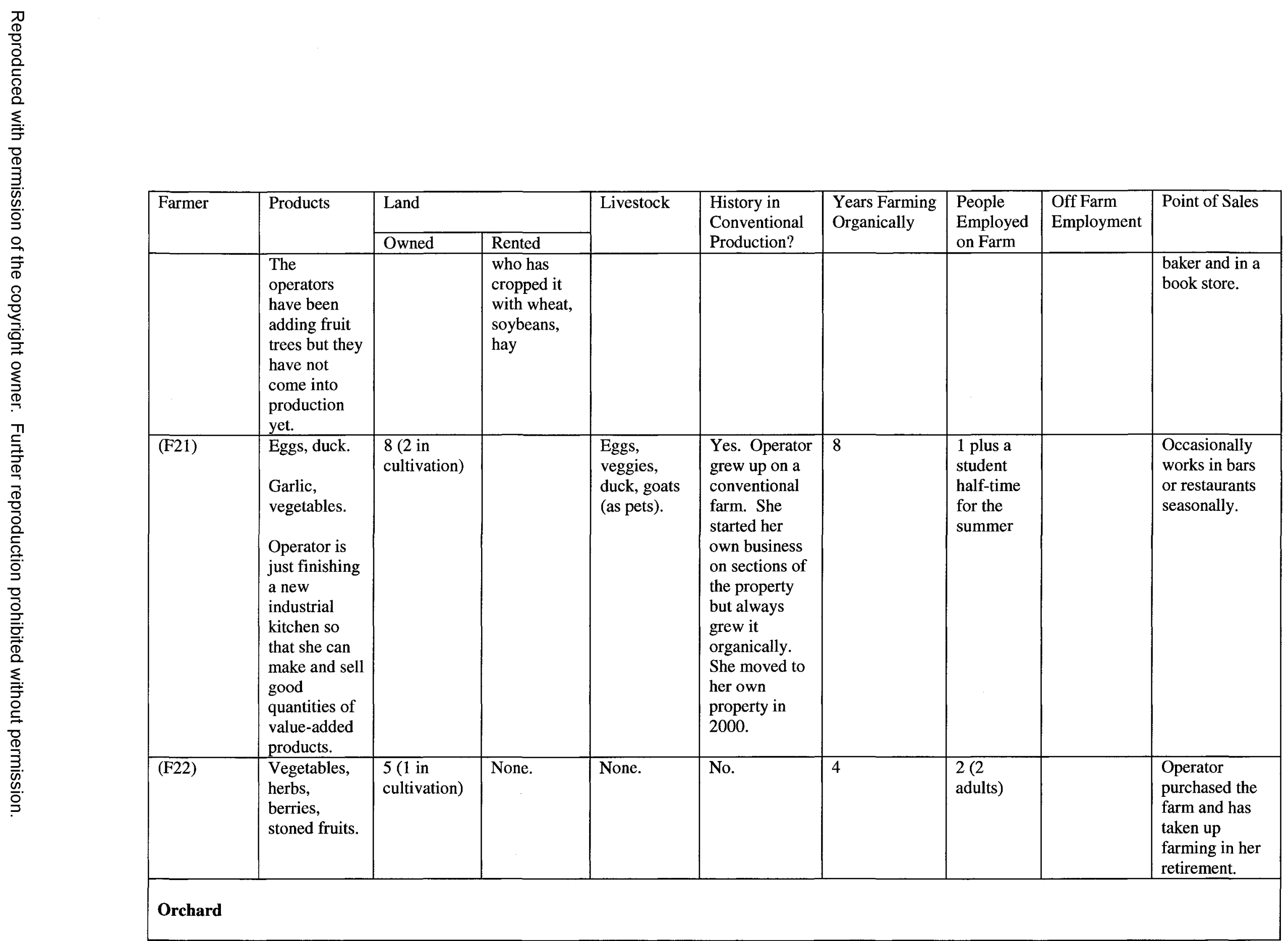




\begin{tabular}{|c|c|c|c|c|c|c|c|c|c|}
\hline \multirow[t]{2}{*}{ Farmer } & \multirow[t]{2}{*}{ Products } & \multicolumn{2}{|l|}{ Land } & \multirow[t]{2}{*}{ Livestock } & \multirow{2}{*}{$\begin{array}{l}\text { History in } \\
\text { Conventional } \\
\text { Production? }\end{array}$} & \multirow[t]{2}{*}{$\begin{array}{l}\text { Years Farming } \\
\text { Organically }\end{array}$} & \multirow{2}{*}{$\begin{array}{l}\text { People } \\
\text { Employed } \\
\text { on Farm }\end{array}$} & \multirow[t]{2}{*}{$\begin{array}{l}\text { Off Farm } \\
\text { Employment }\end{array}$} & \multirow[t]{2}{*}{ Point of Sales } \\
\hline & & Owned & Rented & & & & & & \\
\hline (F23) & $\begin{array}{l}\text { Apples. } \\
\text { Value-added } \\
\text { apple } \\
\text { products. }\end{array}$ & 50 & & None. & $\begin{array}{l}\text { Yes. One of } \\
\text { the operators } \\
\text { grew up on a } \\
\text { conventional } \\
\text { farm. }\end{array}$ & 5. & $\begin{array}{l}2(2 \\
\text { adults, } 1 \\
\text { younger } \\
\text { child }) \text {. }\end{array}$ & & $\begin{array}{l}\text { Operator runs } \\
\text { art as }\end{array}$ \\
\hline
\end{tabular}




\section{Appendix 3: Organic Farming Practices amongst Organic Farmers in South-eastern Ontario}

\begin{tabular}{|c|c|c|c|}
\hline$\underline{\text { Practice }}$ & Purpose & $\underline{\text { Structure }}$ & $\begin{array}{l}\text { Observations and Farmer } \\
\text { Comments }\end{array}$ \\
\hline $\begin{array}{l}\text { Maintaining diversified crop } \\
\text { rotations }\end{array}$ & $\begin{array}{l}\text { - Soil management: enhances and } \\
\text { balances soil fertility since } \\
\text { different crops use and } \\
\text { contribute different nutrients. } \\
\text { - Pest and disease management: } \\
\text { alternates the 'hosts' available } \\
\text { to pests and diseases; certain } \\
\text { crops suppress pest or disease } \\
\text { populations through their } \\
\text { chemical or biological growth } \\
\text { habits. } \\
\text { - Weed management: alternates } \\
\text { the planting pattern such that } \\
\text { weeds cannot become firmly } \\
\text { established physically; } \\
\text { alternates the nutrient balance of } \\
\text { the soil so that the same weeds } \\
\text { are not favoured year after year; } \\
\text { certain crops suppress weeds } \\
\text { through their chemical or } \\
\text { biological growth habits. }\end{array}$ & $\begin{array}{l}\text { - Temporal crop rotation systems } \\
\text { rotate parcels of the farm (e.g. } \\
\text { different fields) through the crop } \\
\text { sequence over multiple years. } \\
\text { No crop is grown in the same } \\
\text { field two years in a row. Many } \\
\text { farmers maintained a parcel of } \\
\text { their farm in each of the } \\
\text { 'phases' or years of the rotation. } \\
\text { - Farmers avoid monocropping. } \\
\text { - More elaborate amongst those } \\
\text { who grow field rather than } \\
\text { horticultural crops or on those } \\
\text { portions of the farm where field } \\
\text { crops are grown since the } \\
\text { smaller area used in } \\
\text { horticultural production makes } \\
\text { such a rotation system more } \\
\text { difficult. } \\
\text { - Crops and sequences comprising } \\
\text { rotations vary greatly amongst } \\
\text { farmers. Amongst field crop } \\
\text { farmers and areas, the average } \\
\text { length of rotation was } 4 \text { years, } \\
\text { the average number of crops in a } \\
\text { rotation was } 5 \text {. Rotations } \\
\text { typically included a mix of } \\
\text { cereals (wheats, buckwheat, rye, } \\
\text { oats, barley, and spelt), legumes } \\
\text { (soybeans and peas for feed; red } \\
\text { clover, alfalfa and timothy for } \\
\text { forage), oilseeds (flax and }\end{array}$ & $\begin{array}{l}\text { - Farmers indicated that they had } \\
\text { given great thought to the choice } \\
\text { and positioning of each crop in } \\
\text { the rotation, explaining carefully } \\
\text { the various benefits of each } \\
\text { crop. } \\
\text { - For most farmers, crop } \\
\text { rotations are not fixed. Rather, } \\
\text { the farmers noted that they were } \\
\text { still in the process of } \\
\text { determining what 'works' for } \\
\text { their farm, and as such } \\
\text { continued to experiment with } \\
\text { the different crops and } \\
\text { sequencing. Some felt pressure } \\
\text { from their certifying body to } \\
\text { have their rotation "settled". } \\
\text { - In choosing crops for their } \\
\text { rotation, farmers gave primary } \\
\text { consideration to their ecological } \\
\text { benefit. The price they would } \\
\text { receive for the crop, the labour } \\
\text { involved in production, their } \\
\text { familiarity and experience with } \\
\text { a crop, and the ease of } \\
\text { availability and quality of seed } \\
\text { stock were rated as secondary } \\
\text { considerations. }\end{array}$ \\
\hline
\end{tabular}




\begin{tabular}{|c|c|c|c|}
\hline Practice & Purpose & $\underline{\text { Structure }}$ & $\begin{array}{l}\text { Observations and Farmer } \\
\text { Comments }\end{array}$ \\
\hline & & hemp), and corn. & \\
\hline Growing cover crops & $\begin{array}{l}\text { - Soil management: restores } \\
\text { nutrients to soil; increases } \\
\text { biomass; reduces compaction } \\
\text { and erosion (by shortening the } \\
\text { time in which the soil is bare). } \\
\text { - Water management: increases } \\
\text { water infiltration. } \\
\text { - Pest management: create } \\
\text { beneficial insect habitat. } \\
\text { - Weed management: helps } \\
\text { prevent weeds from becoming } \\
\text { established. }\end{array}$ & $\begin{array}{l}\text { - Crops are not harvested as a } \\
\text { cash or feed crop, but are } \\
\text { planted between (temporally- } \\
\text { speaking) harvested crops or } \\
\text { intercropped with trees in } \\
\text { orchards. } \\
\text { - Crops grow out over their life- } \\
\text { span, and when they have died } \\
\text { their residue is ploughed back } \\
\text { into the soil as a "green } \\
\text { manure". } \\
\text { - Many farmers underseed one of } \\
\text { their cereal crops with } \\
\text { leguminous crops such as red } \\
\text { clover or timothy which remain } \\
\text { in place after the cereal is } \\
\text { harvested. Farmers who keep } \\
\text { pasture typically turn that field } \\
\text { over to pasture for the following } \\
\text { year(s) of the rotation; those } \\
\text { who do not go directly into the } \\
\text { next rotation year the following } \\
\text { spring. }\end{array}$ & $\begin{array}{l}\text { Most farmers incorporate at } \\
\text { least one cover crop into their } \\
\text { rotations; although these crops } \\
\text { are not harvested for sale or for } \\
\text { feed, most farmers consider that } \\
\text { they play a central role in the } \\
\text { productive cycle of their farms. }\end{array}$ \\
\hline Composting & $\begin{array}{l}\text { - Soil management: adds organic } \\
\text { matter and nutrients to the soil } \\
\text { to enhance structure and } \\
\text { fertility. } \\
\text { - Water management: aids water } \\
\text { retention by adding humus to } \\
\text { the soil. }\end{array}$ & $\begin{array}{l}\text { - Waste that gets composted can } \\
\text { consist of livestock manure and } \\
\text { bedding, crop residues, and } \\
\text { household organics, but } \\
\text { components must be balanced to } \\
\text { ensure the proper carbon to } \\
\text { nitrogen balance in the resulting } \\
\text { pile. } \\
\text { - Waste is piled in such a way that } \\
\text { it will "cook" (i.e., achieve a }\end{array}$ & $\begin{array}{l}\text { - Composting felt by some to be } \\
\text { the backbone of organic farming } \\
\text { due to it's prominence in the } \\
\text { writings of the pioneers of the } \\
\text { movement. Others are less } \\
\text { explicitly focused on } \\
\text { composting. } \\
\text { - Farmers describe compost } \\
\text { making as a labour intensive } \\
\text { process, and one that required }\end{array}$ \\
\hline
\end{tabular}




\begin{tabular}{|c|c|c|c|}
\hline Practice & Purpose & Structure & $\begin{array}{l}\text { Observations and Farmer } \\
\text { Comments }\end{array}$ \\
\hline & & $\begin{array}{l}\text { high temperature on the interior } \\
\text { of the pile) in order to kill off } \\
\text { weed seeds and pathogens; the } \\
\text { pile requires regular watering } \\
\text { and aeration to encourage } \\
\text { microbes to decompose residues } \\
\text { into a useable nutrient form. }\end{array}$ & $\begin{array}{l}\text { careful planning, precision and } \\
\text { skill. In these senses, compost- } \\
\text { making was often likened to a } \\
\text { "science". }\end{array}$ \\
\hline $\begin{array}{l}\text { Planting and maintaining hedge- } \\
\text { and fencerows, and wooded areas }\end{array}$ & $\begin{array}{l}\text { - Soil management: reduces the } \\
\text { wind profile over the farm and } \\
\text { thus soil erosion. } \\
\text { - Water management: aids water } \\
\text { infiltration into adjacent fields. } \\
\text { - Livestock management: provide } \\
\text { shade for livestock. } \\
\text { - Pest management: serves as } \\
\text { habitat for pest predators. } \\
\text { - Recreation: serves as sites } \\
\text { where farmers and farm children } \\
\text { can walk and play. } \\
\text { - Other functions: serves as } \\
\text { habitat for transient and } \\
\text { established populations of birds } \\
\text { and animals. }\end{array}$ & $\begin{array}{l}\text { - Fence and hedgerows are } \\
\text { maintained or planted between } \\
\text { fields } \\
\text { - Areas less suitable to crop } \\
\text { growth-such as wet pockets or } \\
\text { very rocky areas returned to } \\
\text { natural vegetation. }\end{array}$ & $\begin{array}{l}\text { - Farmers felt that wet or rocky } \\
\text { areas of the farm which they } \\
\text { returned to a natural state would } \\
\text { make a bigger contribution to } \\
\text { the overall functioning of the } \\
\text { farm in that state they could } \\
\text { have made through growing } \\
\text { crops. } \\
\text { - Some farmers maintained sugar } \\
\text { bushes in the woodlots or cut } \\
\text { wood from them for personal } \\
\text { use or commercial sale. } \\
\text { - Farmers maintain these areas } \\
\text { deliberately, rather than out of } \\
\text { neglect (see Guthman } 2000 \text { ). } \\
\text { - Farmers delighted in recounting } \\
\text { the lists of wildlife they had } \\
\text { seen on their farms during } \\
\text { interviews. Their interest in } \\
\text { maintaining wild spaces and } \\
\text { species on their farms often } \\
\text { motivated their naturalization } \\
\text { efforts. }\end{array}$ \\
\hline $\begin{array}{l}\text { Raising animals and growing crops } \\
\text { on the same farm (maintaining } \\
\text { mixed farms) }\end{array}$ & $\begin{array}{l}\text { Soil management: livestock } \\
\text { provide manure for compost and } \\
\text { fields; growing forage and } \\
\text { pasture crops balances nutrients }\end{array}$ & $\begin{array}{l}\text { - The majority of organic farmers } \\
\text { in this study maintain mixed } \\
\text { farms: of the } 16 \text { farmers in this } \\
\text { study who raise at least some }\end{array}$ & $\begin{array}{l}\text { - Organic farming philosophy } \\
\text { emphasizes self-sufficiency } \\
\text { within farming systems through } \\
\text { reducing as much as possible }\end{array}$ \\
\hline
\end{tabular}




\begin{tabular}{|c|c|c|c|}
\hline Practice & Purpose & Structure & $\begin{array}{l}\text { Observations and Farmer } \\
\text { Comments }\end{array}$ \\
\hline & $\begin{array}{l}\text { in the soil. } \\
\text { Livestock management: field } \\
\text { crops provide food for livestock. }\end{array}$ & $\begin{array}{l}\text { field crops, only four were not } \\
\text { also raising livestock and one of } \\
\text { these had arranged to have his } \\
\text { neighbour's livestock grazed on } \\
\text { his land. } \\
\text { - Those raising livestock } \\
\text { (including dairy cattle, beef } \\
\text { cattle, pigs, sheep, goats, } \\
\text { rabbits, ducks, geese and } \\
\text { chickens) provide for the } \\
\text { majority of their animals' food } \\
\text { needs through crops raised on } \\
\text { the farm, although some farmers } \\
\text { did import additional feed such } \\
\text { as hay from neighbouring farms, } \\
\text { or, less commonly, feed } \\
\text { supplements from feed and seed } \\
\text { distributors. }\end{array}$ & $\begin{array}{l}\text { off-farm inputs for the soil and } \\
\text { livestock, namely fertilizer and } \\
\text { feed. } \\
\text { - A number of farmers felt that } \\
\text { farms that did not maintain both } \\
\text { crops and animals were } \\
\text { unbalanced, or that they did not } \\
\text { reflect the situation one finds in } \\
\text { nature, which seemed, in their } \\
\text { eyes, to bring its organic status } \\
\text { into question. }\end{array}$ \\
\hline $\begin{array}{l}\text { Providing adequate housing space } \\
\text { and access to the out-of-doors for } \\
\text { livestock. }\end{array}$ & $\begin{array}{l}\text { Livestock management: } \\
\text { promotes good health for } \\
\text { animals; provides for ethical } \\
\text { treatment and life-cycle for the } \\
\text { animal. }\end{array}$ & $\begin{array}{l}\text { - Livestock housing is designed } \\
\text { to reflect the natural lifecycle } \\
\text { and habits of the animal. } \\
\text { - Livestock may not be caged and } \\
\text { must have free range access to } \\
\text { rotated pasture as weather and } \\
\text { season permits. }\end{array}$ & $\begin{array}{l}\text { Farmers felt that it was } \\
\text { nourishing for animals to have } \\
\text { access to the out of doors, and } \\
\text { have developed many } \\
\text { innovative animal housing } \\
\text { arrangements such as mobile } \\
\text { housing units that ensure the } \\
\text { animal will always have access } \\
\text { to fresh pasture. } \\
\text { Farmers are worried that } \\
\text { legislation which has been } \\
\text { passed in other provinces that } \\
\text { restrict outdoor access for } \\
\text { chickens, ostensibly as a way of } \\
\text { preventing the spread of Avian } \\
\text { Flu, will also come to pass in }\end{array}$ \\
\hline
\end{tabular}




\begin{tabular}{|c|c|c|c|}
\hline Practice & Purpose & Structure & $\begin{array}{l}\text { Observations and Farmer } \\
\text { Comments }\end{array}$ \\
\hline & & & Ontario. \\
\hline $\begin{array}{l}\text { Growing heritage varieties of crops } \\
\text { and raising rare breeds of livestock }\end{array}$ & $\begin{array}{l}\text { - Pest and disease management: } \\
\text { heritage crops and rare breeds of } \\
\text { livestock were often bred for } \\
\text { enhanced disease and pest } \\
\text { resistance and are felt to } \\
\text { superior to modern cultivars and } \\
\text { breeds in these respects. } \\
\text { - Improved taste and storability of } \\
\text { crops: heritage varieties of } \\
\text { horticultural crops were often } \\
\text { bred for enhanced taste and } \\
\text { storability and are felt to be } \\
\text { superior to modern cultivars in } \\
\text { these respects. } \\
\text { Off-farm benefits: preserves } \\
\text { biodiversity. }\end{array}$ & $\begin{array}{l}\text { - Growing heritage varieties of } \\
\text { crops and raising rare breeds of } \\
\text { livestock aren't explicitly } \\
\text { codified in most standards } \\
\text { (although some do suggest that } \\
\text { preference be given to } \\
\text { indigenous strains), or even } \\
\text { generally agreed upon as a } \\
\text { central practice in organic } \\
\text { farming. Nonetheless, this was } \\
\text { a tremendously common } \\
\text { practice amongst farmers in this } \\
\text { study, with } 19 \text { out of } 24 \\
\text { participants growing or raising } \\
\text { at least one heritage crop or rare } \\
\text { breed of livestock. }\end{array}$ & $\begin{array}{l}\text { - For some farmers, their interest } \\
\text { in growing organically is } \\
\text { articulated to a notion of } \\
\text { tradition. Farmers were clearly } \\
\text { pleased at the idea of raising } \\
\text { rare breeds or growing heritage } \\
\text { varieties, explaining the history } \\
\text { of each during the interviews. } \\
\text { Similarly, they indicated that } \\
\text { customers were increasingly } \\
\text { interested in these products. }\end{array}$ \\
\hline $\begin{array}{l}\text { Avoiding the use of synthetic } \\
\text { chemicals on the farm }\end{array}$ & $\begin{array}{l}\text { Avoidance of associated risks to } \\
\text { the environment both on-farm } \\
\text { (soil fertility and structure, } \\
\text { water quality) and off (impact } \\
\text { on wildlife population). } \\
\text { Avoidance of health risks for } \\
\text { farmer (in the act of spraying) } \\
\text { and the public (through spraying } \\
\text { and through the consumption of } \\
\text { pesticide laden foods). }\end{array}$ & $\begin{array}{l}\text { Farmers do not use synthetic } \\
\text { fertilizers, pesticides, herbicides } \\
\text { or fungicides on their farms. }\end{array}$ & $\begin{array}{l}\text { Many farmers who had run or } \\
\text { worked previously on a } \\
\text { conventional farm were } \\
\text { motivated to become organic } \\
\text { after first-hand experiences of } \\
\text { the detrimental health and } \\
\text { environmental effects of such } \\
\text { chemicals. They related stories } \\
\text { of bouts of illness and tiredness } \\
\text { after spraying their fields, while } \\
\text { two who themselves came from } \\
\text { farm families had witnessed a } \\
\text { notable decline in soil health } \\
\text { and quality and wildlife } \\
\text { populations on their farms with } \\
\text { increasing chemical use. }\end{array}$ \\
\hline
\end{tabular}




\begin{tabular}{|c|c|c|c|}
\hline Practice & Purpose & $\underline{\text { Structure }}$ & $\begin{array}{l}\text { Observations and Farmer } \\
\text { Comments }\end{array}$ \\
\hline & & & $\begin{array}{l}\text { - Researchers have noted that in it } \\
\text { has become common practice } \\
\text { amongst some organic farmers } \\
\text { and regional movements to } \\
\text { replace non-organic inputs with } \\
\text { commercially prepared organic } \\
\text { inputs (i.e., fertilizers made of } \\
\text { natural rather than synthetic } \\
\text { ingredients, commercially } \\
\text { extracted and distributed } \\
\text { minerals). This was not a } \\
\text { widespread practice in the study } \\
\text { region, although a few farmers } \\
\text { did use small quantities of } \\
\text { commercially prepared organic } \\
\text { products (especially in } \\
\text { biodynamic preparations) or } \\
\text { mineral applications as a pest } \\
\text { control mechanism. For most } \\
\text { farmers, this seems to remain a } \\
\text { questionable practice, because it } \\
\text { appropriates part of the organic } \\
\text { farming practice, yielding } \\
\text { control to agribusiness capital. }\end{array}$ \\
\hline $\begin{array}{l}\text { Avoiding the use of antibiotics in } \\
\text { livestock }\end{array}$ & $\begin{array}{l}\text { Avoidance of risks to health (of } \\
\text { the consumer, through the } \\
\text { consumption of hormone- or } \\
\text { antibiotic-rich animal products } \\
\text { or contaminated drinking water) } \\
\text { and to the environment (through } \\
\text { the contamination of water and } \\
\text { soil via hormone- or antibiotic- } \\
\text { rich waste). }\end{array}$ & $\begin{array}{l}\text { - Farmers avoid the use of } \\
\text { hormones, antibiotics, and other } \\
\text { animal drugs in animal feed or } \\
\text { by direct administration for the } \\
\text { purpose of stimulating the } \\
\text { growth or production of } \\
\text { livestock. } \\
\text { - Antibiotics may be used in order } \\
\text { to restore health to a sick }\end{array}$ & $\begin{array}{l}\text { Farmers in the study region are } \\
\text { increasingly excited about and } \\
\text { looking to homeopathy for } \\
\text { livestock herds as a way to } \\
\text { manage disease. }\end{array}$ \\
\hline
\end{tabular}




\begin{tabular}{|c|c|c|c|}
\hline Practice & Purpose & $\underline{\text { Structure }}$ & $\begin{array}{l}\text { Observations and Farmer } \\
\text { Comments }\end{array}$ \\
\hline & & $\begin{array}{l}\text { animal, but this animal and its } \\
\text { products lose their organic } \\
\text { 'status' and can't be sold or } \\
\text { represented as organic within } \\
\text { the food stream. }\end{array}$ & \\
\hline $\begin{array}{l}\text { Avoiding the growth of genetic } \\
\text { modified organisms. }\end{array}$ & $\begin{array}{l}\text { Avoidance of risks to health (of } \\
\text { both farm livestock and } \\
\text { consumers through the } \\
\text { consumption genetically } \\
\text { modified food) and to the } \\
\text { environment both on-farm } \\
\text { (through the contamination of } \\
\text { adjacent crops in the growing or } \\
\text { transport process) and off } \\
\text { (through genetic drift into } \\
\text { adjoining populations of wild } \\
\text { plants and habitats). biodiversity } \\
\text { of crops and livestock raised on } \\
\text { the farm and to wild } \\
\text { environments (through the } \\
\text { potential escape of modified } \\
\text { genes into non-modified } \\
\text { varieties and wild species), and } \\
\text { are potentially dangerous to the } \\
\text { health of the animals (including } \\
\text { humans) that consume them. }\end{array}$ & $\begin{array}{l}\text { Farmers do not grow any } \\
\text { genetically modified crops on } \\
\text { their farms, and may not feed } \\
\text { their livestock genetically } \\
\text { modified crops. }\end{array}$ & $\begin{array}{l}\text { - In the study region, farmers find } \\
\text { transgenic engineering a } \\
\text { particularly aberrant process, } \\
\text { likening it to "major messing } \\
\text { with the stuff of life" or } \\
\text { "mucking about with nature". } \\
\text { Farmers repeatedly pointed out } \\
\text { that this was a feat that could } \\
\text { never be accomplished by } \\
\text { nature, unlike the genetic } \\
\text { variation that could come into } \\
\text { effect through the crossing of } \\
\text { crop and livestock varieties, } \\
\text { activities which farmers have } \\
\text { depended on replicating for } \\
\text { centuries. }\end{array}$ \\
\hline
\end{tabular}

